\title{
Strategy for Advancement of IRP in Public Power \\ Volume 2: Technical Appendices
}

Cynthia J. Garrick

Garrick \& Associates

Morrison, Colorado

NREL Technical Monitor: Paul Galen

\section{NPEI}

National Renewable Energy Laboratory 1617 Cole Boulevard Golden, Colorado 80401-3393

A national laboratory of the U.S. Department of Energy Managed by Midwest Research Institute for the U.S. Department of Energy under Contract No. DE-AC36-83CH10093

Prepared under Subcontract No. AAW-3-13353-01

October 1995

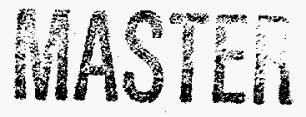




\section{NOTICE}

This report was prepared as an account of work sponsored by an agency of the United States government. Neither the United States government nor any agency thereof, nor any of their employees, makes any warranty, express or implied, or assumes any legal liability or responsibility for the accuracy, completeness, or usefulness of any information, apparatus, product, or process disclosed, or represents that its use would not infringe privately owned rights. Reference herein to any specific commercial product, process, or service by trade name, trademark, manufacturer, or otherwise does not necessarily constitute or imply its endorsement, recommendation, or favoring by the United States government or any agency thereof. The views and opinions of authors expressed herein do not necessarily state or reflect those of the United States government or any agency thereof.

Available to DOE and DOE contractors from:

Office of Scientific and Technical Information (OSTI)

P.O. Box 62

Oak Ridge, TN 37831

Prices available by calling (615) 576-8401

Available to the public from:

National Technical information Service (NTIS)

U.S. Department of Commerce

5285 Port Royal Road

Springfield, VA 22161

(703) $487-4650$ 


\section{DISCLAIMER}

Portions of this document may be illegible electronic image products. Images are produced from the best available original document. 


\section{Contents}

Appendix A: Needs Assessment Summary Report $\ldots \ldots \ldots \ldots \ldots \ldots \ldots \ldots \ldots \ldots$. . . . . .

Appendix B: Public Power Survey . . . . . . . . . . . . . . . . . . . . B-1

Appendix C: Federal and State IRP Policies . . . . . . . . . . . . . . . . .

Appendix D: Technical and Economic Market Characterization . . . . . . . . . . . D-1 


\section{Appendix A}

\section{Needs Assessment Summary Report}

Prepared by:

Garrick \& Associates

Principal Investigator: Cynthia J. Garrick

Originally prepared in October 1993 


\section{Introduction}

NREL and subcontractor Garrick \& Associates are conducting the Advancement of IRP in Public Power Program, sponsored by DOE. The program is intended to develop a consistent strategy for DOE to advance IRP practices in the publicly and cooperatively owned utility sector. ${ }^{1}$ The IRP advancement program includes two major tasks: key participant involvement and strategy development.

The Program's initial task is to involve key public and cooperative utility organizations and their constituents in the development of the IRP advancement strategy. ${ }^{2}$ Key Participant Involvement is accomplished through two distinct subtasks: Needs Assessment and Steering Committee Involvement. The Needs Assessment identifies key participant needs, expectations, common interests, issues, and divergences that must be addressed by the IRP program. The results of this effort, which are presented in this "Needs Assessment Summary Report," provide a foundation for the specific strategy development efforts conducted later in the IRP project.

The remaining sections of this report present the approach to the Needs Assessment subtask and summarize the findings of this effort. The Approach section delineates the major components of the overall Needs Assessment approach. This is followed by a summary of the key participants' expectations for the overall IRP advancement program and the resulting advancement strategy. The Key Participant IRP Activity section summarizes the IRP services and requirements sponsored by the key participant organizations. The final section, Barriers and Solutions Identification, discusses a number of limits to publicly and cooperatively owned utility IRP advancement that the key participants feel the IRP advancement strategy needs to address. This final section also presents a number of solutions recommended by the key participants for addressing the various IRP advancement barriers.

\footnotetext{
${ }^{1}$ Publicly owned utilities (also referred to as government-owned utilities) include state and municipal utilities and joint action agencies. Cooperatively owned utilities (also referred to as rural electric systems) include generation and transmission cooperatives and distribution cooperatives. While the publicly and cooperatively owned utility sector is very diverse, these utilities are all not-for-profit entities that are owned and controlled by their consumers.

${ }^{2}$ The key participants for this project are APPA, NRECA, REA (renamed the Rural Utilities Service in December 1994), BPA, SEPA, SWPA, TVA, and WAPA. Representatives from each of these organizations serve on the project Steering Committee. However, because BPA and TVA joined the Steering Committee after the Needs Assessment was completed, these two organizations are not addressed in detail in this summary.
} 


\section{Approach}

The overall approach to the Needs Assessment subtask involves seven major steps:

1. Objectives definition;

2. Needs Assessment framework design;

3. Information requirements delineation;

4. Initial individual discussions with key participants;

5. Group discussion with Steering Committee;

6. Individual comprehensive interviews with key participants; and

7. Findings assimilation and summary report development.

The three primary objectives of the Needs Assessment subtask were:

- To understand the key participants' expectations for the overall project and the resulting IRP advancement strategy;

- To provide an overview of the various IRP activities that are sponsored by the key participants; and

- To identify barriers that the key participants believe the IRP advancement strategy needs to address, as well as potential solutions to these barriers.

An overall Needs Assessment framework was designed to satisfy all of these objectives. This framework uses a series of discussions with representatives of each key participant organization to assess IRP needs. These discussions include initial individual discussions with representatives of each organization, group discussion and brainstorming during the June 1993 Steering Committee meeting, and comprehensive interviews with each key participant organization. In support of this framework, Needs Assessment information requirements were also developed. This involved developing guidelines and questionnaires to obtain the information necessary to satisfy all three subtask objectives.

Initial individual Needs Assessment discussions were held with key participants during June 1993. These discussions focused on project-related expectations and perspectives, as well as on expectations for the resulting IRP strategy. Group discussion of IRP needs occurred during the June 22 and 23, 1993, Steering Committee meeting. These discussions also explored common interests and divergent viewpoints of the various key participants. Comprehensive interviews with representatives of each organization were held during June and July 1993 to further articulate key participant IRP activity and to discuss barriers and solutions for IRP advancement. The findings from all of these Needs Assessment discussions were then assimilated and are presented in this summary report.

The Needs Assessment findings presented in this report provide a foundation for the specific strategy development efforts to be conducted later in the IRP advancement program. By providing DOE with an understanding of the key participants' expectations, the findings ensure appropriate involvement of each organization in the strategy development process and enhance the effectiveness of the resulting strategy. The Needs Assessment also provides a summary of the various IRP activities that are sponsored by the key participants, which will be incorporated into the final IRP strategy document to provide an overview of key participant IRP efforts to date. Finally, the Needs Assessment findings play a major role in identifying barriers that the IRP advancement strategy needs to address, as well as potential solutions for these barriers. These various barriers and solutions were characterized and evaluated during the development of DOE's IRP advancement strategy. 


\section{Project and Advancement Strategy Expectations}

The Needs Assessment provides an understanding of the key participants of Advancement of IRP in Public Power expectations. This includes their expectations for the overall project, as well as their expectations for the resulting IRP advancement strategy.

\section{Project Expectations}

The Needs Assessment findings indicate that the key participants have four primary expectations for the overall Advancement of IRP in Public Power project:

1. To work together as a group to maximize IRP-related efforts, ranging from sharing of information to developing new products and services;

2. To obtain a better indication of DOE's and the administration's IRP-related directions and priorities;

3. To obtain and/or direct resources (e.g., money, data, products, services, etc.) to meet the IRP needs of publicly and cooperatively owned utilities. These needs are amplified by significant budget and staff cuts currently faced by most of the key participant organizations; and

4. To work jointly with DOE to ensure that the agency's publicly and cooperatively owned utility efforts are appropriately and effectively directed.

\section{Advancement Strategy Expectations}

The key participants' expectations for the resulting IRP advancement strategy provide specific direction to DOE in the development of this strategy. The key participants encourage DOE to produce a resultsoriented 5-year strategic plan to employ the collective resources of DOE, other appropriate federal entities, and the various publicly and cooperatively owned utility organizations. The key participants feel that the strategy should build upon current IRP activities within the publicly and cooperatively owned utility sector to increase IRP-related personnel and financial and technical resources.

The strategy should provide a framework for consistent IRP approaches and activities across this diverse sector, which includes about 3,000 utilities that account for about $25 \%$ of the nation's electricity sales. The key participants also feel that the strategy should reflect a marketing, rather than regulatory, approach to IRP advancement. The key participants expect that the strategy will allocate specific resources to, and assign responsibilities for, implementation of the strategy. 


\section{Key Participant IRP Activity}

The key participants in DOE's of IRP in Public Power project have considerable experience with fostering the development of IRP. All six organizations-APPA, NRECA, REA, SEPA, SWPA, and WAPA - sponsor a range of IRP-related activities; these are summarized in Figure A-1. As shown in the figure, all key participants sponsor education and information dissemination services for their publicly or cooperatively owned utility constituents. In addition, most provide technical assistance and methods/tools development services and a few conduct applied research, sponsor data development and transfer services, or offer financial assistance and incentives. In addition, REA, SEPA, SWPA, and WAPA all place IRP requirements or policies on some or all of their customers.

\begin{tabular}{|c|c|c|c|c|c|c|c|}
\hline & 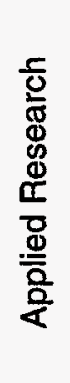 & 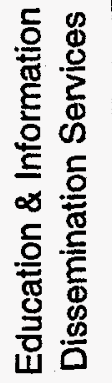 & 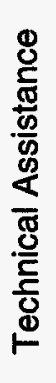 & 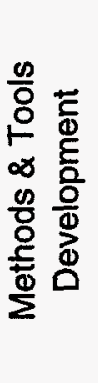 & 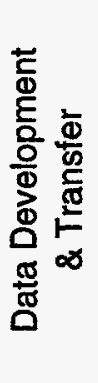 & 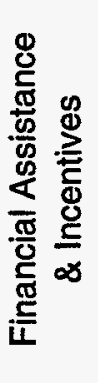 & $\begin{array}{l}\text { ò } \\
\text { on } \\
\underline{n} \\
\underline{\underline{I}}\end{array}$ \\
\hline APPA & $\checkmark$ & $\checkmark$ & $\checkmark$ & $\checkmark$ & $\checkmark$ & & N/A \\
\hline NRECA & $\checkmark$ & $\checkmark$ & $\checkmark$ & & $\checkmark$ & & N/A \\
\hline REA & & $\checkmark$ & $\checkmark$ & & & $\checkmark$ & $\checkmark$ \\
\hline SEPA & & $\checkmark$ & & $\checkmark$ & & & $\checkmark$ \\
\hline SWPA & & $\sqrt{ }$ & $\checkmark$ & $\checkmark$ & & & $\checkmark$ \\
\hline WAPA & $\checkmark$ & $\checkmark$ & $\checkmark$ & $\sqrt{ }$ & $\sqrt{ }$ & 1 & $\checkmark$ \\
\hline
\end{tabular}

Figure 1. Key participant IRP activities

This section provides an overview of the IRP experience and activities of the project's key participants, based upon the findings of the Needs Assessment. The IRP activities of the BPA and the TVA are also briefly summarized. While these two organizations are not key participants in the IRP advancement project, any discussion of IRP within the public utility sector is incomplete without acknowledgment of their significant experience and efforts. ${ }^{3}$ Because the following discussion is presented chronologically, the BPA and TVA summaries come first, followed by an overview of each key participant's IRP activities.

\footnotetext{
${ }^{3}$ BPA and TVA both joined the project Steering Committee shortly after completion of the Needs Assessment.
} 
The practice of IRP by publicly and cooperatively owned utilities began at least as early as 1980 . In that year, passage of the Northwest Power Act provided the framework for regional resource planning by the BPA, utilities, and others in the four-state Pacific Northwest region (Washington, Oregon, Idaho, and western Montana). Under the Act, the Northwest Power Planning Council (NWPPC), which is funded through BPA's rates, is assigned the responsibility of developing and adopting a regional conservation and electric power plan. The NWPPC adopted its first plan in 1983, with revisions following in 1986 and 1991. The 1991 plan calls for the region to acquire about half of its new resource needs between now and the year 2000 from DSM resources (i.e., about 1500 average MW of DSM are projected). BPA and its 120 utility customers, along with the region's six IOUs, have developed acquisition plans and schedules designed to achieve the NWPPC's projected levels of conservation and efficiency.

The centralized, regional planning practiced by the NWPPC and BPA are consistent with BPA's charter, which requires it to meet the future electric needs of its customers. The agency's active role in planning and development of the region's future power facilities includes development of a biannual Resource Program to determine the specific resources BPA will acquire over the coming 10 years to meet loads and to help implement the Northwest Power Plan adopted by the NWPPC. Development of the Resource Program is a collaborative effort involving customers and outside interests in determining how much power will be needed and which resources to acquire. BPA's Area Offices also develop Local Conservation Plans and work with individual customers to implement the plans.

The TVA was also one of the first government-owned utility agencies to prepare long-range plans for supply and demand resources. In the early 1980s, TVA began practicing IRP to optimize the supply of electrical resources to its 160 full-requirements customers (or "distributors") in Alabama, Georgia, Kentucky, Mississippi, North Carolina, Tennessee, and Virginia. The agency also developed one of the nation's largest conservation programs during the 1980s. EPAct reinforces TVA's IRP commitment by requiring the agency to conduct a least-cost planning program. EPAct delineates a number of requirements for TVA's program, including involving distributors in the planning and implementation of cost-effective energy-efficiency options and providing appropriate assistance to distributors (e.g., education and information dissemination, technical and financial assistance, etc.). TVA launched a new IRP process in November 1992 that focuses on identifying and meeting customer resource needs.

BPA and TVA are the only federal power agencies with direct responsibility for planning and acquiring resources to meet their publicly and cooperatively owned utility customers' loads. WAPA, SWPA, and SEPA sell only a portion of the electric power and energy required by most of their customers, who must plan for and acquire additional resources. ${ }^{4}$ As a result, these key participants focus their IRP activities on encouraging and assisting customer IRP efforts.

The roots of WAPA's IRP program lie in the Energy Services Program that it began in 1980. In 1981, WAPA published its "Customer Guidelines and Acceptance Criteria" (G\&AC), which required all customers signing new firm power contracts to develop conservation and renewable energy programs. This requirement became Federal law in 1984, with the passage of Title II of the Hoover Power Plant Act. As part of a required review of the G\&AC provisions in 1991, WAPA proposed an Energy Planning and Management Program (EPAMP), which would link long-term customer planning with its power marketing program.

When EPAct was passed in October 1992, it included an amendment to Title II of the Hoover Power Plant Act, which regulates WAPA to require its customers to prepare IRPs. The EPAct regulations closely

\footnotetext{
${ }^{4}$ WAPA supplies less than $30 \%$ of the electrical energy required by the majority of its customers, while SEPA and SWPA both provide less than $15 \%$.
} 
parallel WAPA's proposed EPAMP and set seven criteria for WAPA's approval of customer IRP submittals. In addition, EPAct establishes specific penalties for noncompliance by WAPA customers, including rate surcharges and reduced power allocations. WAPA's IRP requirements (which are to be finalized in the spring of 1995) will have a profound effect on WAPA's $600+$ customers, including more than 400 publicly and cooperatively owned utilities in 15 western states. ${ }^{5}$ WAPA estimates that less than $10 \%$ of its customers are currently "covered" by an IRP. ${ }^{6}$ Those customers that are covered by an IRP are predominantly large utilities (e.g., Kansas City Board of Public Utilities and Sacramento Municipal Utility District) or utilities that are required to conduct IRP in response to state PUC mandates (e.g., Arizona Electric Power Cooperative and its seven member distribution cooperatives).

WAPA offers a wide variety of services to support its customers' energy efficiency, renewable energy, and IRP efforts. Since the inception of its Energy Services program in 1981, WAPA has provided equipment loans, workshops, peer matches, awards, and an array of other services. IRP support activities sponsored by WAPA include IRP workshops, technical assistance to selected customers for the development of IRPs, and development of improved DSM data for use in resource planning. WAPA launched a major initiative in 1988 to develop a set of IRP support tools to help small- to mid-sized utilities analyze supply-side and demand-side management alternatives as part of an IRP process. The Resource Planning Guide ( $R P G$ ), which was jointly developed with SWPA, includes six workbooks and associated computer software. It was released in April 1994 and offered at no cost to the customers of WAPA and SWPA.

To accomplish its Energy Services program, WAPA has committed significant personnel and financial resources. Its program staff has grown from about 18 FTEs in 1980 to approximately 37 FTEs in 1993, and is anticipated to grow to $50+$ individuals within the next 5 years. The program's FTE are spread throughout the agency's 15-state service territory and consist of about half WAPA personnel and half contractor personnel. The fiscal year (FY) 1993 Energy Services program budget of $\$ 4.4$ million is equivalent to about $0.5 \%$ of the agency's total budget. This budget has increased steadily from $\$ 500,000$ in FY 1981, and is planned to increase further to $\$ 5$ million in FY 1995, subject to federal funding availability.

SWPA's Energy Efficiency and Renewable Resources (EERR) program provides IRP-related services to the agency's 90 customers in Kansas, Missouri, Oklahoma, Arkansas, Texas, and Louisiana. At present, the program's main focus is information dissemination. For example, SWPA purchases efficiency and renewable energy publications at bulk and distributes them to its customers. SWPA also has co-sponsored WAPA workshops for publicly and cooperatively owned utilities in Kansas because a number of these utilities receive power allocations from both agencies. SWPA has an equipment loan program and is cofunding RPG development with WAPA. SWPA's EERR program is staffed by one of the agency's 186 FTEs.

In 1992, SWPA developed an IRP clause for inclusion in all new or updated power contracts that states"...the customer agrees to the extent practical to perform activities associated with IRP in securing future power resources... ." The contract clause does not establish a schedule for customer IRP efforts, nor does it require customers to submit an IRP to SWPA. In addition, the clause will not be incorporated into most customer contracts in the near term because most purchasers have long-term contracts in place. Currently, only a few of SWPA's 90 customers practice IRP. However, SWPA estimates that at least 50\%

\footnotetext{
${ }^{5}$ In addition to some 400 publicly and cooperatively owned utilities, WAPA serves approximately 200 other customers, including IOUs, state agencies, and other federal agencies.

${ }^{6} \mathrm{~A}$ utility is considered to be "covered" by an IRP if it either practices IRP on its own or is included within an IRP prepared by another entity (e.g., a generation and transmission [G\&T] cooperative, joint action agency, BPA, TVA, etc.).
} 
of its customers will be covered by an IRP within the next 5 years. This estimation reflects an increase in voluntary IRP practice, coupled with the compliance of SWPA's Kansas customers with WAPA's requirements. In addition, some of the states in SWPA's service territory are currently going through an IRP rulemaking process that may affect a number of publicly and cooperatively owned utilities.

SEPA's IRP activities were initiated in 1991, when an IRP management plan was submitted to DOE headquarters for approval and a program management position was established at SEPA. To date, the program has focused primarily on education and information dissemination services for the agency's 300 publicly and cooperatively owned utilities located in ten southeastern states. These services have included holding meetings with customers to plan IRP activities in various regions, making presentations at numerous customer board meetings and annual meetings, and sponsoring several orientation seminars and training workshops. In 1993, SEPA adopted a new power marketing policy for its Cumberland Basin Project that includes an Energy and Economic Efficiency Measures clause stating that "each customer who purchases Southeastern's power is encouraged to participate in an integrated resource plan that considers both supply and demand side alternatives." The clause also states that "all Southeastern customers shall agree to encourage the efficient use of energy by ultimate customers." This clause will affect the agency's ten Cumberland Basin Project customers (including several suppliers who serve numerous distribution utilities) as soon as the power sales contracts for this project are renewed. SEPA also anticipates adding this IRP clause to all future power sales contracts. SEPA provided $\$ 55,000$ to co-fund APPA's "What Works in DSM" project and will participate in funding further development and implementation of the RPG.

SEPA's IRP program may be relatively new, but the agency's customers include a number of the nation's leaders in publicly and cooperatively owned utility IRP. SEPA estimates that more than $50 \%$ of its 300 utility customers are currently covered by an IRP. This reflects TVA's IRP activities along with extensive IRP practice amongst SEPA's cooperative customers. Virtually all of the cooperative systems (i.e., G\&Ts and their member distribution cooperatives) served by SEPA practice IRP, either voluntarily or under state requirements, along with several municipal systems. To support customer IRP efforts, SEPA dedicates one of its 42 staff persons to its IRP program. Program expenses are currently limited to personnel salary and miscellaneous expenses (e.g., publications, workshop costs, etc.).

APPA provides a range of IRP-related services to its $1,700+$ members. These services assist members in reaping the benefits of IRP, since APPA estimates that less than $10 \%$ of its members are currently covered by an IRP. APPA sponsors education courses and workshop sessions on IRP and develops IRP tools such as the "What Works in DSM" manual and associated training courses currently being developed. APPA developed and maintains a database of innovative public power projects, including supply-side and demand-side resource projects, to facilitate information sharing among its members.

APPA's Demonstration of Energy-Efficient Developments (DEED) program also provides financial assistance for IRP-related efforts. For example, a recent DEED grant supports a circuit rider who conducts commercial and industrial energy audits for the Nebraska Municipal Power Pool's public utility customers and their end-users. APPA has committed significant financial and personnel resources to support its IRP-related services. The program budget has grown from approximately $\$ 200,000$ in 1989 to close to $\$ 350,00$ in 1993 . The 1993 budget represents close to $5 \%$ of APPA's total budget. Staffing for these services averages about three FTE out of APPA's total staff of 60.

NRECA has supported the DSM and IRP efforts of its $900+$ member cooperatives for a number of years. To support the estimated $10 \%$ to $24 \%$ of its members currently covered by an IRP, as well as the remaining members who are not, NRECA provides education, information, and direct consulting assistance. For example, NRECA representatives speak at customer meetings, participate in training programs coordinated by statewide cooperative associations and federal power agencies, and support 
individual utility resource planning and implementation efforts. IRP-related topics also are addressed at NRECA's annual Marketing and DSM Conference and in various publications. NRECA has formed an IRP task force, consisting of G\&T representatives, consultants, and others, which meets periodically to address IRP issues. In addition, an IRP Technical Advisory Committee (TAC) of the G\&T managers group was formed during 1993. Currently, approximately four of NRECA's 500+ employees provide IRPrelated services. Because NRECA charges its members a fee for the majority of these services (e.g., education programs, consulting assistance, etc.), the agency has no IRP budget per se.

IRP is a fundamental consideration within the REA's loan review process. The REA considers Part 1710 of the agency's 1992 rule on "General and Pre-loan Policies and Procedures Common to Insured and Guaranteed Loans" to be an IRP requirement for the nation's cooperatively owned utilities. The rule requires two primary documents-power requirements studies and construction work plans-to be submitted by its borrowers on a routine basis. REA's requirements reflect various elements of the IRP process, with greatest emphasis on load forecasting, DSM, and supply-side activities. With the passage of the 1993 Rural Electric Restructuring Act, REA's IRP-related authority has expanded. REA now provides loans for a wider range of resources (including all types of DSM) and requires an IRP plan prior to approval of loans that include funds for DSM and/or renewable energy systems.

REA also provides information support and technical assistance to its borrowers. This includes sponsoring load forecasting workshops, participating in workshops sponsored by G\&Ts and federal power agencies, and assisting G\&T borrowers in resource planning. These services are primarily accomplished through the part-time commitment of one of REA's 175 electric division staff.

In 1992, APPA, NRECA, WAPA, SWPA, and SEPA established an IRP Working Group. In founding the group, the various organizations recognized the similarity of their IRP missions and needs. The group's objectives include cross-fertilization of IRP advancement approaches, coordination of efforts to avoid duplication, and joint projects to take advantage of economies of scale. The IRP Working Group meets on a regular basis (2-4 times per year). 


\section{Barriers and Solutions Identification}

A number of barriers to IRP advancement-for both the key participants and their constituents-are identified by the Needs Assessment. These are barriers that DOE's IRP advancement strategy needs to address. The Needs Assessment also identified a number of potential solutions to these barriers, which the key participants believe should be incorporated into DOE's strategy. These various barriers and solutions are discussed below.

\section{Barriers to IRP Advancement}

The key participants identified a number of barriers that limit IRP advancement within the public utility sector. These include:

- Conservative attitudes of utility boards and managers;

- Financial and manpower constraints;

- Unavailable or unreliable data;

- Lack of coordination or cooperation between non-vertically integrated suppliers and distributors in such areas as pricing and DSM resource implementation;

- Inconsistent regulations;

- Perceptions that IRP is biased toward conservation and DSM activities;

- Access to transmission; and

- Limitations to the key participant agencies' ability to advance IRP, including procurement problems and constraints dictated by authorizing legislation.

Conservative attitudes among utility boards and managers is one of the most significant barriers to IRP advancement, according to the key participants. Many publicly and cooperatively owned utilities are focused on operational issues and emphasize traditional supply-side approaches. As a result, IRP's worth is not perceived in the same light as these traditional activities. Often, utility boards and managers take a "wait and see" attitude toward IRP and do not adopt the practice unless it is required by an outside entity. The key participants indicated that utility boards (e.g., city councils and cooperative directors) are particularly conservative with respect to IRP. To a lesser extent, the Steering Committee representatives also indicated that conservative executives and managers within their own agencies represent a barrier to IRP advancement.

Most of the key participants emphasized that financial and manpower constraints pose a serious barrier to public utility IRP advancement. However, one representative emphasized that utility resources can be reallocated if other, more serious, barriers are overcome (e.g., pricing issues, data limitations, etc.). Limited financial and personnel resources represent a particular challenge for the numerous small- to medium-sized public utilities; however, this barrier also applies to many larger systems. In fact, all key participants indicated that financial and manpower constraints are a barrier to IRP advancement within their own agencies. The consensus among the key participants is that manpower constraints represent a more significant barrier than financial limitations. Manpower constraints include both a lack of available personnel and a lack of personnel with IRP experience and expertise.

Several key participants emphasized the link between resource limitations and conservative attitudes among utility boards and managers. Financial and manpower constraints within publicly and cooperatively owned utilities can lead to low management priority for IRP activities (i.e., IRP loses out to traditional utility activities). Alternatively, strong board and/or management commitment to IRP can result in increased resource expenditures for IRP. 
Current limitations to the availability of reliable data on DSM resources and other non-traditional planning issues (e.g., externalities) also present a barrier to IRP practice for the nation's publicly and cooperatively owned utilities. One key participant stated, "If good data doesn't exist, you can't do a good IRP," and another indicated that some utilities are currently "making bad decisions with bad data."

A lack of coordination or cooperation between suppliers and distributors is another barrier limiting IRP advancement for non-vertically integrated utility systems (e.g., G\&Ts and their member distribution cooperatives and joint action agencies and their local utility members). This barrier reflects equity and cost-allocation issues that are typically difficult for these systems to resolve, leading to a lack of coordination or even outright non-cooperation. Because IRP tends to bring equity and cost-allocation issues to the forefront, its practice can be particularly challenging for non-integrated publicly and cooperatively owned utility systems.

According to key participants, two equity and cost-allocation issues that are typically addressed as part of an IRP are pricing and DSM resource implementation. Wholesale pricing structures that are not costbased can send inappropriate price signals to retail systems, preventing cost-effective resource planning decisions. Disagreements over appropriate wholesale and retail pricing can prevent non-integrated systems from developing optimal rate structures. The implementation of DSM resources, and other decentralized resource options also creates significant equity and cost-allocations issues. For example, non-integrated utility systems face challenges in equitably distributing the benefits of DSM resources implemented in the service area of a particular distribution utility across the entire system. One key participant speculates that IRP may lead to the "disintegration" of some non-vertically integrated publicly and cooperatively owned utility systems.

Inconsistent IRP regulations are another barrier to IRP advancement identified by the key participants. Multiple IRP requirements faced by some publicly and cooperatively owned utilities (e.g., state, regional, and/or national) can result in administrative burdens and potential conflicts. For example, REA has concerns about dual reporting because about 600 of its borrowers are customers of federal power agencies that may establish different IRP submittal criteria and schedules. Further, utilities with multiple IRP requirements could face incompatible or contradictory criteria, which could present serious conflicts for individual utilities as well as for the regulating agencies. Finally, the key participants emphasized that the lack of a consistent and appropriate IRP process for publicly and cooperatively owned utilities has limited the legitimization of this planning practice.

Many publicly and cooperatively owned utilities perceive that the primary purpose of IRP is to promote conservation or DSM activities. Representing IRP in this manner (i.e., "painting of IRP in DSM colors") reduces utility acceptance. This barrier is particularly problematic in regions with significant surplus electrical resources. Transmission access is another barrier to public utility IRP advancement. Because most publicly and cooperatively owned utilities do not own extensive transmission, (many pay for wheeling over another utility's lines and others are joint participants in facilities owned by another prime player), their ability to acquire and move resources is often limited.

The key participants cited several barriers that limit their agency's own ability to advance IRP. First, the federal procurement process can prohibit valuable interagency IRP cooperation. For example, SEPA experienced significant difficulties providing funding to APPA for the "What Works in DSM" project. And WAPA and other federal agencies have attempted unsuccessfully to contract with NRECA. The authorizing legislation for a federal power agency also can constrain IRP advancement. For example, WAPA indicated that it is unable to "practice what it preaches" (a complaint issued by customers) because it has no legal authority to develop and implement resource options. 


\section{Potential Solutions}

The Needs Assessment identifies a number of potential solutions to the above barriers for consideration in DOE's IRP advancement strategy. These include:

- Increased education and information dissemination;

- Development of IRP tools for smaller utilities;

- Data development, especially in the DSM and externalities areas;

- Technical assistance to supplement personnel resources;

- Financial assistance and incentives;

- Development of consistent IRP requirements;

- Pricing reform; and

- Transmission planning and access by federal power agencies.

Increased education and information dissemination is a high-priority solution for addressing many of the above-identified barriers. According to the key participants, education and information dissemination needs include increased training for their staff and policy makers, as well as training for utility managers and boards. Suggested information dissemination channels include using existing state and regional utility association networks and developing bulletin board services and regional IRP clearinghouses. Information dissemination activities should emphasize the sharing of utility IRP experiences and success stories. In addition, education and outreach activities are needed within the financing community (i.e., lenders and bond rating agencies), as well as manufacturing and industry associations (e.g., the manufactured housing industry).

The development of tools for publicly and cooperatively owned utility resource planning can help overcome IRP advancement barriers, including financial and manpower constraints. The key participants indicated that this solution is particularly relevant to the publicly owned utility sector, which includes hundreds of smaller utilities. G\&T cooperatives and other large supplier/distributor systems typically use more sophisticated resource planning tools, which are available from private companies or utility research organizations such as EPRI (e.g., DSMANAGER, PROSCREEN, UPLAN, etc.). This solution should focus on the development of methods and tools for DSM screening and impact and process evaluation, as well as on the development of "turnkey" DSM packages to facilitate implementation of these resource options. In addition, there is a real need for methods and tools to consider and value various external resource costs (e.g., environmental and social costs). Such methods and tools should be robust enough to accommodate the diverse applications for addressing externalities within the IRP process, thus allowing each user to apply the tool according to the local situation.

Publicly and cooperatively owned utilities also need reliable data to make accurate IRP decisions. Specific solutions suggested by the key participants include quantification and validation of DSM data, improved data on environmental externalities, and expanded information on alternative resource technologies (e.g., agricultural efficiency technologies). In addition, localized data acquisition is needed, as are data gathering and coordination at the regional and/or federal levels.

Technical assistance is another potential solution to IRP advancement barriers. For example, utility personnel resources can be supplemented by consulting services provided through state and regional utility associations. Circuit riders-who share their expertise among a number of small utilities-could help ease manpower constraints. Mobile IRP technical centers also could be established to assist small, dispersed utilities.

Several key participants indicated that financial assistance and incentives are needed to overcome IRP advancement barriers. One participant suggests cost-shared funding for additional key participant and/or 
constituent utility IRP staff. For example, the assistance could cover $50 \%$ of salaries for a limited time period (say 3 years) with the expectation that the recipient organization continues to fund the position on a long-term basis. Other suggestions include the development of financing mechanisms and incentives for the acquisition of alternative resources. One key participant suggested that DOE offer awards for superior IRP performance for various types and sizes of public utilities.

IRP requirements can be a solution for overcoming barriers to IRP advancement. While key participants generally consider such requirements, or regulations, to be undesirable solutions, they also recognize the inevitability of some state and federal mandates. As one participant stated, the IRP advancement project "needs to examine the regulatory issues and opportunities-frankly, it is one of the few things that has worked." Another suggested that it may be "better to have IRP requirements and not need them, rather than to need them and not have any." However, another key participant emphasized that "regardless of legislation that may exist, it is the marketing approach-not the enforcement approach-that really works. It is critical to sell the benefits of IRP and get people on board."

All the key participants agree that the development of consistent IRP requirements for publicly and cooperatively owned utilities is an overriding need. Consistent IRP definitions and criteria, as well as reporting formats and submittal frequencies, are key to legitimizing the IRP process and reducing administrative burdens. Specific solutions suggested by participants focus on working with federal and state regulating agencies to coordinate efforts and develop consistent IRP requirements.

Pricing reform can help overcome IRP barriers that are particularly troublesome for non-vertically integrated publicly and cooperatively owned utility systems. Key participants suggest aligning rates with cost-of-service and developing appropriate rate designs consistent with resource planning needs.

Federal power agencies such as WAPA, which owns and manages an extensive transmission grid, can help overcome barriers to publicly and cooperatively owned utility transmission access. Federal transmission planning can reflect IRP principles and consider customer needs. In addition, federal power grids can facilitate public utility access to alternative resources. For example, WAPA has provided customers with enhanced transmission access through a number of means, including line extensions to alternative resource projects, purchase of renewable energy project power, and contractual agreements with customers to increase their access to resource options.

To ensure that DOE's IRP advancement strategy makes the best use of available resources, the key participants recommend targeting utilities that have a significant need for help. For example, the strategy could target utilities in regions with a current need for new resources or those that are approaching load resource balance (i.e., minimize efforts in surplus regions). Other targets for IRP advancement could be publicly and cooperatively owned utilities with high supplemental supply costs or those facing stringent air quality or other environmental requirements. In addition, the key participants suggest that regional IRP working groups be established to assist in strategy development and to target priority solutions.

Once the IRP advancement targets, or priorities, have been identified, key participants suggest investing DOE resources to assist utility leaders to successfully implement IRP. These models of success can then provide a foundation for educating and assisting other publicly and cooperatively owned utilities in the adoption of IRP practices. 


\section{Appendix B}

\section{Public Power Survey}

Prepared by:

Garrick \& Associates

Principal Investigator: Cynthia J. Garrick

Originally prepared in July 1994 


\section{Acknowledgments}

The extensive survey results presented in this report were made possible by the contributions of the Advancement of IRP in Public Power Steering Committee. The efforts of the following Committee members are greatly appreciated: Barry Moline of the American Public Power Association, Mike Bull and Eric Westman of the Bonneville Power Administration, Rob Church and Mike Oldak of the National Rural Electric Cooperative Association, Georg Shultz of the Rural Electrification Administration, Bill Stewart and Kim Ledbetter of Southeastern Power Administration, Jerry Martin of Southwestern Power Administration, Dr. Lynn Maxwell of the Tennessee Valley Authority, and Theresa Williams and Randy Manion of Western Area Power Administration.

Special thanks to the American Public Power Association (APPA) for sponsoring the IRP survey for publicly owned utilities. APPA's involvement was critical to the achievement of required response rates for their constituent utilities. Georg Shultz' contributions to the IRP survey of cooperative utilities is also greatly appreciated. Mr. Shultz was instrumental to the success of the cooperative survey. 


\section{Summary}

This report, Public Power Survey, presents the findings of a survey of publicly and cooperatively owned utilities throughout the United States. The survey was sponsored by DOE and conducted by NREL and subcontractor Garrick \& Associates as part of the DOE-sponsored Advancement of IRP in Public Power program.

Through its Advancement of IRP in Public Power efforts, DOE is developing a 5-year strategy to advance IRP practice in the publicly and cooperatively owned utility sector, which accounts for $25 \%$ of the nation's electricity sales. In support of the overall IRP advancement program, NREL and Garrick \& Associates surveyed publicly and cooperatively owned utilities across the United States to accomplish the following:

- Establish a baseline for the current level of IRP activity;

- Identify factors (e.g., drivers and barriers) that influence IRP activity; and

- Determine the level of interest in various types of IRP advancement assistance, including information, tools, data, and technical and financial assistance.

An extensive mail survey was performed during late 1993 and the first half of 1994. Given the diversity of publicly and cooperatively owned utilities, the survey sample was stratified into four utility types: two types of publicly owned (or government-owned) utilities, joint action agencies (JAAs) and municipal utilities, and the two types of cooperatively owned utilities, generation and transmission cooperatives (G\&Ts) and distribution cooperatives. Each of the four utility types was further stratified by geographic region to identify regional variations in public utility IRP activities and needs. The six regions addressed in the survey reflect the regions served by the various federal power agencies, including the BPA, SEPA, SWPA, TVA, and WAPA. A "Non-PMA" region was also defined as those areas not served by a federal power agency-primarily in the northeastern and central/mid-western states.

IRP questionnaires were sent to more than 1,450 publicly and cooperatively owned utilities, including all of the nation's JAAs and G\&Ts and a statistically valid sample of municipal utilities and distribution cooperatives. More than 650 utilities responded, providing reliable findings at a minimum level of confidence of $90 \%$.

The Publicly Owned Utilities section of this report presents the survey results for JAAs and municipal utilities, while the Cooperatively Owned Utilities section presents survey results for G\&Ts and distribution cooperatives. The survey findings provide a reference point regarding the current IRP practices of the four types of utilities, as well as the reasons for and limitations to these practices. The findings also indicate numerous types of IRP assistance that are desired by publicly and cooperatively owned utilities, including data, tools, information, and technical and financial assistance. The results of this survey will be interpreted and used as a major source for the development of DOE's IRP Advancement Strategy. 


\section{Contents}

Introduction $\ldots \ldots \ldots \ldots \ldots \ldots \ldots \ldots \ldots \ldots \ldots \ldots \ldots \ldots \ldots \ldots \ldots$

Integrated Resource Planning $\ldots \ldots \ldots \ldots \ldots \ldots \ldots \ldots \ldots \ldots \ldots \ldots$

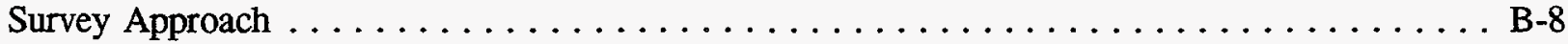

Publicly Owned Utilities . . . . . . . . . . . . . . . . . . . . . . B-12

Joint Action Agencies $\ldots \ldots \ldots \ldots \ldots \ldots \ldots \ldots \ldots \ldots \ldots \ldots \ldots \ldots \ldots$. . . . . . . . . . . . . . . .

Municipal Utilities $\ldots \ldots \ldots \ldots \ldots \ldots \ldots \ldots \ldots \ldots \ldots \ldots \ldots \ldots \ldots \ldots \ldots$

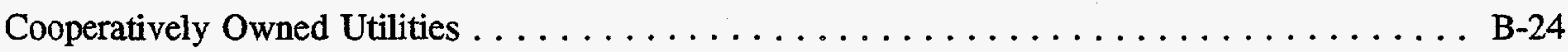

G\&T Cooperatives . . . . . . . . . . . . . . . . . . . . . . . . B-24

Distribution Cooperatives $\ldots \ldots \ldots \ldots \ldots \ldots \ldots \ldots \ldots \ldots \ldots \ldots \ldots \ldots \ldots \ldots$ B-31

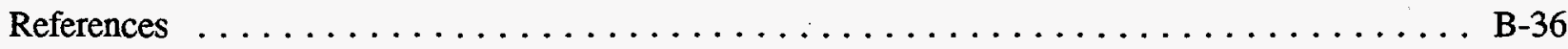

Attachment A: Glossary of Terms . . . . . . . . . . . . . . . . . . . B-37

Attachment B: Publicly Owned Utility Survey Instrument $\ldots \ldots \ldots \ldots \ldots \ldots \ldots \ldots \ldots$

Attachment C: G\&T Cooperative Survey Instrument $\ldots \ldots \ldots \ldots \ldots \ldots \ldots \ldots \ldots$

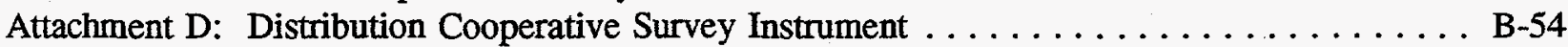

Attachment E: Regional IRP Assistance Needs $\ldots \ldots \ldots \ldots \ldots \ldots \ldots \ldots \ldots \ldots$. . . . . . . . . . . 


\section{List of Figures}

Page

1. Survey regions $\ldots \ldots \ldots \ldots \ldots \ldots \ldots \ldots \ldots \ldots \ldots \ldots \ldots \ldots \ldots$

2. Responding joint action agencies that prepare IRPs, by region $\ldots \ldots \ldots \ldots \ldots \ldots \ldots$ B-14

3. Reasons for joint action agency IRP $\ldots \ldots \ldots \ldots \ldots \ldots \ldots \ldots \ldots \ldots \ldots$ B-14

4. Limitations to joint action agency IRP $\ldots \ldots \ldots \ldots \ldots \ldots \ldots \ldots \ldots \ldots \ldots \ldots$

5. Responding municipal utilities that prepare IRPs, by region $\ldots \ldots \ldots \ldots \ldots \ldots \ldots \ldots$ B-20

6. Reasons for municipal utility IRPB-20

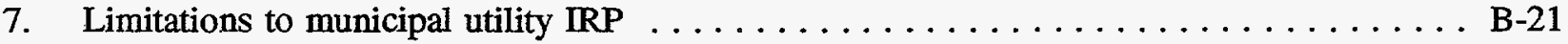

8. G\&T IRP elements: extent of member distribution cooperative involvement . . . . . . . B-27

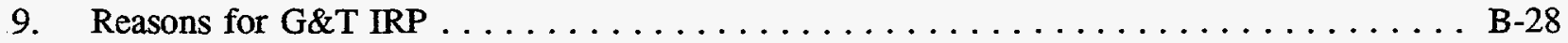

10. Factors influencing G\&T IRP $\ldots \ldots \ldots \ldots \ldots \ldots \ldots \ldots \ldots \ldots \ldots \ldots \ldots \ldots$. . . . . . . $\ldots \ldots$

11. IRP practice of responding distribution cooperatives $\ldots \ldots \ldots \ldots \ldots \ldots \ldots \ldots \ldots$ B-33

12. Factors influencing distribution cooperative IRP $\ldots \ldots \ldots \ldots \ldots \ldots \ldots \ldots \ldots \ldots$

\section{List of Tables}

$\underline{\text { Page }}$

1. Elements of IRP $\ldots \ldots \ldots \ldots \ldots \ldots \ldots \ldots \ldots \ldots \ldots \ldots \ldots \ldots \ldots \ldots \ldots$

2. Statistical Validity of Survey Results $\ldots \ldots \ldots \ldots \ldots \ldots \ldots \ldots \ldots \ldots \ldots$. $\ldots \ldots$

3. Joint Action Agencies: Total Number vs. Survey Respondents . . . . . . . . . . B-13

4. Frequency of Joint Action Agency Practice of Various IRP Elements . . . . . . . . . . B-16

5. Social/Environmental Costing, Risk Analysis, and Public Involvement:

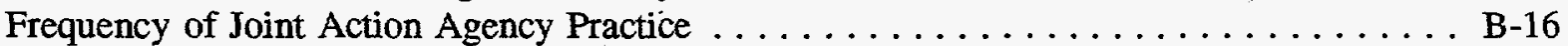

6. Municipal Utilities: Total Number vs. Survey Respondents . . . . . . . . . . . . B-19

7. Frequency of Municipal Utility Practice of Various IRP Elements . . . . . . . . . B B-22

8. Social/Environmental Costing, Risk Analysis, and Public Involvement:

Frequency of Municipal Utility Practice . . . . . . . . . . . . . . . . . B-22

9. G\&T Cooperatives: Total Number vs. Survey Respondents . . . . . . . . . . . . B-25

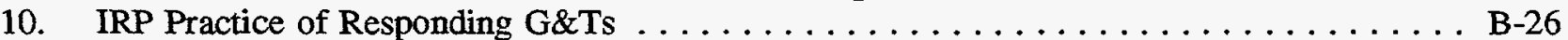

11. Distribution Cooperatives: Total Number vs. Survey Respondents . . . . . . . . . . . B-32 


\section{Introduction}

The nation's 3,000 publicly and cooperatively owned utilities are diverse and vary widely in size. Publicly owned utilities (also referred to as government-owned utilities) include state and municipal utilities and JAAs. Cooperatively owned utilities (also referred to as rural electric systems) include G\&Ts and distribution cooperatives. The largest of these utilities provide electricity to millions of people, while the smallest serve less than one hundred people. Publicly and cooperatively owned utilities are very diverse, yet can be distinguished by several key attributes: they are not-for-profit utilities; they are owned and/or controlled by the people they serve; and they receive preferential access to federal hydroelectricity.

\section{Integrated Resource Planning}

IRP is an approach to utility resource planning that integrates the evaluation of supply-side and demandside options for providing energy services at the least cost. IRP was first introduced in the late 1970s (EPRI 1987) to provide a planning approach that is more adaptable to fundamental changes impacting electric utilities than are traditional methods. These changes include increasing competition, deregulation of electricity generation, greater access to transmission, and increased concern with the environmental consequences of electricity production and use. In addition, there is considerable uncertainty about future load growth, fossil-fuel prices and availability, and the costs and construction lead-times for various resources (Goldman 1989).

As practiced by U.S. electric utilities, IRP typically involves some or all of the IRP elements described in Table 1. While all of the various elements listed in the table can be incorporated within an IRP process, it is important to note that many IRPs include only some of these elements or even additional elements, depending on a utility's particular situation or the nature of a particular IRP requirement. Once an IRP has been developed and approved (by the utility's governing and/or regulatory body[s]), the plan is implemented and resources are acquired. While the plan is in force, the utility monitors changes in its environment and its implementation of the resource plan, and the plan is modified as events and opportunities change over time. 
Table 1. Elements of IRP

\begin{tabular}{l}
\hline IRP Element \\
\hline Load Forecasting \\
Supply-Side Resource \\
Assessment
\end{tabular}

Demand-Side

Resource Assessment

Evaluating demand-side resources for meeting an electric utility's future resource requirements. A demand-side resource assessment may include the examination of peak clipping, valley filling, load shifting, strategic conservation, and strategic load growth.

\section{Consideration of Environmental and/or Social Costs}
Estimating future annual electricity use and peak demand requirements for use in making resource acquisition decisions.

Evaluating supply resources for meeting an electric utility's future resource requirements. A supply-side resource assessment may include the examination of a range of resources, including purchased power, alternative/renewable resources, life extension and re-powering of existing plants, utility construction of power plants, and new or upgraded transmission facilities.

Inclusion of various environmental and social costs and benefits, such as those related to air quality or economic development, in the evaluation of supply-side and demand-side resource options. In addition to the consideration of "internal" costs such as compliance with air quality regulations, many utilities consider "externalities" associated with electrical power production and use, which are not already incorporated in the price of electric services.

Integrated SupplySide and DemandSide Resource

Evaluation

A comparison of supply- and demand-side resources for the purpose of selecting the optimum mix of resources. The comparative evaluation allows equal consideration of both supply- and demand-side resource options.

Uncertainty/Risk Analysis

Analysis of a variety of possible future conditions and the options available to deal with them. By providing information about the relative risks of alternative resource strategies, uncertainty analysis facilitates better resource planning decisions that reduce risk.

Public Involvement

A public planning process ensures that a broad range of interests and potential resource options are considered by utility decision-makers and also helps to build consensus about the best resource plan.

\section{Survey Approach}

Through its Advancement of IRP in Public Power program, DOE is developing a 5-year strategy to advance IRP practice in the publicly and cooperatively owned utility sector, which accounts for about $25 \%$ of the nation's electricity sales. In support of the program, NREL and Garrick \& Associates mailed 
questionnaires to more than 1,450 publicly and cooperatively owned utilities across the United States. The questionnaires were intended to accomplish the following:

- Establish a baseline for the current level of IRP activity;

- Identify factors (e.g., drivers and barriers) that influence IRP activity; and

- Determine the level of public utility interest in various types of IRP advancement assistance.

The survey effort consisted of sample selection, instrument design, and execution of the survey. The mail survey was performed during late 1993 and the first half of 1994. Results of the survey were compiled and analyzed for presentation in this report and for use in development of DOE's IRP Advancement Strategy.

Given the diversity of U.S. publicly and cooperatively owned utilities, the survey sample was stratified into four utility types. These included two types of publicly owned utilities, JAAs and municipal utilities, ${ }^{1}$ and the two types of cooperatively owned utilities, G\&T cooperatives and distribution cooperatives.

A $100 \%$ sample of JAAs and G\&Ts was surveyed, while a statistically valid sample of municipal utilities and distribution cooperatives were contacted. All JAAs and G\&Ts were surveyed for two reasons. First, these utilities have resource planning responsibility for a majority of the nation's municipal utilities and distribution cooperatives. Second, a $100 \%$ sample is required to obtain reliable results, since there are only $38 \mathrm{JAAs}$ and $64 \mathrm{G} \& \mathrm{Ts}$ in the United States. Surveying a sample of the nation's 1,900+ municipal utilities and $850+$ distribution cooperatives provided statistically valid results while limiting the number of contacts made to these typically resource-constrained utilities.

Each of the four utility types was further stratified by geographic region to identify regional variations in public utility IRP activities and needs. The six regions addressed in the survey reflect the regions served by the various federal power agencies, including BPA, SEPA, SWPA, TVA, and WAPA. A "Non-PMA" region was also defined as those areas not served by a federal power agency-primarily in the northeastern and central/midwestern states. Alaska, Hawaii, and the U.S. territories were not addressed in the survey because of the limited number of publicly and cooperatively owned utilities located in these areas. The six regions, which cover the entire continental United States, are illustrated in Figure $1 .^{2}$

Survey results were thus obtained for 24 subsets (i.e., four utility types in each of six regions). These results provide an indication of regional variations in publicly and cooperatively owned utility IRP activity and assistance needs.

\footnotetext{
${ }^{1}$ For the purposes of the survey, the "municipal" utility segment includes municipally owned utilities as well as state-owned utilities and other publicly owned utilities such as public utility districts and irrigation/electrical districts.

${ }^{2}$ The regions defined for the survey are not exact. While PMA regions are based on power marketing territories (which often reflect watershed areas for hydroelectric facilities), the regions defined for the survey are based on state boundaries. Use of state boundaries permits alignment of survey data with EIA data, which is available on a state-by-state basis. In cases where a particular state is served by two PMAs, the state was assigned to the PMA that provides a majority of electricity sales in that state. For example, the entire state of Montana and all utilities located in Montana are assumed to be in the WAPA region, since WAPA provides the majority of electricity to publicly and cooperatively owned utilities in the state (BPA does serve a limited number of utilities in western Montana). The TVA region, which completely overlays the SEPA region geographically and does not conform to any state lines, was not defined by state boundaries. The TVA region was defined based on TVA's actual service territory and an exact list of publicly and cooperatively owned utilities served by TVA.
} 


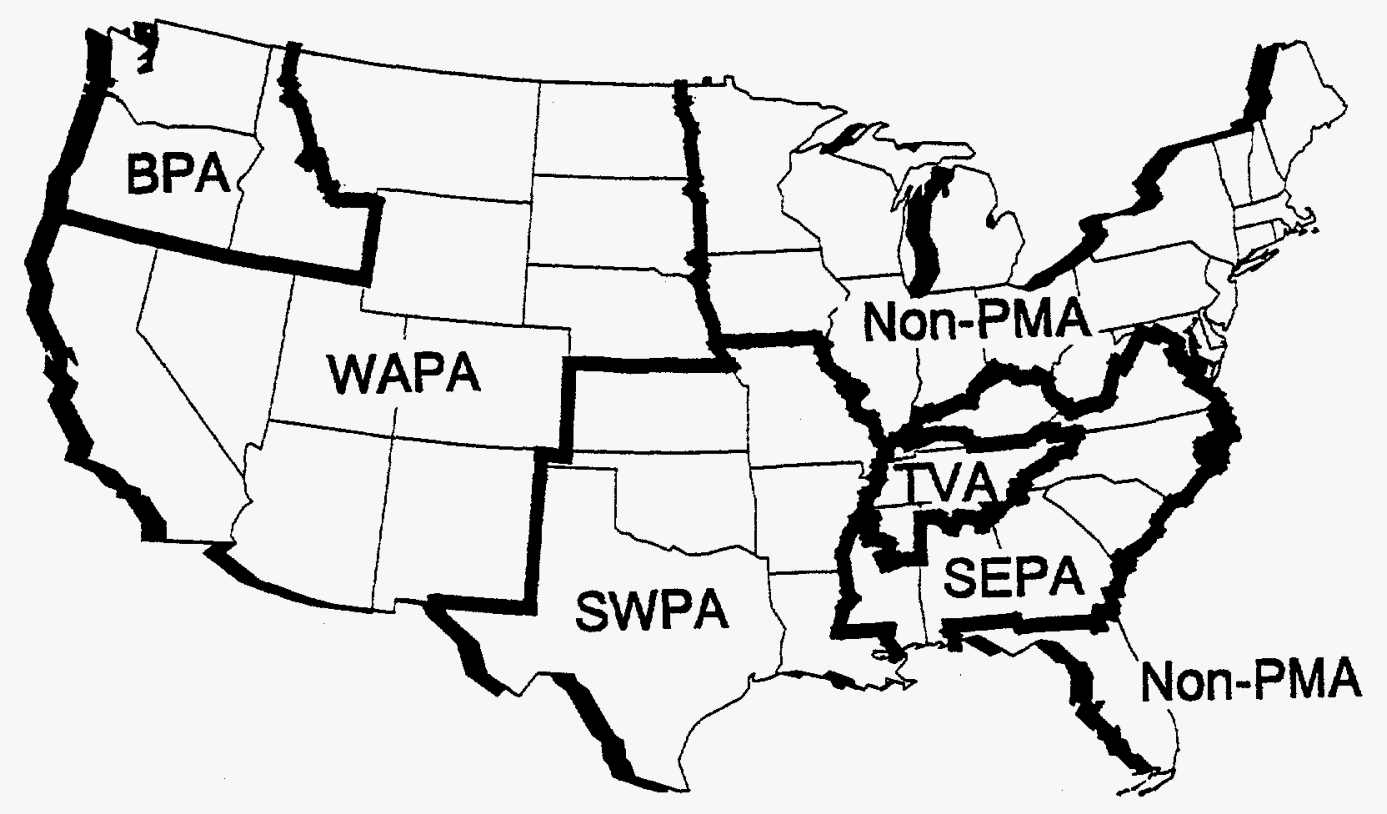

Figure 1. Survey regions

The survey was designed to achieve a $90 \%$ level of confidence with $\pm 10 \%$ margin of error within each of the 24 subsets, to the extent practical. Based on actual responses received within each subset, all subset results provide a minimum level of confidence of $90 \%$. Table 2 presents the margin of error of the survey results at $90 \%$ confidence for each utility type and regional subset. As shown, the margin of error for individual subsets ranges from $0 \%$ (i.e., $100 \%$ response) to more than $20 \%$. The margin of error associated with the "national" results for each of the four types of utilities is within the tolerance of $\pm 10 \%$ in all cases. In fact, the "national" results for both municipal utilities and distribution cooperatives achieve a $95 \%$ level of confidence with $\pm 5 \%$ margin of error. If all government-owned results were aggregated, the combined results would also provide a $95 \%$ level of confidence with $\pm 5 \%$ margin of error, as would aggregated cooperatively owned utility results.

The survey approach also entailed designing survey instruments to obtain the desired IRP information from the various types of publicly and cooperatively owned utilities. This included information regarding utility resource planning activities, reasons for and limitations to IRP, resource planning assistance of interest to these utilities, and resource planning-related utility profiles.

Attachment B provides the publicly owned utility survey, which was mailed to JAAs and municipal utilities during February 1994. Two follow-up mailings were also performed as part of the publicly owned utility survey effort.

Attachments $C$ and D provide the cooperatively owned utility surveys for both the G\&Ts and the distribution cooperatives. More comprehensive and detailed cooperatively owned utility surveys have since been developed to satisfy EPAct reporting requirements, which state that DOE must conduct a 
Table 2. Statistical Validity of Survey Results

(Margin of Error at $\mathbf{9 0 \%}$ Confidence)

\begin{tabular}{|c|c|}
\hline Subset & $\begin{array}{c}\text { Margin of Error } \\
(+\%)\end{array}$ \\
\hline Joint Action Agency & 6.7 \\
\hline BPA region & 0 \\
\hline Non-PMA region & 14 \\
\hline SEPA region & 0 \\
\hline SWPA region & 0 \\
\hline TVA region & $\mathrm{n} / \mathrm{a}$ \\
\hline WAPA region & 14 \\
\hline Municipal Utility & 4.2 \\
\hline BPA region & 8.2 \\
\hline Non-PMA region & 10.2 \\
\hline SEPA region & 10.4 \\
\hline SWPA region & 10.6 \\
\hline TVA region & 8.5 \\
\hline WAPA region & 8.6 \\
\hline G\&T Cooperative & 6.1 \\
\hline BPA region & 21.4 \\
\hline Non-PMA region & 17 \\
\hline SEPA region & 12.3 \\
\hline SWPA region & 8.1 \\
\hline TVA region & n/a \\
\hline WAPA region & 11.5 \\
\hline Distribution Cooperative & 4.3 \\
\hline BPA region & 17.3 \\
\hline Non-PMA region & 9.2 \\
\hline SEPA region & 10.1 \\
\hline SWPA region & 8.7 \\
\hline TVA region & 15.2 \\
\hline WAPA region & 8.9 \\
\hline
\end{tabular}


survey of rural electric cooperative IRP practices and policies. ${ }^{3}$ The cooperative surveys were mailed during April 1994. Follow-up mailings to distribution cooperatives and telephone contacts with each G\&T were also conducted. As part of the EPAct-compliance effort, the REA provided some data regarding cooperative resource planning activities. ${ }^{4}$ The information provided by REA is presented in this report along with the cooperative utility survey findings.

Survey response data for JAAs, municipal utilities, G\&Ts, and distribution cooperatives were separately entered, compiled, and analyzed. Survey results are presented in the following two sections of this report. The Publicly Owned Utilities section presents survey results for JAAs and municipal utilities. The Cooperatively Owned Utilities section presents survey results for G\&Ts and distribution cooperatives. These sections present the current IRP activities of all four types of public utilities. The types of IRP assistance desired by these utilities are also presented.

\footnotetext{
${ }^{3}$ The results of the cooperatives survey are presented both in this report and in the Rural Electric Cooperatives IRP Survey report developed by NREL and Garrick \& Associates. This latter report is directed at the EPAct survey requirement (i.e., it presents only IRP practices and policies information).

${ }^{4}$ In December 1994, the REA became the Rural Utilities Service (RUS). The agency is referred to as REA throughout this document.
} 


\section{Publicly Owned Utilities}

The following sections present the current IRP activity and IRP assistance needs for the joint action agencies and municipal utilities responding to the NREL IRP survey. The Current IRP Activity subsections present the number of utilities indicating that they currently practice IRP and the frequency at which various IRP elements are performed. Reasons for publicly owned utility IRP are also presented, along with limitations to IRP practice. The IRP Assistance Needs subsections indicate utility interest in various types of IRP information, tools, data, and technical and financial assistance. A concise profile of joint action agencies and municipal utilities is also presented. Each Profile section includes a description of the utility sector as a whole and also characterizes survey respondents.

\section{Joint Action Agencies}

\section{Profile}

Joint action agencies are regional organizations formed by groups of utilities (typically by municipals) to jointly build or finance generation and transmission systems, contract for power supply, and share other services. JAAs are typically owned and operated by the member utilities who establish the agencies.

By nature, the primary responsibility of joint action agencies is to supply power to member distribution systems. Some JAAs provide $100 \%$ of their members' electrical requirements, while others serve as supplemental suppliers. The power transmitted by JAAs comes from self-generation and/or purchases from other suppliers. Some agencies purchase all of the wholesale power that they transmit (e.g., from federal power agencies, IOUs, and other public utilities), while others generate a significant portion of the supply. In addition to providing power supply services, many agencies provide other services, such as engineering, public relations, and legal support.

Thirty of the nation's 38 JAAs responded to the NREL IRP survey. As indicated in Table 3, the respondents are dispersed across all regions of the United States, with the exception of the TVA region, which contains no JAAs. One hundred percent of the JAAs located in the BPA, SEPA, and SWPA regions completed the survey, while $70 \%$ of the JAAs located in the Non-PMA and WAPA regions responded. Based on utility profile information provided through the survey, these 30 JAAs are characterized as follows:

- The 1993 annual systems sales of almost $60 \%$ of the agencies exceeded 1 million MWh. One JAA reported 1993 sales of less than 100,000 MWh, while the remainder had sales between 100,000 and 1 million MWh.

- More than $60 \%$ of the JAAs have fewer than 50 electric utility employees and only one has more than 500 employees.

- Half of the JAAs are experiencing service area load growth between $2.1 \%$ and $4 \%$ per year. Another one-third are experiencing $1.1 \%$ to $2 \%$ annual load growth. None of the JAAs report negative load growth.

- Sixty percent of the agencies have surplus capacity and energy resources, while only $7 \%$ are in resource deficit. The remaining agencies describe their situation as one of resource balance. 
Table 3. Joint Action Agencies: Total Number vs. Survey Respondents

\begin{tabular}{l|c|c}
\hline \multicolumn{1}{c|}{ Region } & $\begin{array}{c}\text { Total Number } \\
\text { of JAAs* }\end{array}$ & $\begin{array}{c}\text { Number of JAAs } \\
\text { Responding to Survey }\end{array}$ \\
\hline BPA & 1 & 1 \\
Non-PMA & 13 & 9 \\
SEPA & 6 & 6 \\
SWPA & 5 & 5 \\
TVA & 0 & 0 \\
WAPA & 13 & 9 \\
Total & 38 & 30 \\
\hline
\end{tabular}

* The list of JAAs contacted in the survey was taken from the American Public Power Association and modified as necessary to reflect the utility types and regions addressed in the survey.

\section{Current IRP Activity}

Sixteen of the 30 JAAs responding to the NREL IRP survey indicate that they prepare an IRP. As shown in Figure 2, seven of these JAAs are located in the WAPA region and five are located in the Non-PMA region. The remaining JAAs are located in the SEPA (2) and SWPA (2) regions. As illustrated in Figure 3, these JAAs indicate that the two most important reasons for IRP preparation are "to develop least-cost future resources" and "to become more competitive." In the SEPA and WAPA regions, meeting federal or state requirements is among the top two reasons for IRP, while addressing environmental considerations is a top reason in the Non-PMA region.

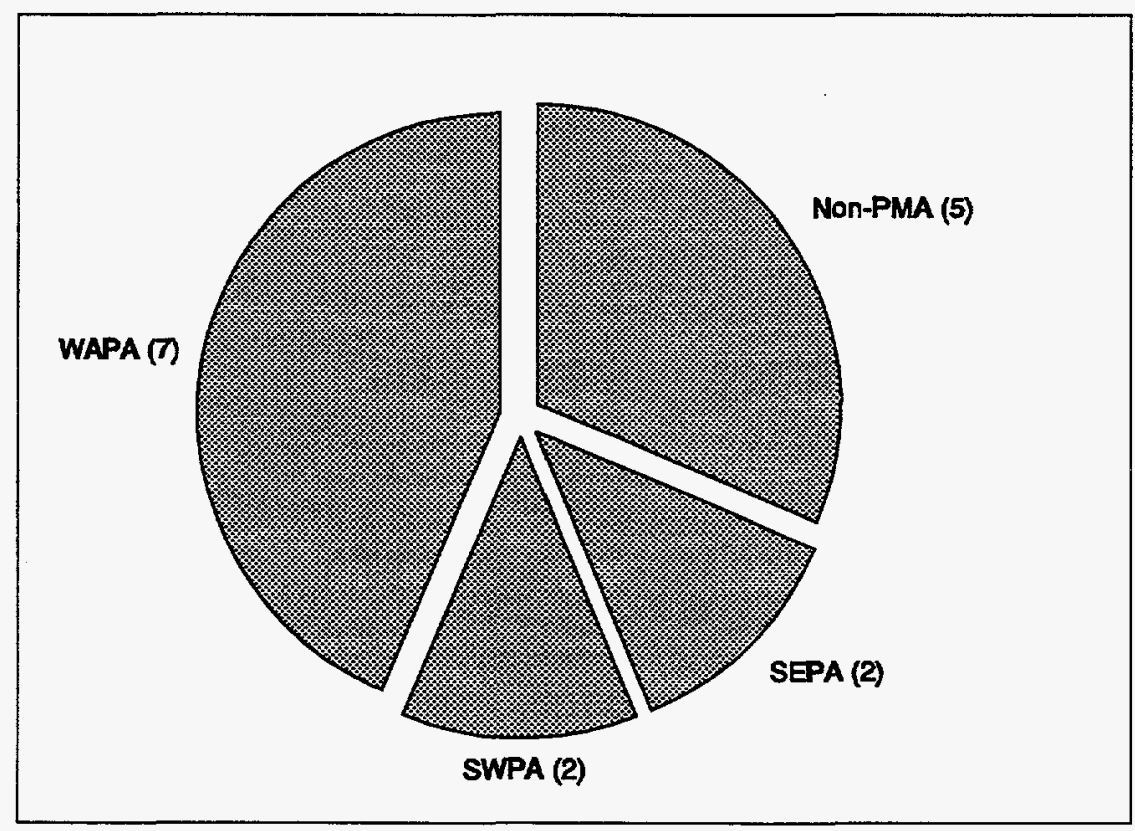

Figure 2. Responding joint action agencies that prepare IRPs, by region 


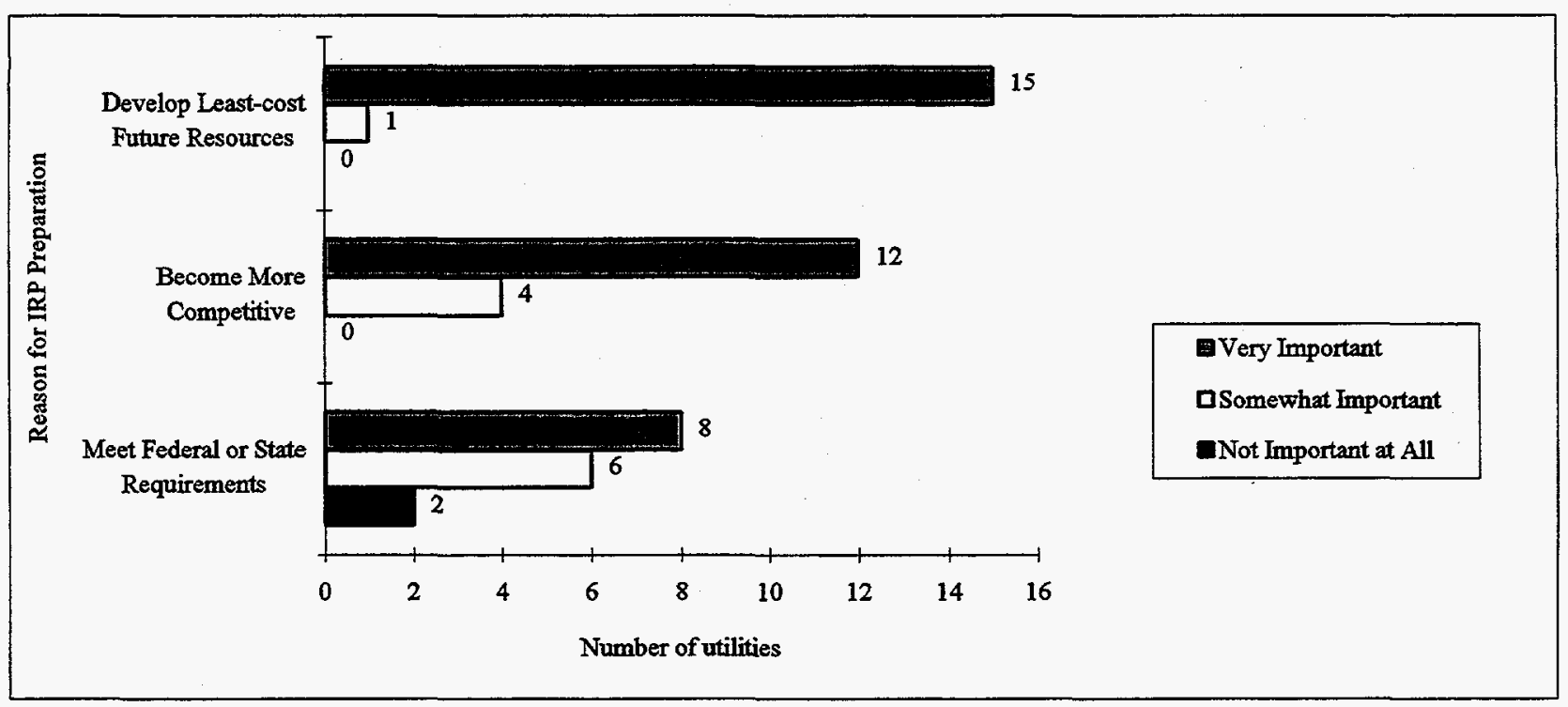

Figure 3. Reasons for joint action agency IRP 
The 14 JAA respondents that do not prepare IRPs provided information regarding reasons preventing utility IRP preparation. The most commonly cited limitations to JAA IRP preparation include surplus supply resources, limited financial and personnel resources, and unavailable/unreliable data (see Figure 4). One-third of the JAAs that do not prepare IRPs also indicate that long-term power contracts and conservative attitudes of utility boards and mangers are reasons for not preparing IRPs.

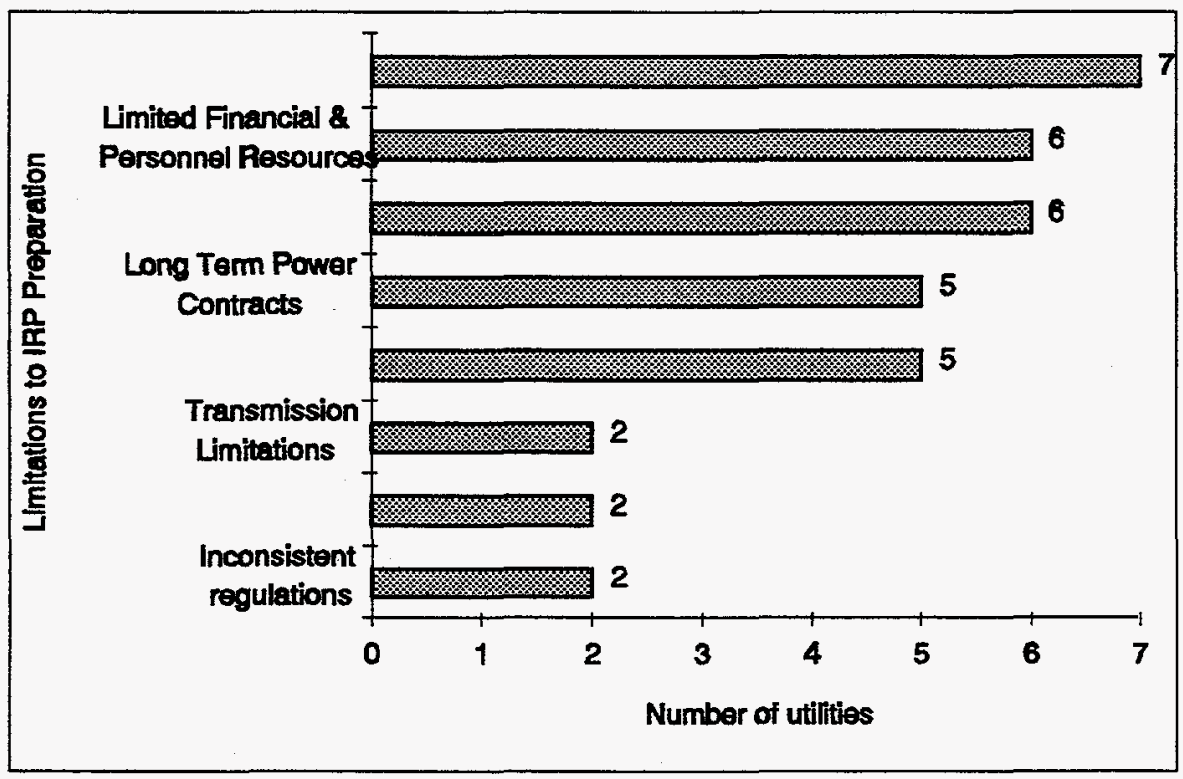

Figure 4. Limitations to joint action agency IRP

The responding JAAs also provided information regarding the frequency at which they practice various IRP elements. Tables 4 and 5 summarize this information and indicate that nearly all responding JAAs practice at least one or more of the elements of IRP, even though they may not necessarily prepare an IRP. Load forecasting and supply-side resource assessments are practiced by all but one or two of the JAAs (see Table 4), and are typically performed on an annual basis. Demand-side resource assessments and integrated supply-side and demand-side resource evaluations are also performed by more than two-thirds of JAA respondents, at frequencies ranging from every year to every 5+ years. As shown in Table 5, a majority of survey respondents indicate that uncertainty/risk analysis and public involvement are "always" performed as part of resource planning. Environmental and/or social costs are "always" considered by seven of the respondents and "sometimes" considered by 13 others.

Table 4. Frequency of Joint Action Agency Practice of Various IRP Elements

\begin{tabular}{l|c|c|c|c|c}
\hline \multicolumn{1}{c|}{ IRP Element } & Annually & $\begin{array}{c}\text { Every } \\
\text { 2 years }\end{array}$ & $\begin{array}{c}\text { Every } \\
3 \text { or 4 } \\
\text { years }\end{array}$ & $\begin{array}{c}\text { Every 5+ } \\
\text { years }\end{array}$ & Never \\
\hline Load Forecasting & 20 & 4 & 3 & 0 & 2 \\
Supply-Side Resource Assessment & 21 & 3 & 1 & 3 & 1 \\
Demand-Side Resource Assessment & 15 & 4 & 4 & 1 & 5 \\
Integrated Supply-Side and Demand- & 7 & 6 & 5 & 2 & 8 \\
Side Resource Evaluation & & & & & \\
\hline
\end{tabular}


Table 5. Social/Environmental Costing Risk Analysis and public Involvement: Frequency of Joint Action Agency Practice

\begin{tabular}{l|c|c|c|c}
\hline & Always & Sometimes & Never & $\begin{array}{c}\text { Don't } \\
\text { Know }\end{array}$ \\
\hline $\begin{array}{l}\text { Consideration of Environmental } \\
\text { and/or Social Costs }\end{array}$ & 7 & 13 & 9 & 0 \\
Uncertainty/Risk Analysis & 20 & 4 & 3 & 1 \\
Public Involvement & 16 & 7 & 4 & 0 \\
\hline
\end{tabular}

\section{IRP Assistance Needs}

The JAAs responding to the survey indicated their level of interest in approximately 25 types of IRP assistance, including information, tools, data, and technical and financial assistance. Based on the responses provided, the 15 types of IRP assistance that are most desired by the nation's JAAs are listed below in priority order.

1. Improved data on DSM impacts (e.g., $\mathrm{kW}, \mathrm{kWh}$, and economics);

2. Improved data on customer facility and end-use characteristics;

3. Improved data on customer attitudes and behavior;

4. Tools for integrated supply-side and demand-side resource evaluation (e.g., workbooks, software, etc.);

5. Publications;

6. Tools for DSM program selection (e.g., workbooks, software, etc.);

7. Grants;

8. Tools for load forecasting (e.g., workbooks, software, etc.);

9. Tools for impact and process evaluation (e.g., workbooks, software, etc.);

10. Improved data on regional power purchase options/costs;

11. Improved data on transmission and distribution options/economics;

12. Workshops and seminars;

13. Improved data on externality costs;

14. Electronic bulletin boards; and

15. Tools for costing externalities (e.g., workbooks, software, etc.).

Attachment E lists the top ten types of IRP assistance desired by JAAs located in each of the survey regions.

\section{Municipal Utilities}

\section{Profile}

Municipal utilities, like schools, parks, police, and fire protection, are a part of local government. They obtain power supply in two ways: self-generation and/or purchase from another supplier. Municipals purchase power from a range of sources, including JAAs, federal and state agencies, investor-owned utilities, and others including independent power producers, distribution cooperatives, etc. The average municipal system serves 1,750 meters, ${ }^{5}$ and two-thirds of municipal utilities serve 3,000 meters or fewer

\footnotetext{
${ }^{5}$ A municipal meter serves an average of three people.
} 
(Moline DSM, 1992). In addition to the nation's 1,800 municipally owned utilities, there are approximately 150 local and regional government-owned utilities that were classified as municipals for the purposes of this survey. These include six state power authorities that generate, transmit, and/or distribute electricity and more than 100 "other" utilities that include public utility districts, irrigation districts, Indian power authorities, and territorial power authorities.

Of the nation's 1,935 "municipal" utilities, 326 responded to the NREL IRP survey. As indicated in Table 6, the respondents are dispersed across all regions of the United States. Based on utility profile information provided through the survey, these 326 municipal utilities are characterized as follows:

- The 1993 annual systems sales of more than one-third of the utilities were less than 50,000 MWh. Less than 20\% reported 1993 sales of greater than 500,000 MWH, while the remainder had sales between 50,000 and 500,000 MWh.

- More than $75 \%$ of the municipals have fewer than 50 electric utility employees and less than $10 \%$ have more than 200 employees.

- Forty percent of the municipal utilities are experiencing service area load growth between $1.1 \%$ and $2 \%$ per year. Another $30 \%$ are experiencing $2.1 \%$ to $4 \%$ annual load growth, while close to $25 \%$ of the utilities report load growth of $0 \%$ to $1.0 \%$. Only a few municipals report either negative load growth or load growth greater than $4.1 \%$ per year.

- Fifty percent of the utilities describe their current electrical supply situation as one of capacity and energy balance, while another $40 \%$ have surplus capacity and energy resources. Less than $10 \%$ are in resource deficit.

Table 6. Municipal Utilities: Total Number vs. Survey Respondents

\begin{tabular}{lcc}
\hline Region & $\begin{array}{c}\text { Total No. } \\
\text { of Municipals* }\end{array}$ & $\begin{array}{c}\text { No. of Municipals } \\
\text { Responding to Survey** }\end{array}$ \\
\hline BPA & 70 & 41 \\
Non-PMA & 798 & 61 \\
SEPA & 209 & 48 \\
SWPA & 387 & 52 \\
TVA & 107 & 50 \\
WAPA & 364 & 74 \\
Total & $\mathbf{1 , 9 3 5}$ & $\mathbf{3 2 6}$ \\
\hline
\end{tabular}

* The list of municipalities contacted in the survey was obtained from the American Public Power Association and modified as necessary to reflect the utility types and regions addressed in the survey.

**Surveys were sent only to a representative sample of municipal utilities. 


\section{Current IRP Activity}

Eighty-two of the 326 municipal utilities responding to the NREL IRP survey indicate that they prepare an IRP. As shown in Figure 5, 22 of these utilities are located in the WAPA region and 19 are located in the Non-PMA region. Another 14 and 13 utilities are located in the BPA and SWPA regions, respectively. The remaining utilities are located in the SEPA (11) and TVA (3) regions. As illustrated in Figure 6, these municipal utilities indicate that the three most important reasons for IRP preparation are "to develop least-cost future resources," "to become more competitive," and "to support utility business objectives."

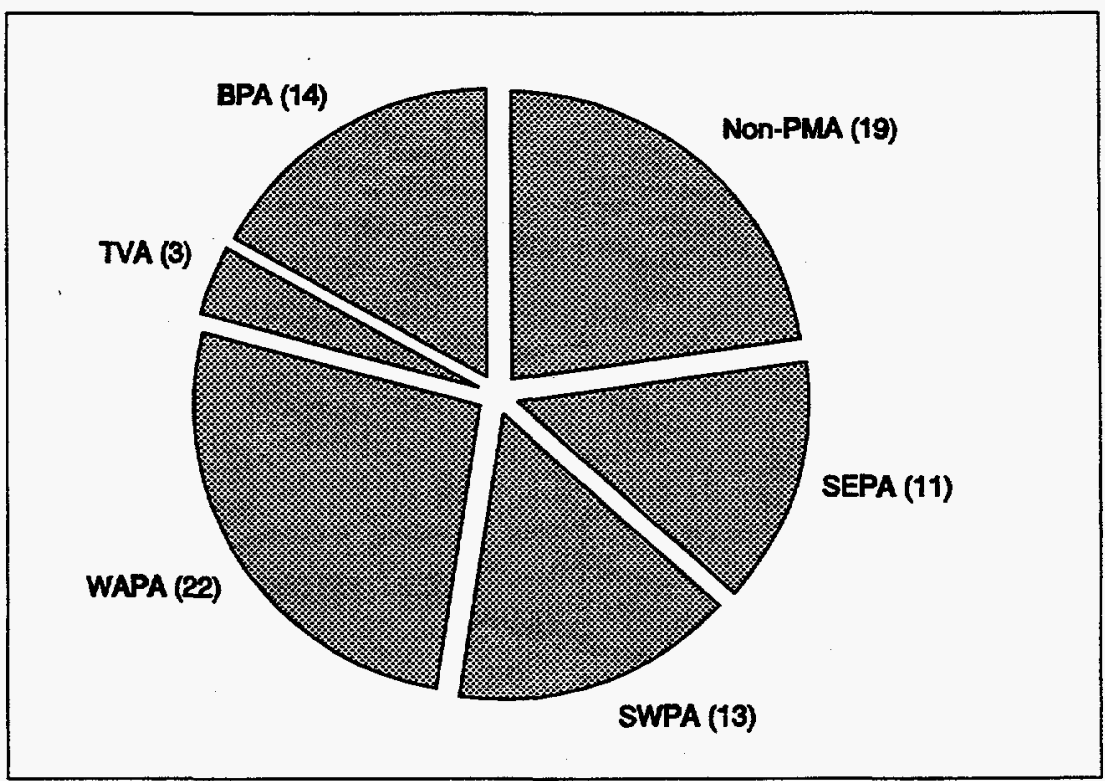

Figure 5. Responding municipal utilities that prepare IRPs, by region

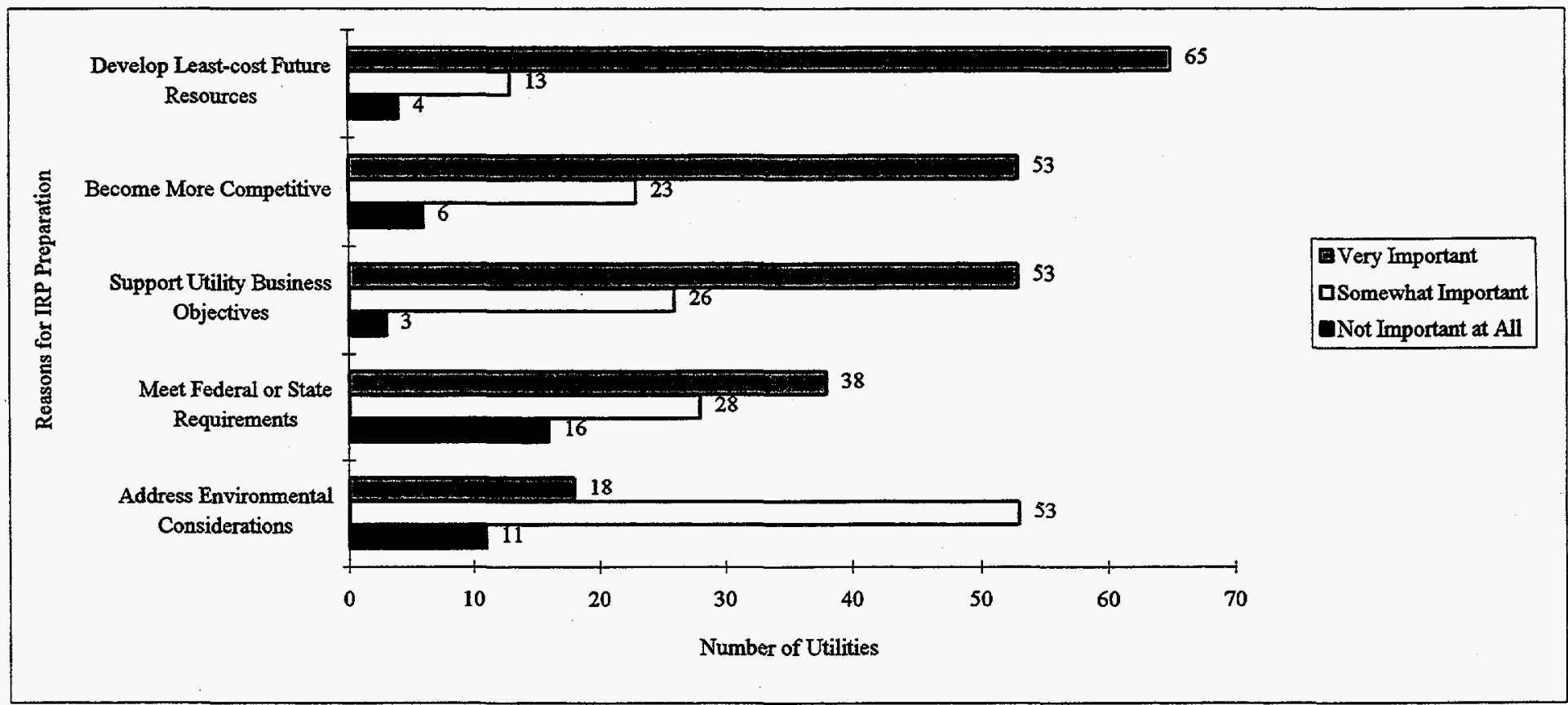

Figure 6. Reasons for municipal utility IRP 
For the 244 municipal utility respondents that do not prepare IRPs, the most commonly cited reasons include limited financial and personnel resources, long-term power contracts, and unavailable/unreliable data (see Figure 7).

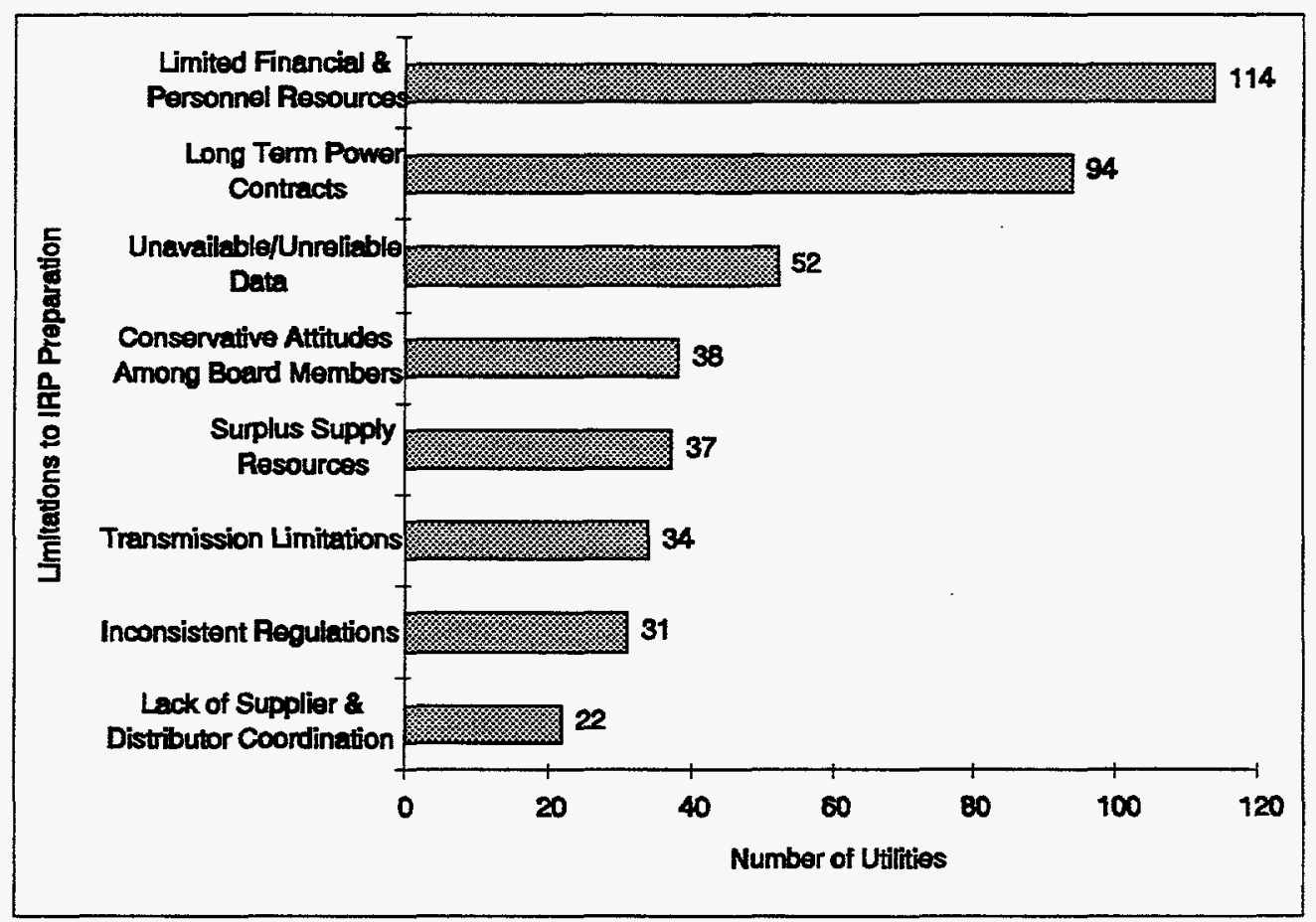

Figure 7. Limitations to municipal utility IRP

Each of the responding municipal utilities provided information regarding the frequency at which they practice various IRP elements (see Tables 7 and 8). Load forecasting is the most widely practiced IRP element, with forecasts typically being developed on an annual basis. Demand- and supply-side resource assessments are performed by a majority of respondents, usually annually. Public involvement and uncertainty analysis activity is also reported by more than half of the municipal utilities. Integrated supply-side and demand-side resource evaluation and consideration of environmental and/or social costs are the least commonly practiced of the IRP elements. 
Table 7. Frequency of Municipal Utility Practice of Various IRP Elements

\begin{tabular}{|c|c|c|c|c|c|}
\hline IRP Element & Annually & $\begin{array}{l}\text { Every } \\
2 \text { years }\end{array}$ & $\begin{array}{c}\text { Every } \\
3 \text { or } 4 \\
\text { years }\end{array}$ & $\begin{array}{c}\text { Every } \\
5+ \\
\text { years }\end{array}$ & Never \\
\hline Load Forecasting & 149 & 23 & 32 & 44 & 57 \\
\hline Supply-Side Resource Assessment & 102 & 25 & 21 & 44 & 107 \\
\hline Demand-Side Resource Assessment & 121 & 24 & 23 & 32 & 101 \\
\hline $\begin{array}{l}\text { Integrated Supply-Side and Demand-Side } \\
\text { Resource Evaluation }\end{array}$ & 47 & 27 & 20 & 40 & 158 \\
\hline
\end{tabular}

Table 8. Social/Environmental Costing, Risk Analysis, and Public Involvement: Frequency of Municipal Utility Practice

\begin{tabular}{lcccc}
\hline & Always & Sometimes & Never & $\begin{array}{c}\text { Don't } \\
\text { Know }\end{array}$ \\
\hline $\begin{array}{l}\text { Consideration of Environmental } \\
\text { and/or Social Costs }\end{array}$ & 74 & 79 & 110 & 39 \\
Uncertainty/Risk Analysis & 100 & 72 & 104 & 26 \\
Public Involvement & 110 & 87 & 93 & 13 \\
\hline
\end{tabular}

\section{IRP Assistance Needs}

The municipal utilities responding to the survey indicated their level of interest in approximately 25 types of IRP assistance, including information, tools, data, and technical and financial assistance. Based on the responses provided, the 15 types of IRP assistance that are most desired by the nation's municipal utilities are listed below in priority order.

1. Publications;

2. Improved data on transmission and distribution options/economics;

3. Tools for load forecasting (e.g., workbooks, software, etc.);

4. Improved data on customer attitudes and behavior;

5. Improved data on DSM impacts (e.g., $\mathrm{kW}, \mathrm{kWh}$, and economics);

6. Tools for DSM program selection (e.g., workbooks, software, etc.);

7. Grants;

8. Improved data on customer facility and end-use characteristics;

9. Workshops and seminars;

10. Improved data on regional power purchase options/costs;

11. Tools for integrated supply-side and demand-side resource evaluation (e.g., workbooks, software, etc.);

12. Audiovisual materials;

13. Peer consultation;

14. Improved data on externality costs;

15. Tools for costing externalities (e.g., workbooks, software, etc.). 
Attachment $\mathrm{E}$ lists the top ten types of IRP assistance desired by municipal utilities located in each of the survey regions. 


\section{Cooperatively Owned Utilities}

The following sections present "Current IRP Activity" and "IRP Assistance Needs" for the G\&Ts and distribution cooperatives responding to the NREL IRP survey. The "Current IRP Activity" subsections present an overview of the IRP practices of the responding cooperatives, including the nature and extent of G\&T and distribution cooperative coordination. Reasons for cooperatively owned utility IRP are also presented, along with limitations to IRP practice. The "IRP Assistance Needs" subsections indicate cooperative utility interest in various types of IRP information, tools, data, and technical and financial assistance. Concise profiles of G\&Ts and distribution cooperatives are also presented. Each profile includes a description of the utility sector as a whole and characterizes survey respondents.

\section{G\&T Cooperatives}

\section{Profile}

Generation and transmission cooperatives are power suppliers owned by several individual distribution cooperatives. G\&Ts are responsible for supplying all of the power required by their distribution cooperative members and do so by generating the power and/or procuring it contractually from public or private utilities. About $44 \%$ of the electricity supplied by the nation's G\&T cooperatives is produced by G\&T-owned plants, another $33 \%$ comes from federal power sources, and the remaining $23 \%$ is purchased from IOUs (NRECA 1990).

More than half of the nation's G\&Ts have full generation and transmission responsibilities. A few of the G\&Ts are referred to as "super G\&Ts" because they are owned by other G\&T cooperatives (referred to as "mid G\&Ts"). The term "paper G\&T" is used to describe a number of organizations owned by the distribution systems that are legally empowered to generate and transmit but have not done so. Instead, they bargain for power for their distribution cooperative members (NRECA 1991). There are also a few "other G\&Ts," most of whom operate a plant and sell the output to one or more other cooperatives.

Forty-seven of the nation's 64 G\&Ts responded to the NREL IRP survey. As indicated in Table 9, the respondents are dispersed across all regions of the United States with the exception of the TVA region where no G\&Ts are located. Based on utility profile information provided through the survey, these 47 G\&Ts are characterized as follows:

- The 1993 annual system sales of more than 75\% of the G\&Ts exceeded 1 million MWh. One G\&T reported 1993 sales of less than $100,000 \mathrm{MWh}$, while the remainder had sales between 100,000 and 1 million MWh.

- The number of employees at reporting G\&Ts ranges from less than 50 to more than 1,000 , with an average of between 201 and 500 employees.

- A majority of the reporting G\&Ts are experiencing service area load growth between $1.1 \%$ and $4 \%$ per year.

- A majority of reporting G\&Ts have surplus capacity and energy resources, while many others are in resource balance. Few of the G\&Ts are in resource deficit. 
Table 9. G\&T Cooperatives: Total Number vs. Survey Respondents

\begin{tabular}{lcc}
\hline \multicolumn{1}{c}{ Region } & $\begin{array}{c}\text { Total No. } \\
\text { of G\&Ts* }\end{array}$ & $\begin{array}{c}\text { No. of G\&Ts } \\
\text { Responding to Survey }\end{array}$ \\
\hline BPA & 3 & 2 \\
Non-PMA & 11 & 7 \\
SEPA & 9 & 7 \\
SWPA & 21 & 17 \\
WAPA & 20 & 14 \\
Total & 64 & 47 \\
\hline
\end{tabular}

* The G\&Ts contacted in the survey represent all generation and transmission cooperatives recognized by the National Rural Electric Cooperatives Association and/or the Rural Electrification Administration.

\section{Current IRP Activity}

Table 10 presents an overview of the IRP practices of the 47 responding G\&Ts. For each of the IRP elements, the Table indicates the percentage of G\&Ts that fall into each of the following categories:

- Currently conducts the IRP element;

- Starting to perform the IRP element;

- Provided an "other" response regarding practice of the IRP element;

- Does not perform the IRP element; and

- No answer provided.

Table 10. IRP Practice of Responding G\&Ts

\begin{tabular}{lccccc}
\hline \multicolumn{1}{c}{$\quad$ IRP Element } & $\begin{array}{c}\text { Currently } \\
\text { Conducts }\end{array}$ & $\begin{array}{c}\text { Starting } \\
\text { to } \\
\text { Perform }\end{array}$ & $\begin{array}{c}\text { Other } \\
\text { Answer }\end{array}$ & $\begin{array}{c}\text { Does } \\
\text { Conduct }\end{array}$ & $\begin{array}{c}\text { No } \\
\text { Answer* }\end{array}$ \\
\hline Load Forecasting & $81 \%$ & $0 \%$ & $0 \%$ & $4 \%$ & $13 \%$ \\
Supply-Side Resource Assessment & $79 \%$ & $0 \%$ & $2 \%$ & $15 \%$ & $4 \%$ \\
$\begin{array}{l}\text { Demand-Side Resource Assessment } \\
\text { Consideration of Environmental and/or Social }\end{array}$ & $74 \%$ & $6 \%$ & $6 \%$ & $9 \%$ & $4 \%$ \\
Costs & $64 \%$ & $2 \%$ & $4 \%$ & $26 \%$ & $4 \%$ \\
$\begin{array}{l}\text { Integrated Supply-Side and Demand-Side Resource } \\
\text { Evaluation }\end{array}$ & $60 \%$ & $9 \%$ & $2 \%$ & $26 \%$ & $4 \%$ \\
Uncertainty/Risk Analysis & & & & & \\
Public Involvement & $77 \%$ & $0 \%$ & $0 \%$ & $19 \%$ & $4 \%$ \\
\hline
\end{tabular}

* "No Answer" responses include the following: (1) non-REA borrowers for whom REA has no load forecasting records; (2) several G\&Ts that elected not to provide responses to the IRP survey questions and instead explained their utility's IRP practices in a letter; and (3) a few cases where individual questions were not answered. 
As shown in the table, a majority of G\&Ts indicated that they currently conduct all IRP elements. More than $80 \%$ of the G\&Ts reported load forecasting and public involvement activities. Seventy-four to $80 \%$ of the G\&Ts reported supply-side and demand-side resource assessment and risk analysis practice. Environmental and/or social costs are considered by $64 \%$ of the responding G\&Ts, while $60 \%$ of these utilities report integrated supply-side and demand-side resource evaluations.

A limited number of G\&Ts reported that the practice of certain IRP elements is currently under development, but not yet completed. For example, $6 \%$ of respondents indicated that a demand-side resource evaluation process is under development and $9 \%$ responded that the utility is currently developing an integrated approach for evaluating supply-side and demand-side resource options. In addition, a few G\&Ts provided "other" responses regarding IRP practices.

As many as $25 \%$ of the $47 \mathrm{G} \&$ Ts reported that they do not practice one or more of the IRP elements listed in Table 10. These include G\&Ts with full resource planning responsibilities, as well as "mid," "paper," and "other" G\&Ts with varying degrees of planning responsibility. A number of respondents indicated that they do not directly perform various IRP elements because they are not applicable to the utility. For example, one G\&T indicated that BPA holds the full-requirements contracts with all of its distribution cooperatives and also prepares the resource plans. Several "mid" G\&Ts indicated that IRP responsibilities are vested in the "super" G\&T. An "other" G\&T responded to the survey through a brief letter stating that the organization's singular purpose is to own and operate a power plant that provides output to two other cooperatives. The G\&T, which does not own or maintain any transmission or distribution lines, stated that "most of the information requested [in the survey] is not applicable or available."

The involvement of member distribution cooperatives is a key aspect of G\&T cooperative IRP practice, as the member systems both own and govern the G\&Ts. Figure 8 summarizes the extent of member distribution cooperative involvement in each IRP element for the 47 responding G\&Ts. The figure reflects

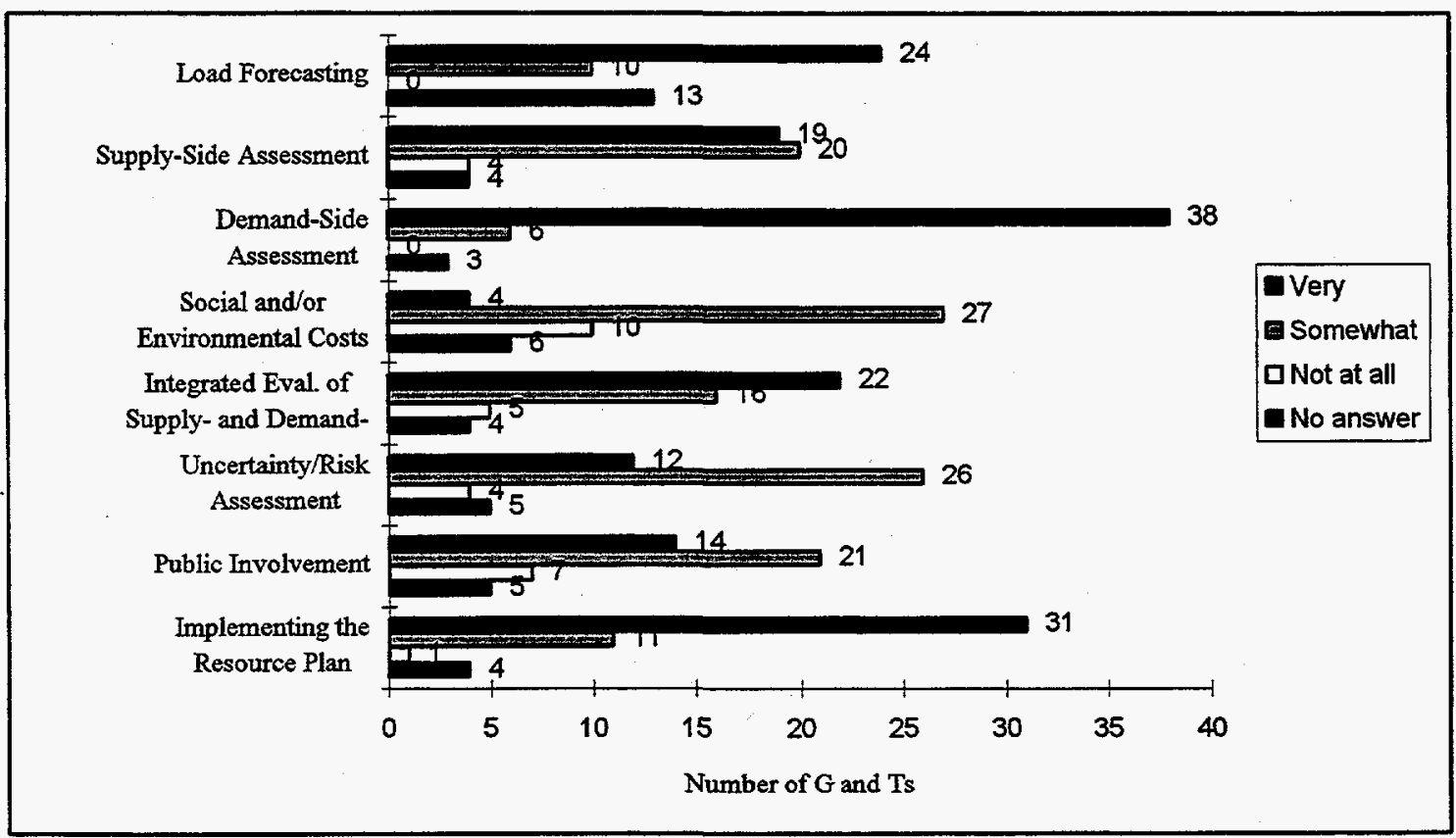

Figure 8. G\&T IRP elements: extent of member distribution cooperative involvement 
the planning responsibilities of the G\&Ts relative to their member distribution cooperatives. For example, 38 of the G\&Ts" distribution cooperatives are "very" involved in demand-side assessments and 31 of the cooperatives are "very" involved in implementing the resource plan. These aspects of IRP are characterized by greater distributor (and end-user) involvement than other IRP elements that are more directly tied to the G\&Ts' resource planning responsibilities.

As illustrated in Figure 9, G\&T survey respondents indicate that the most important reason for IRP preparation is "to meet State PUC requirements." Other important reasons include "to develop least-cost future resources," "to support utility business objectives," and "to become more competitive." REA requirements are cited by half of the G\&Ts as an important reason for IRP. In the WAPA region, federal PMA requirements are cited as the principal reason for conducting an IRP.

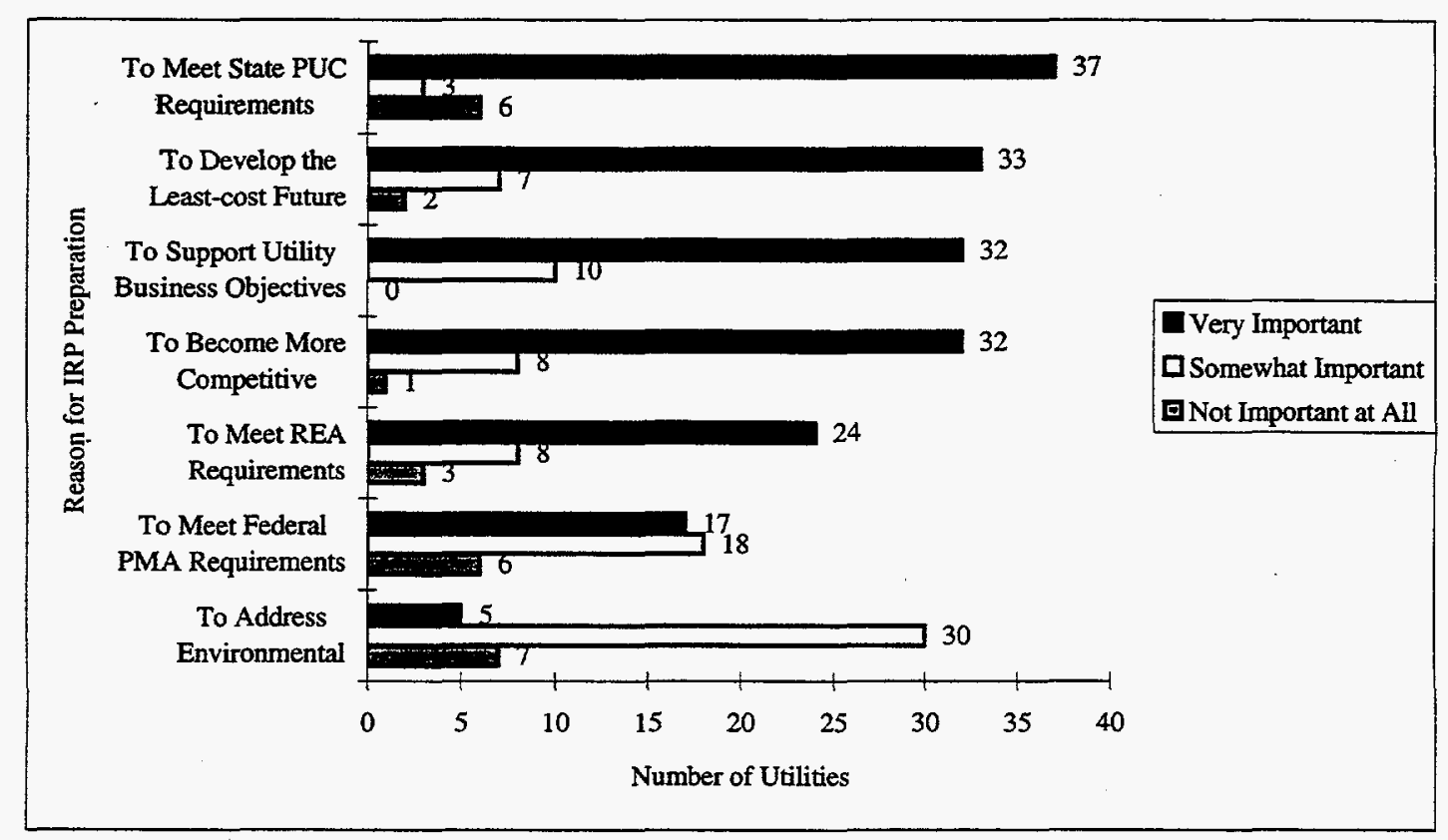

Figure 9. Reasons for G\&T IRP

The G\&T respondents also provided information regarding factors influencing utility IRP analyses. The most common factors influencing IRP include long-term power purchase contracts, surplus supply resources, long-term all-requirements contracts with member systems, and limited financial and personnel resources (see Figure 10). 


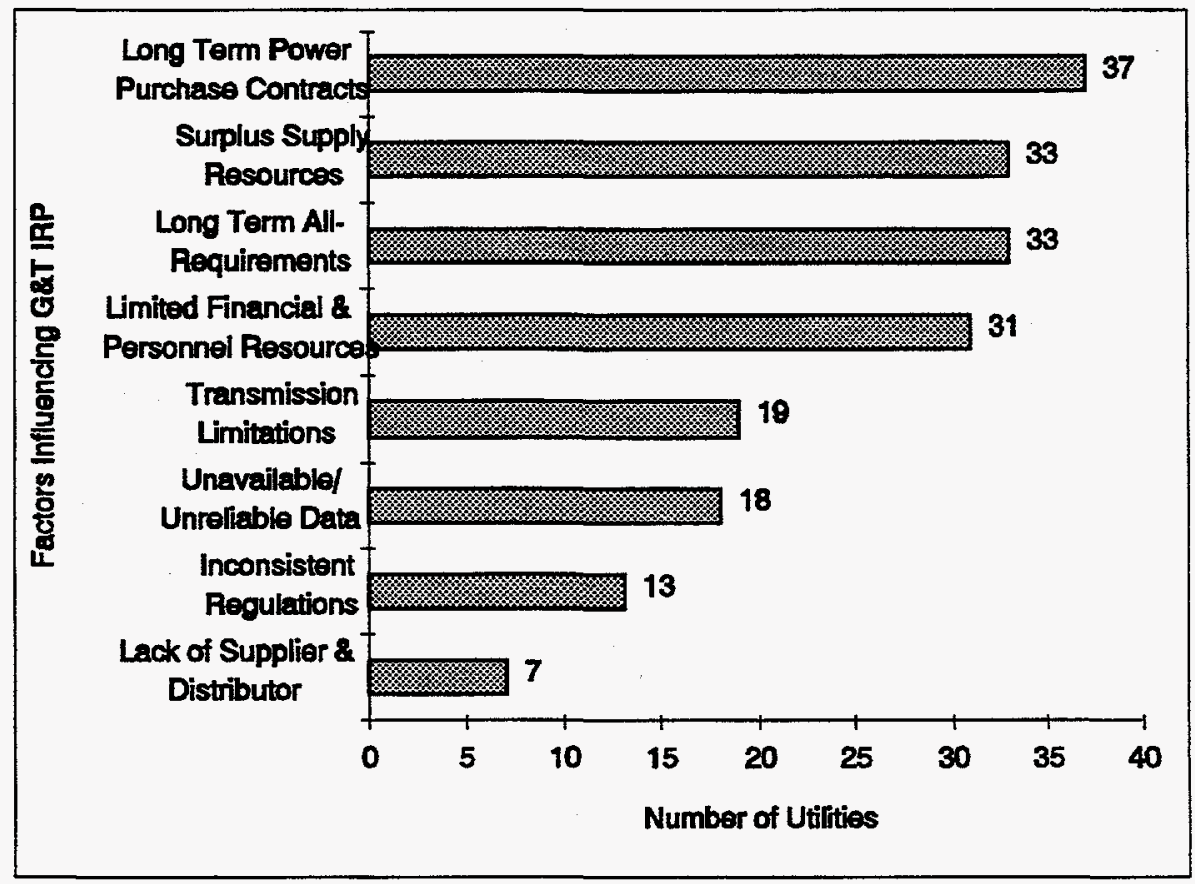

Figure 10. Factors influencing G\&T IRP

\section{IRP Assistance Needs}

The G\&Ts responding to the survey indicated their level of interest in approximately 25 types of IRP assistance, including information, tools, data, and technical and financial assistance. Based on the responses provided, the 15 types of IRP assistance that are most desired by the nation's G\&Ts are listed below in priority order.

1. Improved data on DSM impacts (e.g., KW, KWh, and economics);

2. Improved data on customer facility and end-use characteristics;

3. Tools for integrated supply-side and demand-side resource evaluation (e.g., workbooks, software, etc.);

4. Tools for integration of wholesale and retail (rate) impacts;

5. Tools for impact and process evaluation of DSM programs;

6. Improved data on customer attitudes and behavior;

7. Publications;

8. Tools for DSM program selection;

9. Workshops and seminars;

10. Improved data on transmission and distribution options/economics;

11. Tools for load forecasting (e.g., workbooks, software, etc.);

12. Peer consultation;

13. Grants;

14. Improved data on regional power purchase options/costs; and

15. Information hotlines and clearinghouses. 
Attachment $E$ lists the top ten types of IRP assistance desired by G\&Ts located in each of the survey regions.

\section{Distribution Cooperatives}

\section{Profile}

Distribution cooperatives are rural electric cooperatives that deliver electricity to residential, agricultural, and other consumers who are generally located in rural areas. More than 880 distribution cooperatives provide electric service in more than $80 \%$ of the counties in the United States. Distribution cooperatives that are member-owners of a G\&T cooperative (approximately 780 ) receive $100 \%$ of their electricity requirements from the G\&T. The nation's remaining "independent" distribution cooperatives (about 100) obtain their power supplies directly from federal power agencies (e.g., BPA and TVA), IOUs, self-generation, or other sources.

Of the 859 distribution cooperatives located in the continental United States, 256 responded to the NREL IRP survey. As indicated in Table 11, the respondents are spread across all regions of the country. Based on utility profile information provided through the survey, these 256 distribution cooperatives are characterized as follows:

- Almost $80 \%$ of the responding distribution cooperatives are full-requirements members of a G\&T cooperative. Fourteen percent of the respondents purchase the majority of their power supplies from a federal power agency (e.g., BPA, TVA, WAPA, etc.), while the remaining distributors obtain the majority of their power supplies from either an investor-owned utility or some "other" source, such as a state power agency or self-generation.

- The responding distribution cooperatives had average 1993 annual system sales of $242,000 \mathrm{MWh}$, with an average of 14,000 residential, commercial, industrial, and/or agricultural meters.

- More than $60 \%$ of the distribution cooperatives have fewer than 50 electric utility employees and less than $5 \%$ have more than 200 employees.

- More than one-third of the distribution cooperatives are experiencing service area load growth between $2.1 \%$ and $4 \%$ per year. Another $30 \%$ are experiencing $1.1 \%$ to $2 \%$ annual load growth, while close to $20 \%$ of the cooperatives report load growth of $0 \%$ to $1.0 \%$. Only a few distribution cooperatives report negative load growth, with the remaining cooperatives $(10+\%)$ reporting load growth greater than $4.1 \%$ per year. 
Table 11. Distribution Cooperatives: Total Number vs. Survey Respondents

\begin{tabular}{lcc}
\hline Region & $\begin{array}{c}\text { Total No. } \\
\text { of Distributors* }\end{array}$ & $\begin{array}{c}\text { No. of Distributors } \\
\text { Responding to Survey }\end{array}$ \\
\hline BPA & 40 & 14 \\
Non-PMA & 272 & 62 \\
SEPA & 149 & 46 \\
SWPA & 203 & 62 \\
TVA & 49 & 18 \\
WAPA & 146 & 54 \\
Total & 859 & 256 \\
\hline
\end{tabular}

* The distribution cooperatives contacted in the survey represent distribution cooperatives recognized by the National Rural Electric Cooperatives Association and/or the Rural Electrification Administration. Distribution utilities owned by local or regional governments (e.g., public utility districts) were not considered cooperatively owned utilities even if they are REA borrowers. These utilities were considered to be government-owned utilities and were contacted under the survey of "municipal" utilities.

\section{Current IRP Activity}

Fourteen of the 256 responding distribution cooperatives indicated that they prepare their own IRP, independent of a power supply organization. Some of these distribution cooperatives are members of a G\&T, while others purchase power from a federal power agency or IOU and/or generate power.

The remaining 242 distribution cooperatives practice resource planning in conjunction with their G\&T or other power supplier. Thus, distribution cooperative IRP practice is best described by the nature and extent of involvement in power supplier IRP activities.

Figure 11 summarizes the IRP practice of the 256 distribution cooperatives responding to the NREL IRP survey. For each of the IRP elements, the figure indicates the number of distribution cooperatives that fall into each of the following categories:

- IRP element is conducted by distribution cooperative (does their own);

- Distribution cooperative participates with power supplier in conducting the IRP element (participates with power supplier);

- Distribution system is included in power supplier's practice of IRP element (power supplier does it);

- The IRP element is not practiced by or for the distribution cooperative (not done at all); and

- No answer provided. 


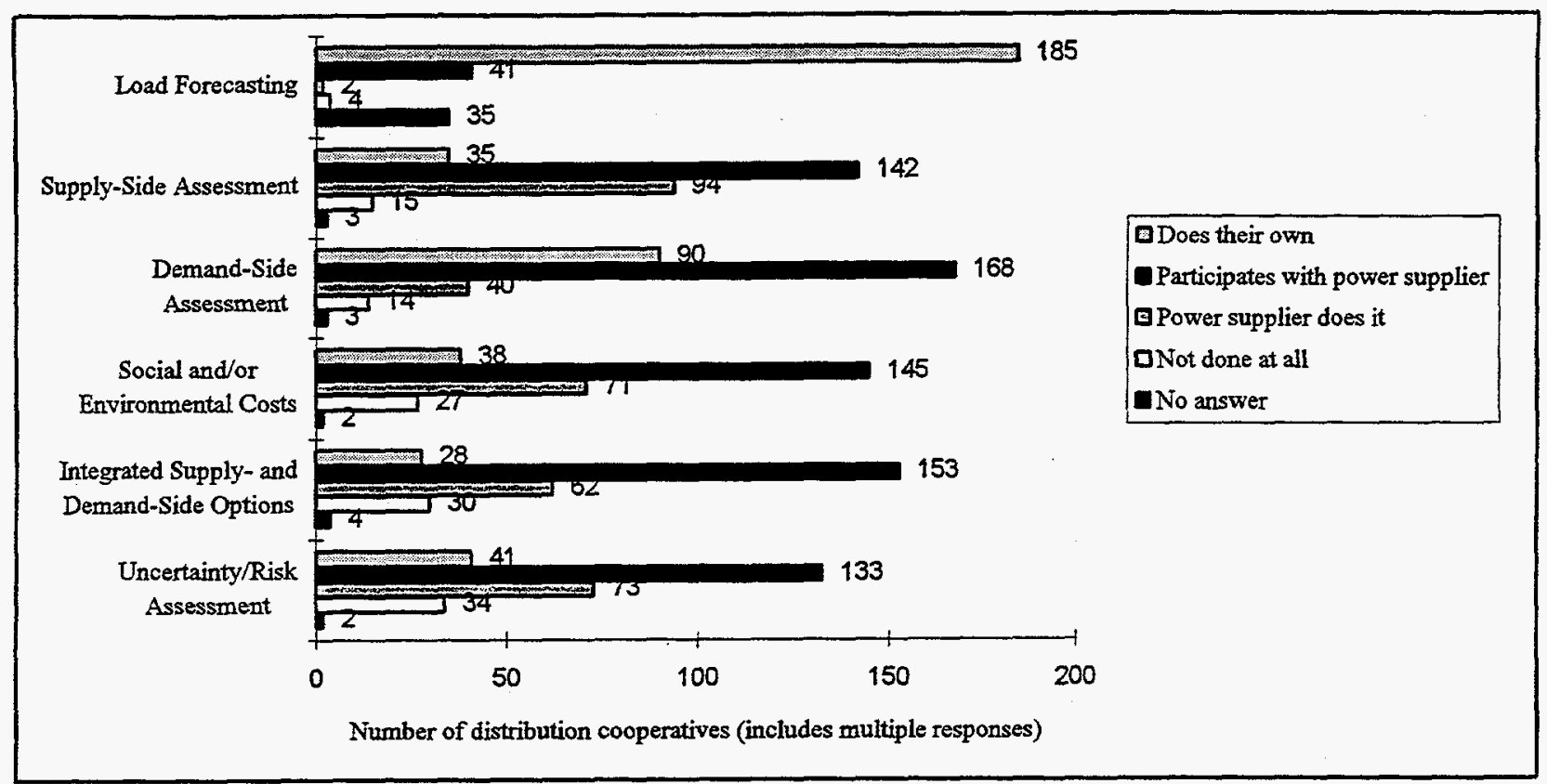

Figure 11. IRP practice of responding distribution cooperatives

As shown in the figure, the majority of the rsponding distribution cooperatives participate with their power supplier in all IRP elements. Distribution cooperatives participate to the greatest extent with their power suppliers in load forecasting ( $72 \%$ of distributors participate) and to the least extent in risk analysis (52\% of distributors participate). In addition, many distribution cooperatives also perform various IRP elements on their own, with load forecasting and demand-side assessments being the most prevalent independent activities. More than $100(45 \%)$ of the distribution cooperatives prepare their own, independent, load forecasts. Ninety $(35 \%)$ of the distributors indicate that they perform their own demand-side resouce evaluations.

In many cases, distribution cooperatives are included within IRP efforts performed solely by G\&Ts or other power suppliers. For example, 94 (37\%) of the respondents indicate that their system is included in supply-side evaluations done solely by the power supplier. Risk analysis is the least practiced IRP element-34 distribution cooperatives report no risk assessment activities whatsoever.

The distribution cooperative respondents also provided information regarding factors influencing utility IRP analyses and resulting plans. As shown in Figure 12, the most commonly cited factors influencing IRP include all-requirements power purchase contracts, limited financial and personnel resources, and longterm power sales contracts. 


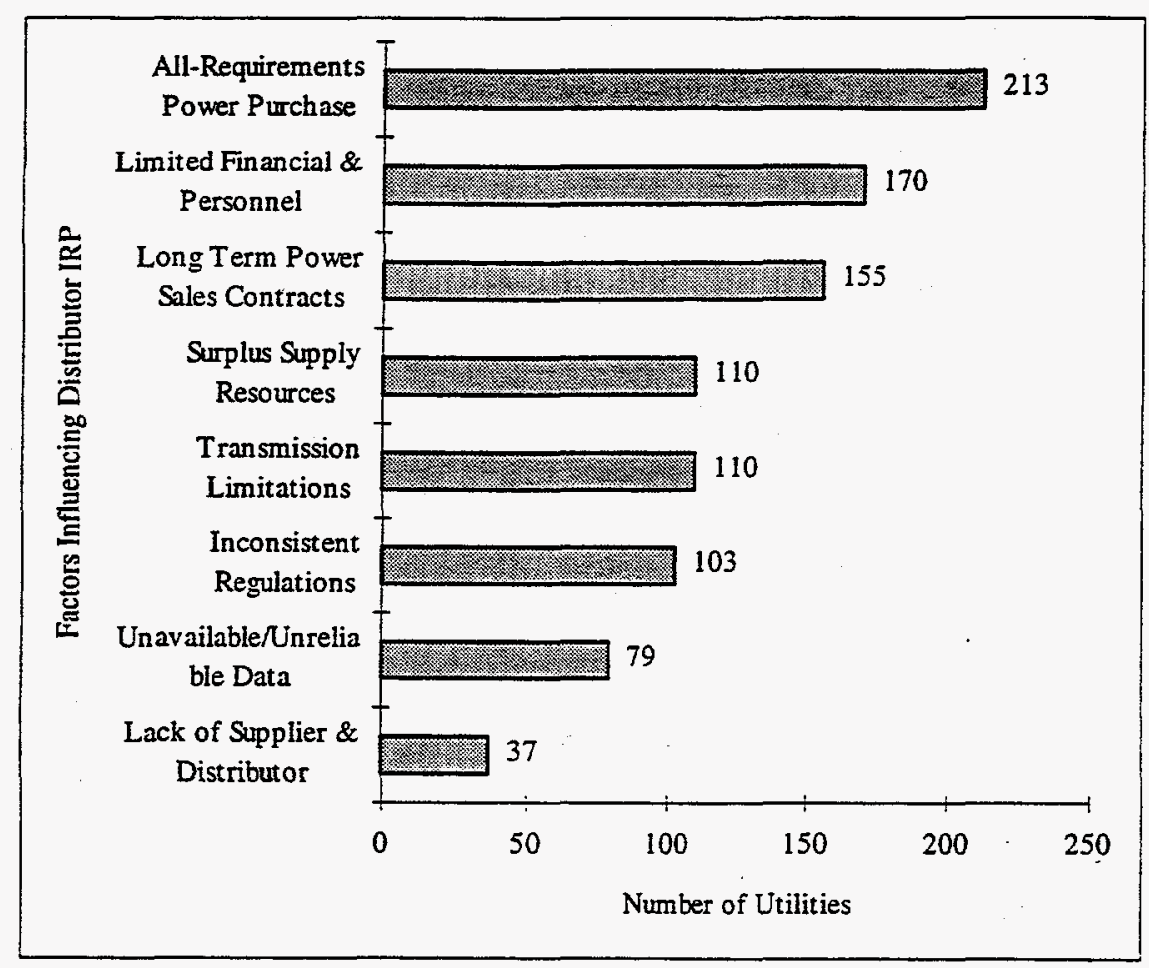

Figure 12. Factors influencing distribution cooperative IRP

\section{IRP Assistance Needs}

The distribution cooperatives responding to the survey indicated their level of interest in approximately 25 types of IRP assistance, including information, tools, data, and technical and financial assistance. Based on the responses provided, the 15 types of IRP assistance that are most desired by the nation's distribution cooperatives are listed below in priority order.

1. Improved data on customer attitudes and behavior;

2. Improved data on DSM impacts (e.g., KW, KWh, and economics);

3. Grants;

4. Publications;

5. Improved data on customer facility and end-use characteristics;

6. Tools for load forecasting (e.g., workbooks, software, etc.);

7. Improved data on transmission and distribution options/economics;

8. Tools for DSM program selection;

9. Audiovisual materials;

10. Tools for impact and process evaluation of DSM programs;

11. Tools for integration of wholesale and retail (rate) impacts;

12. Workshops and seminars;

13. Tools for integrated supply- and demand-side resource evaluation (e.g., workbooks, software, etc.);

14. Cost-shared funding; and

15. Information hotlines and clearinghouses.

Attachment $E$ lists the top ten types of IRP assistance desired by distribution cooperatives located in each of the survey regions. 


\section{References}

Electric Power Research Institute and Barakat, Howard and Chamberlain, Inc. for EPRI. 1987. Moving Toward Integrated Resource Planning; Understanding the Theory and Practice of Least-Cost Planning and Demand-Side Management. EM-5065. February.

Garrick and Associates for National Renewable Energy Laboratory. 1994. Rural Electric Cooperatives IRP Survey Report. June.

Garrick, C., Garrick, J., Rue, D. for National Renewable Energy Laboratory. 1993. Scoping Study of Integrated Resource Planning Needs in the public Utility Sector. June.

Goldman, C., Hirst, E., and Krause, F. 1989. "Least-Cost Planning in the Utility Sector: Progress and Challenges." Washington, D.C.: U.S. Department of Energy; Berkeley, CA: Lawrence Berkeley Laboratory; Oak Ridge, TN: Oak Ridge National Laboratory. May.

Moline, B. 1992. Demand-Side Management in Public Power - The Quiet Revolution - Findings from a Survey of Publicly-Owned Utilities. American Public Power Association, Washington, D.C. January.

National Rural Electric Cooperative Association (NRECA). 1990. Rural Electric Sourcebook. Washington, D.C.: National Rural Electric Cooperative Association.

National Rural Electric Cooperative Association. 1991. The G\&Ts-Power Providers for America's Rural Electric System. Work performed by National Rural Electric Cooperative Association, Washington, D.C. January.

Shultz, G. 1994. Chief of Energy Forecasting Branch, Rural Electrification Administration, IRP information provided for G\&T borrowers as well as frequent telephone input. 
Attachment A

Glossary of Terms

B-31 


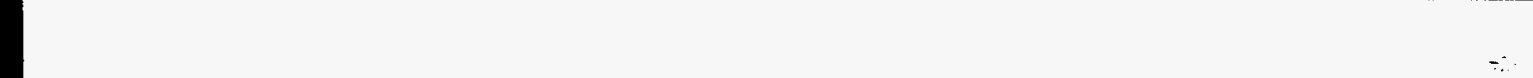


Automated Reliability and Cost Evaluation: A supply-side resource assessment method that uses the same process as manual generation planning, but automates the optimization process.

Banks for Cooperatives (BC): Authorized by Congress to lend to rural utilities, BCs lend concurrently with REA. This provided financing in conjunction with the guaranteed loan program, which includes refinancing of Federal Financing Bank loans.

Borrowers Environmental Report (BER): A support document required by REA for loan approval. The BER is used to determine what effect the construction of the facilities included in the Construction Work Plan will have on the environment.

Capital Credits: Funds credited to rural electric cooperative members that equate to their ownership equity in the system.

Consideration of Environmental and/or Social Costs: A component of IRP that involves inclusion of various environmental and social costs and benefits, such as those related to air quality or economic development. In addition to the consideration of "internal" costs (e.g., compliance with air quality regulations), many utilities consider "externalities" associated with electrical power production and use, which are not already incorporated in the price of electric services.

Cooperatively Owned Utilities: Rural electric cooperatives that include both distribution cooperatives and generation and transmission (G\&T) cooperatives.

Demand-Side Management (DSM): The planning, implementation, and monitoring of those utility activities designed to influence customer use of electricity in ways that will produce desired changes in the utility's load shape. DSM is designed to produce changes in the time pattern and magnitude of a utility's load.

Demand-Side Resource Assessment: A component of IRP that involves evaluating demand-side resources for meeting an electric utility's future resource requirements. A demand-side resource assessment may include the examination of peak clipping, valley filling, load shifting, strategic conservation, strategic load growth, and other DSM options.

Direct Quantification: Also referred to as "monetization," this costing approach assigns a monetary value to environmental and/or social costs of various resource options. Two approaches for "costing out" environmental costs include the damage-cost approach and the control-cost approach.

Distribution Cooperatives: Rural electric cooperatives that deliver electricity to residential and other consumers generally located in rural America. Distribution cooperatives are member-owned and were originated in the 1930 s to bring power to rural America.

Econometric Forecasting: A load forecasting method that uses econometric models to explain movements in $\mathrm{kWh}$ sales and $\mathrm{kW}$ peak by looking at the underlying factors or variables such as population, employment, income, weather, appliance ownership, and rates.

End-Use Forecasting: A load forecasting method that uses end-use models, also called engineering or accounting models, to forecast $\mathrm{kWh}$ sales by counting up $\mathrm{kWh}$ use from each electrical appliance and machine. 
Environmental and/or Social Adder: Use of a percentage adder that either increases the cost of supplyside resources or decreases the cost of demand-side resources. This method uses a simple percentage multiple of the direct cost of the resource option to reflect the cost of environmental harm.

Expert Opinion/Delphi Forecasting: A load forecasting method that uses information from external sources rather than numerical data. These methods rely on judgment, outside information, and independent forecasts to forecast utility $\mathrm{kWh}$ sales and $\mathrm{kW}$ peak.

Federal Power Agencies: U.S. government agencies that are involved in the generation, transmission, and/or distribution of electricity.

G\&T Cooperatives: Generation and transmission cooperatives (also known as power supply cooperatives) are power suppliers owned by several individual rural electric distribution cooperatives. Generally, they are responsible for supplying all of the power needed by their distribution cooperative members and do so by either generating the power or procuring it contractually from public or investor-owned organizations.

Identity Forecasting: A load forecasting method that forecasts $\mathrm{kW}$ peak using separate forecasts of load factor and $\mathrm{kWh}$ sales and definition relationships between them.

Integrated Resource Planning: An approach to utility resource planning that integrates the evaluation of both supply- and demand-side options for providing adequate, reliable, safe energy services at the least cost.

Integrated Supply-Side and Demand-Side Resource Evaluation: A component of IRP that involves a comparison of supply- and demand-side resources for the purpose of selecting the optimum mix of resources. The comparative evaluation allows equal consideration of both supply- and demand-side resource options.

Investor-Owned Electric Utility (IOU): An electric utility organized as a tax-paying business, usually financed by the sale of securities in the free market, and whose properties are managed by representatives regularly elected by their shareholders.

Joint Action Agencies: Regional organizations formed by groups of utilities (typically by municipals) to jointly build or finance generation and transmission systems and share other services.

Levelized Bus-Bar Cost: A supply-side resource assessment method that analyzes generating unit decisions on a unit basis only, not recognizing how the units may be operated in a power system.

Load Forecasting: A component of IRP that involves estimating future annual electricity use and peak demand requirements, for use in making resource allocation decisions.

Manual Reliability and Cost Evaluation: Also referred to as manual generation planning, a widely used supply-side resource assessment procedure that combines the disciplines of reliability.

Mid G\&Ts: G\&Ts that own a super G\&T.

Municipal Electric Utilities (Municipals): Electric utilities that are owned and operated by local governments or municipalities. 
National Rural Electric Cooperative Association (NRECA): A nonpartisan and nonprofit organization owned and controlled by the rural electric systems that make up its membership. NRECA was established as a service organization for its members where activities are coordinated, problems solved, and services shared.

National Rural Utilities Cooperative Finance Corporation (CFC): A self-help financing institution created in 1969 by the nation's rural electric cooperatives out of a need for additional funding for the rural electrification program. CFC serves as the primary source of private financing for the program and supplements financing provided by the REA.

Paper G\&Ts: G\&Ts that are legally empowered to generate and transmit but have not done so. Typically, they bargain for power for their distribution cooperative members.

Participant Test: A demand-side resource assessment test that measures the benefits and costs to the customer of participating in the specific DSM program.

Portfolio Analysis: A risk analysis method that involves identification of two or more plans, each keyed to a different set of objectives (e.g., environmental quality, financial performance, etc.). The different plans are generally subjected to sensitivity analysis and/or probabilistic analysis, and the performance of each is compared to the others.

Probabilistic Analysis: A risk analysis method that involves assignment of probabilities to different values of key variables (i.e., by assigning probabilities or drawing a continuous distribution). Outcomes are then identified that are associated with the different combinations of values for the key factors.

Public Involvement: A component of IRP that involves a public planning process to ensure that a broad range of interests and potential resource options are considered by utility decision-makers and to help build consensus about the best resource plan.

Publicly Owned Utilities: All utilities that are owned by federal, state, or local governments. These utilities can be broken into five major subcategories: federal, state, municipal, joint action agency, and other (e.g., public utility districts, irrigation districts, etc.).

Qualitative Treatment of Environmental Costs: This method typically involves assessing externalities by relative degrees of environmental degradation without formally assessing the costs.

Ratepayer Impact Measure (RIM) Test: A demand-side resource assessment test that measures the impacts on customer bills or rates due to changes in the utility revenues and operating costs as a result of the program.

Rural Electrification Administration: A federal agency created to provide loans for rural electrification. It also provides technical assistance where needed to support the security of the loans. The term REA has often been used erroneously as a synonym for the locally-owned cooperatives whose growth has been financed with loans from the agency.

Rural Electric Cooperatives: Consumer-owned utilities established to provide electric service to rural America. See distribution cooperatives and G\&T cooperatives.

Scenario Analysis: A risk analysis method that involves constructing alternative futures, each containing internally consistent combinations of key uncertain factors, and then identifying suitable combinations of supply-side and demand-side resources for each scenarios. The distinguishing feature of scenario analysis 
is that alternative visions of the future are created first, and then appropriate combinations of resources are identified to fit each future.

Screening Curve Method: A supply-side resource assessment method that involves plotting the results of the levelized bus-bar analysis on a graph to illustrate total levelized annual cost in dollars per year versus plant capacity factor.

Sensitivity Analysis: A risk analysis method that involves development of a preferred combination of options, often referred to as a plan. Key uncertainty factors are then varied to see how the plan responds to these variations.

Societal Test: A demand-side resource assessment test that is a variant of the TRC test and includes the effects of externalities such as acid rain, excludes tax credit benefits, and may have a different discount rate.

State Power Authorities: State-owned utilities that are involved in the generation, transmission, and/or distribution of electricity.

Super G\&Ts: G\&Ts that are owned by other G\&T cooperatives.

Supply-Side Resource Assessment: A component of IRP that involves evaluating supply resources for meeting an electric utility's future resource requirements. A supply-side resource assessment may include the examination of a range of resources, including purchased power, alternative/renewable resources, life extension and re-powering of existing plants, utility construction of power plants, and new or upgraded transmission facilities.

Time-Series Forecasting: A load forecasting method that involves the extrapolation of historical patterns, not just a simple trend.

Time-Trend Forecasting: A load forecasting method that involves the extrapolation of a historical trend.

Total Resource Costs (TRC) Test: A demand-side resource assessment test that measures net costs of a DSM program as a resource option based on the estimated total costs of the program, including both participant and utility program costs.

Uncertainty/Risk Analysis: A component of IRP that involves analysis of a variety of possible future conditions and the options available to deal with them. An uncertainty analysis provides information about the relative risks of alternative resource strategies. Its primary purpose is to facilitate better resource planning decisions that reduce risk.

Utility Cost Test: A demand-side resource assessment test that measures the net costs of a DSM program as a resource option based on the costs incurred by the utility (including incentives paid out) and excluding any net costs incurred by participants. 


\section{Attachment B}

\section{Publicly Owned Utility Survey Instrument}




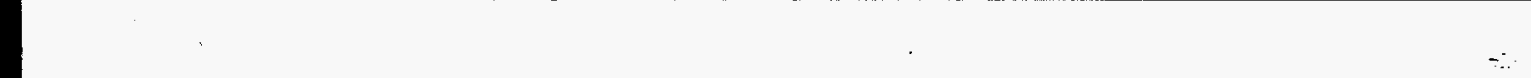




\section{INTEGRATED RESOURCE PLANNING AT PUBLIC POWER UTILITIES}

The purpose of this questionnaire is to gather information about your utility's integrated-resource planning (IRP) activities and interests. This information will help the U.S. Department of Energy define an appropriate and effective strategy to meet the Energy Policy Act's goal to "increase the use of integrated resource planning." Please answer all questions. Unless instructed otherwise, please circle the number of your answer. If you wish to make comments, use the margins or a separate sheet of paper. If you have any questions, contact Cynthia Garrick at (303) 697-1991 or Barry Moline at (202) 467-2932.

\section{A. What is IRP? Why Prepare an IRP?}

Integrated resource planning (IRP) is a method of utility planning in which both supply- and demand-side options are evaluated using comparable terms and methods to determine a combination of utility activities that will yield reliable and adequate energy services at the lowest cost.

A-1 Does your utility prepare an integrated resource plan?

1 Yes

2. No (Skip to A-3, then continue to section B)

A-2 Why does your utility prepare an IRP? Indicate the relative importance of the following reasons for doing IRP.

(Circle your answer)
1. To support utility business objectives.
Very
Somewhat
Not at All
2. To address environmental considerations.
Very
Somewhat
Not at All
3. To meet federal or state requirements.
Very
4. To develop the least-cost future resources
Very
Somewhat
Not at All
5. To become more competitive.
Very
Somewhat
Not at All
6. Other
Somewhat Not at All

A-3 If you answered "No" to A-1 above, are the following reasons preventing your utility from preparing an IRP?
1. Surplus supply resources.
2. Long term power contracts Yes No
3. Transmission limitations. ..Yes No
4. Limited financial \& personnel resources Yes No
5. Unavailable/unreliable data. .Yes No
6. Lack of supplier \& distributor coordination Yes No
7. Conservative attitudes among board members \& managers Yes
8. Inconsistent regulations. Yes No
9. Other

(Circle your answer)

\section{B. Your Utility's Resource Planning Activities}

B-1 How often does your utility develop a multi-year load forecast?

1. Annually

2. Every 2 years

3. Every 3 or 4 years

4. Every 5 years or more

5. Never

B-2 How often does your utility evaluate supply-side rescures options?

1. Annually

2. Every 2 years

3. Every 3 or 4 years

4. Every 5 years or more

5. Never
B-3 How often does your utility evaluate demand-side resource options?

1. Annually

2. Every 2 years

3. Every 3 or 4 years

4. Every 5 years or more

5. Never

B-4 Does your utility consider social or environmental costs and bcricfits (c.ฐ, air quialitity, etc.) associaticu with supply- and demand-side resource options? 
B-5 How often does your utility conduct an integrated evaluation of supply- and demand-side resources?
1. Annually
2. Every 2 years
3. Every 3 or 4 years
4. Every 5 years or more
5. Never

B-6 Does your utility analyze the uncertainties and risks associated with different electricity resource scenarios?

1 Yes, always

2. Sometimes

3. No

4. Don't know
B-7 Does your utility involve people other than employees in its resource planning process and decisions?
1 Yes, always
2. Sometimes
3. No
4. Don't know

B-8 If you answered "Yes, always" or "Sometimes" to B-7, what public involvement approach(s) are used? (Circle all that apply)

1. Involvement of utility's governing board

2. Advisory group, task force, or committee

3. Public hearings

4. Focus groups and workshops

5. Collaborative process

6. Public interest surveys

7. Other

\section{Resource Planning Assistance}

C-1 Indicate whether or not your utility has received the following types of IRP assistance during the past three years.

1. Information (e.g., publications, workshops)

(Circle your answer)

2. IRP tools (e.g., software, guidebooks) Yes No

3. Technical assistance (e.g. studies, consultations) Yes

No

4. Financial assistance (e.g., loans, grants) Yes No

5. IRP data development (i.e., developing key resource planning data) Yes No Yes No

C-2 Please rank the five types of IRP assistance listed in C-1 in terms of your utility's desire to obtain such assistance during the next five years. (Please write the number of each assistance type on appropriate line below)
\#1 Priority:
\#2 Priority:
\#3 Priority:
\#4 Priority:
\#5 Priority:

C-3 For assistance which you indicated "Yes" in C-1, what organizations provided the assistance? (Circle all that apply)

1. National utility organization (e.g., APPA)

2. Federal power agency (e.g., BPA, SEPA, SWPA, TVA, WAPA)

3. Regional or state utility group (e.g., statewide associations)

4. Joint action agency

5. Private organization (e.g., consultant, information service)

6. Other

Please answer the following questions to indicate your interest in IRP assistance, training, and financing opportunities.

C-4 How interested would your utility be in the following types of IRP-related information?

(Circle your answer)

1. Publications.

Very Somewhat

2. Audiovisual materials. Very Somewhat

3. Workshops and seminars Very Somewhat

4. Correspondence courses Very Somewhat

5. Electronic bulletin boards. Very Somewhat

Not at All

Not at All

Not at All

Not at All

Not at All
Don't Know

Don't Know

Don't Know

Don't Know

Don't Know

6. Other 
C-5 How interested would your utility be in tools (e.g., workbooks, software) to address the following topics?

(Circle your answer)

1. Load forecasting

Very Somewhat Not at All

2. DSM program selection

Very Somewhat

Not at All

Don't Know

3. Externalities costing (e.g., environmental impacts).

Very Somewhat

4. Integrated supply- \& demand-side resource evaluation.

Very Somewhat

Not at All

Don't Know

5. Impact \& process evaluation

Very Somewhat

Not at All

Don't Know

6. Other

C-6 How interested would your utility be in the following types of IRP-related technical assistance?

(Circle your answer)

1. Information hotlines \& clearinghouses

Very Somewhat

Not at All

2. Circuit rider* Very Somewhat

Not at All

Don't Know

3. Peer consultation. Very Somewhat

Not at All

Don't Know

4. On-site assistance

Very Somewhat

Not at All

Don't Know

5. Other

* An IRP circuit rider is a resource planning expert shared by several utilities in a region.

C-7 How interested would your utility be in the following types of IRP-related financial assistance?

(Circle your answer)

1. Loans

Very Somewhat Not at All Don't Know

2. Cost shared funding

Very Somewhat

3. Grants.

Very Somewhat

Not at All

Don't Know

4. Collective funding by group of utilities

Very Somewhat

Not at All

Don't Know

5. Awards for IRP performance.

Not at All Don't Know

6. Other

C-8 How interested would your utility be in obtaining improved data in the following areas?

(Circle your answer)

1. Transmission \& distribution options/economics.

Very Somewhat

Not at All

2. Regional power purchase options/costs

Very Somewhat

3. DSM impacts (e.g., KW, KWH, \& economic).

Very Somewhat

4. Externality costs (e.g., environmental impacts)

Very Somewhat

5. Customer facility \& end-use characteristics

Very Somewhat

6. Customer attitudes \& behavior.

Very Somewhat

Not at All

Not at All

Not at All

Not at All

Not at All

Don't Know

Don't Know

Don't Know

7. Other

C-9 Questions C-4 through C-8 presented various types of IRP assistance which could be of interest to your utility. What other types of IRP-related assistance are you interested in?

\section{Your Utility's Profile}

D-1 Please describe your utility's current electrical supply situation.

1. Capacity

(Circle your answer)

2. Energy 
D-2 Average annual load growth in your service area.

1. Negative Load Growth

2. 0 to $1.0 \%$

3. 1.1 to $2.0 \%$

4. 2.1 to $4.0 \%$

5. $4.1 \%$ or greater

D-3 What is the source of "peak load" (not baseload) power used by your utility?

1. Your utility's own generation

2. A power supply organization in which you have ownership (e.g., joint action agency)

3. A federal power agency (e.g., BPA, SEPA, SWPA, TVA, WAPA)

4. An investor-owned utility

5. Other

D-4 Is purchased power your utility's most expensive supply-side resource?

1. Yes

2. No (Skip to D-6)

D-5 How soon does the power purchase contract expire?

1. Less than 3 years

2. 3 to 6 years

3. 7 to 10 years

4. 11 to 15 years

5. More than 15 years

(If your utility does not sell wholesale power, skip to D-8)

D-6 Your utility's average wholesale energy rates.

1. Less than $2 \phi / \mathrm{KWH}$

2. $2 \phi / \mathrm{KWH}$ to $4 \phi / \mathrm{KWH}$

3. $4 \phi / K W H$ to $6 \phi / K W H$

4. $6 \notin / \mathrm{KWH}$ to $8 \notin / \mathrm{KWH}$

5. Greater than $8 \notin / K W H$
D-7 Your utility's average wholesale capacity rates.

1. Less than $\$ 3 / \mathrm{KW}$-month

2. $\$ 3 / \mathrm{KW}$ to $\$ 6 / \mathrm{KW}$-month

3. $\$ 6 / \mathrm{KW}$ to $\$ 10 / \mathrm{KW}$-month

4. $\$ 10 / \mathrm{KW}$ to $\$ 14 / \mathrm{KW}$-month

5. Greater than $\$ 14 / \mathrm{KW}$-month

(If your utility does not sell retail power, skip to D-10)

D-8 Your utility's average retail energy rates for general service commercial consumers.

1. Less than $2 \phi / K W H$

2. $2 \notin / \mathrm{KWH}$ to $4 \phi / \mathrm{KWH}$

3. $4 \phi / \mathrm{KWH}$ to $7 \phi / \mathrm{KWH}$

4. $7 \notin / \mathrm{KWH}$ to $10 \notin / \mathrm{KWH}$

5. Greater than $10 \notin / \mathrm{KWH}$

D-9 Your utility's average retail demand rates for general service commercial consumers.

1. Less than $\$ 4 / \mathrm{KW}$-month

2. $\$ 4 / \mathrm{KW}$ to $\$ 8 / \mathrm{KW}$-month

3. $\$ 8 / \mathrm{KW}$ to $\$ 12 / \mathrm{KW}$-month

4. $\$ 12 / \mathrm{KW}$ to $\$ 16 / \mathrm{KW}$-month

5. Greater than $\$ 16 / \mathrm{KW}$-month

D-10 Total number of electric utility employees.
1. Less than 50
2. 50 to 200
3. 201 to 500
4. 501 to 1000
5. Greater than 1000

D-11 1993 annual system sales.

1. Less than $50,000 \mathrm{MWH}$

2. 50,000 to $100,000 \mathrm{MWH}$

3. 100,001 to $500,000 \mathrm{MWH}$

4. 500,001 to $1,000,000 \mathrm{MWH}$

5. Greater than $1,000,000 \mathrm{MWH}$

As part of this study, we will also be contacting a limited number of public power utilities by telephone. If we do call you, we will ask a few brief questions about your utility's specific resource planning methods and needs. The information that we obtain from these discussions will benefit public nnwer utilities across the U.S. If you are interested in participating in a telephone interview, please provide your name and telephone number.

Name: Utility: Telephone: 


\section{Attachment C}

G\&T Cooperative Survey Instrument 


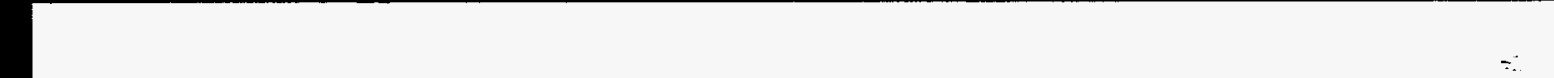




\section{INTEGRATED RESOURCE PLANNING AT RURAL ELECTRIC COOPERATIVES}

This questionnaire gathers information about your utility's integrated-resource planning (IRP) activities and interests. The information will help the U.S. Department of Energy to meet the Energy Policy Act's requirement to survey electric cooperative IRP practices and policies and to define a strategy to "increase the use of integrated resource planning." Please answer all questions. Unless instructed otherwise, please circle the number of your answer. If you wish to make comments, use the margins or a separate sheet of paper. If you have any questions, contact Cynthia Garrick at (303) 697-1991.

\section{A. Your Utility's Resource Planning Activities}

Integrated resource planning (IRP) is a method of utility planning in which both supply- and demand-side options are evaluated using comparable terms and methods to determine a combination of utility activities that will yield reliable and adequate energy services at the lowest cost. Please answer the following questions regarding your utility's involvement in the following IRP activities. Note that the REA has already provided some information regarding your planning activities (e.g., load forecasting).

A-1 How often does your utility evaluate supply-side resource options?

A-5 What approaches does your utility use to consider social or environmental costs and benefits (e.g., air quality, etc.) associated with supply- and demand-side resource options? (Circle all that apply)

1. On an on-going basis

2. Annually

3. Every 2 years

4. Every 3 years

5. Other

A-2 What method(s) are used for supply-side planning and analysis? (Circle all that apply)

1. Levelized bus-bar cost

2. Screening curves analysis

3. Manual evaluation of reliability and cost

4. Automated reliability and cost analysis

5. Hybrid manual and automated analysis

6. Other

A-3 How often does your utility evaluate demand-side resource options?

A-6 How often does your utility conduct an integrated evaluation of supply- and demand-side resources?

1. On an on-going basis

2. Annually

3. Every 2 years

4. Every 3 or 4 years

5. Every 5 years or more

6. Other

A-7 What methods are used to integrate supply- and demand-side resource options? (Circle all that apply)

1. Sequential selection, with supply-side considered first

2. Sequential selection, with demand-side considered first

3. Simultaneous supply- and demand-side resource selection, using consistent criteria

4. Other 
A-8 What methods does your utility employ to analyze the uncertainties and risks associated with different electricity resource options? (Circle all that apply)

1. Scenario analysis

2. Sensitivity analysis

3. Portfolio analysis

4. Probabilistic analysis

5. Don't analyze risks and uncertainties

6. Other
A-9 What public involvement approaches does your utility use as part of resource planning and decision-making? (Circle all that apply)

1. Involvement of utility's governing board

2. Involvement of member systems (e.g., advisory group or task force)

3. Involvement of end-use consumers (e.g., workshops, focus groups, surveys)

4. Involvement of outside parties (e.g., public interest groups, etc.)

5. Other

A-10 What is the cost of your utility's integrated resource planning efforts (do not include resource acquisition/ implementation costs)? dollars/year full-time equivalent employees

Other costs

\section{B. IRP Preparation}

B-1 Indicate the relative importance to your utility of the following reasons for doing IRP.

1. To support utility business objectives. Very

(Circle your answer)

2. To address environmental considerations Very

3. To meet existing and/or anticipated REA requirements.......................... Very

4. To meet existing and/or anticipated federal PMA requirements........... Very

5. To meet existing and/or anticipated state PUC requirements................. Very

6. To develop the least-cost future resources Very

7. To become more competitive. Very

Somewhat Somewhat Somewhat Somewhat Somewhat Somewhat Somewhat
Not at All

Not at All

Not at All

Not at All

Not at All

Not at All

Not at All

8. Other

B-2 Do any of the following factors significantly influence your utility's IRP analyses?
1. Surplus supply resources
(Circle your answer)
2. Long term power purchase contracts. Yes
No
3. Long term all-requirements contracts with member systems Yes
No
4. Transmission limitations. Yes
5. Limited financial \& personnel resources
Yes
No
6. Unavailable/unreliable data.
Yes
No
7. Lack of supplier \& distributor coordination
Yes
No
8. Inconsistent regulations.
Yes
No
9. Other

\section{Member System Involvement}

C-1 To what extent has or will your G\&T involve its member systems in the following resource planning activities?

1. Demand-side assessment

Very

2. Supply-side assessment. Very

3. Incorporation of social and/or environmental costs Very

4. Integrated evaluation of supply- and demand-side options Very

5. Uncertainty/risk assessment Very

6. Public involvement for resource planning

7. Implementing the resource plan.
(Circle your answer)

Somewhat

Somewhat

Somewhat

Somewhat

Somewhat

Somewhat

Somewhat
Not at All

Not at All

Not at All

Not at All

Not at All

Not at All

Not at All 


\section{Resource Planning Assistance}

In developing its IRP advancement strategy, the Department of Energy is interested in identifying areas where it can provide assistance to rural electric cooperatives. Potential types of assistance include, but are not limited to:

1. Information (e.g., publications, workshops)

2. IRP tools (e.g., software, guidebooks)

3. Technical assistance (e.g. studies, consultations)

4. Financial assistance (e.g., loans, grants)

5. IRP data development (i.e., developing key resource planning data)

D-1 Please rank the five types of IRP assistance listed above in terms of your utility's desire to obtain such assistance during the next five years. (Please write the number of each assistance type on appropriate line below)
\#1 Priority:
\#2 Priority:
\#3 Priority:
\#4 Priority:
\#5 Priority:

Please answer questions D-2 through D-6 to indicate your utility's interest in obtaining various types of IRP assistance.

D-2: How interested would your utility be in the following types of IRP-related information?

(Circle your answer)

1. Publications Very Somewhat

Not at All Don't Know

2. Audiovisual materials

Very Somewhat

Not at All

3. Workshops and seminars

Very Somewhat

Not at All

Very Somewhat

Not at All

Very Somewhat

Not at All

Don't Know

4. Correspondence courses.

5. Electronic bulletin boards.

Don't Know

6. Other

D-3 How interested would your utility be in tools (e.g., workbooks, software) to address the following topics?

(Circle your answer)

1. Load forecasting. Very Somewhat

Not at All

Very Somewhat

Not at All

Very Somewhat

Not at All

Very Somewhat

Not at All

Very Somewhat

Not at All

Very Somewhat

Not at All

Don't Know

Don't Know

5. Impact \& process evaluation of DSM programs

6. Integration of wholesale and retail impacts.

7. Other

D-4 How interested would your utility be in the following types of IRP-related technical assistance?

(Circle your answer)

1. Information hotlines \& clearinghouses

Very Somewhat

Not at All Don't Know

2. Circuit rider*

Very Somewhat

Not at All

Very Somewhat

Not at All

Don't know

3. Peer consultation

Very Somewhat

Not at All

Don't Know

4. On-site assistance

5. Other

* An IRP circuit rider is a resource planning expert shared by several utilities in a region. 
D-5 How interested would your utility be in the following types of IRP-related financial assistance?

(Circle your answer)

1. Loans Very Somewhat Not at All

2. Cost shared funding Very Somewhat

3. Grants Very Somewhat

4. Collective funding by group of utilities Not at All Not at All Very Somewhat

6. Awards for IRP performance Not at All Very Somewhat

Not at All Don't Know

7. Other

D-6 How interested would your utility be in obtaining improved data in the following areas?

(Circle your answer)

1. Transmission \& distribution options/economics. Very Somewhat Not at All

2. Regional power purchase options/costs. Very Somewhat

3. DSM impacts (e.g., $\mathrm{KW}, \mathrm{KWH}, \&$ economic) Very Somewhat

4. Externality costs (e.g., environmental impacts). Very Somewhat

5. Customer facility \& end-use characteristics Very Somewhat

6. Customer attitudes \& behavior Not at All Don't Know Not at All Don't Know Not at All Don't Know 7. Other Very Somewhat

D-7 Questions D-2 through D-6 presented various types of IRP assistance which could be of interest to your utility. What other types of IRP-related assistance are you interested in?

D-8 How likely would your utility be to obtain IRP assistance from the following organizations if each offered IRP services to cooperatives?

(Circle your answer)

1. National utility organization (e.g., NRECA, EPRI) Very Somewhat Not at All Don't Know

2. Federal power agency (e.g., BPA, SEPA, SWPA, TVA, WAPA) Very Somewhat Not at All Not at All

3. Rural Electrification Administration Very Somewhat

4. Regional or state utility group (e.g., statewide associations)......... Very Somewhat Not at All Don't Know

5. Private organization (e.g., consultant, information service) Very Somewhat

Not at All

Don't Know

6. Other

\section{E. Your Utility's Profile}

E-1 Your utility's average wholesale energy rates.

1. Less than $2 \varnothing / \mathrm{KWH}$

2. $2 \notin / \mathrm{KWH}$ to $4 \notin / \mathrm{KWH}$

3. $4 \phi / \mathrm{KWH}$ to $6 \phi / \mathrm{KWH}$

4. $6 \notin / \mathrm{KWH}$ to $8 \phi / \mathrm{KWH}$

5. Greater than $8 \notin / \mathrm{KWH}$

6. This information is not available for release (i.e., confidential)

E-2 Your utility's average wholesale capacity rates.

1. Less than $\$ 3 / \mathrm{KW}$-month

2. $\$ 3 / \mathrm{KW}$ to $\$ 6 / \mathrm{KW}$-month

3. $\$ 6 / \mathrm{KW}$ to $\$ 10 / \mathrm{KW}$-month

4. $\$ 10 / \mathrm{KW}$ to $\$ 14 / \mathrm{KW}$-month

5. Greater than $\$ 14 / \mathrm{KW}$-month

6. This information is not available for release (i.e., confidential)
E-3 Your utility's 1993 annual system sales.

1. Less than $50,000 \mathrm{MWH}$

2. 50,000 to $100,000 \mathrm{MWH}$

3. 100,001 to $500,000 \mathrm{MWH}$

4. 500,001 to $1,000,000 \mathrm{MWH}$

5. Greater than $1,000,000 \mathrm{MWH}$ 


\section{G\&T Information Provided by the Rural Electrification Administration}

The REA provided G\&T data for the following IRP questions. As a result, these questions were not included in the surveys sent to G\&Ts.

How often does the utility develop a multi-year load forecast?
1. Annually
2. Every 2 years
3. Every 3 or 4 years
4. Every 5 years or more
5. Never

Does the utility develop a range of demand forecasts (e.g., high, medium, and low forecasts)
1. Yes, always
2. Sometimes
3. No
4. Don't know

What forecasting method(s) are used? (Circle all that apply)
1. Time-Trend
2. Time-Series
3. Expert Opinion/Delphi
4. Identity
5. End-Use
6. Econometric
7. Don't know
8. Other

To what extent does the G\&T involve its distribution members in the following resource planning activities?

Multi-year load forecasting......

Very Somewhat

Not at All

Utility's current electrical supply situation.

1. Capacity.

(Circle answer)

2. Energy.

Deficit Balance

Deficit Balance

Surplus

Surplus

Average annual load growth in service area.

1. Negative Load Growth

2. 0 to $1.0 \%$

3. 1.1 to $2.0 \%$

4. 2.1 to $4.0 \%$

5. $4.1 \%$ or greater

Source of "peak load" (not baseload) power used by utility?

1. Utility's own generation

2. A power supply organization in which you have ownership (e.g., joint action agency)

3. A federal power agency (e.g., BPA, SEPA, SWPA, TVA, WAPA)

4. An investor-owned utility

5. Other

Is purchased power the utility's most expensive supply-side resource?

1. Yes

2. No (Skip next question)

Total number of electric utility employees.

1. Less than 50

2. 50 to 200

3. 201 to 500

4. 501 to 1000

5. Greater than 1000 



\section{Attachment D}

Distribution Cooperative Survey Instrument 


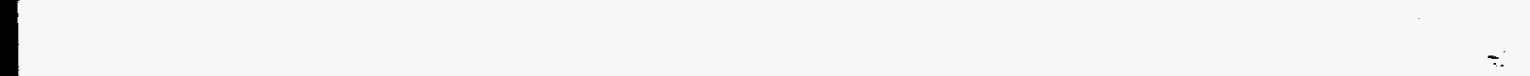




\section{INTEGRATED RESOURCE PLANNING AT RURAL ELECTRIC COOPERATIVES}

This questionnaire gathers information about your system's integrated-resource planning (IRP) activities and interests. The information will help the U.S. Department of Energy to meet the Energy Policy Act's requirement to survey electric cooperative IRP practices and policies and to define a strategy to "increase the use of integrated resource planning." Please answer all questions. Unless instructed otherwise, please circle the number of your answer. If you wish to make comments, use the margins or a separate sheet of paper. If you have any questions, contact Cynthia Garrick at (303) 697-1991.

\section{A. Your Power Supplier}

A-1 Please indicate which of the following sources provides the majority of your rural electric system's power supply. (Circle only one answer)

1. A power supply organization in which you have an ownership interest (e.g., G\&T)

2. A federal power agency (e.g., BPA, TVA, etc.)

3. An investor-owned utility

4. Other (e.g., system's own generation)

A-2 Please identify your power supplier

B. Your System's Resource Planning Activities

Integrated resource planning (IRP) is a method of utility planning in which both supply-and demand-side options are evaluated using comparable terms and methods to determine a combination of utility activities that will yield reliable and adequate energy services at the lowest cost. Please indicate the nature of your system's involvement in the following IRP activities. Circle all answers which apply to your system.

B-1 Does your system prepare its own IRP, independent of a power supplier?

1 Yes

2. No

B-2 Describe your system's load forecasting activities.

1. Develop our own load forecasts

2. Participate in developing power supplier's load forecasts

3. Our system is included in load forecasts done solely by power supplier

4. No load forecasting activities

B-3 Describe your system's supply-side resource evaluation activities.

1. Perform our own supply-side resource evaluations

2. Participate in power supplier's supply-side evaluations

3. Our system is included in supply-side evaluations done solely by power supplier

4. No supply-side evaluation activities
B-4 Describe your system's demand-side resource evaluation activities.

1. Perform our own demand-side resource evaluations

2. Participate in power supplier's demand-side evaluations

3. Our system included in demand-side evaluations done solely by power supplier

4. No demand-side evaluation activities

B-5 Describe how your system considers social or environmental costs and benefits (e.g., air quality, etc.) associated with supply- and demand-side resource options.

1. Consider these costs and benefits on our own

2. Participate in power supplier's consideration of such costs and benefits

3. Environmental/social costs and benefits considered solely by power supplier

4. No consideration of these costs and benefits 
B-6 Describe your system's integrated supply- and demand-side resource evaluation activities.

1. Conduct our own integrated resource evaluations

2. Participate in power supplier's integrated resource evaluations

3. Our system is included in integrated resource evaluations done solely by power supplier

4. No integrated resource evaluation activities
B-8 What public involvement approaches does your system use as part of resource planning and implementation?

1. Involvement of system's governing board

2. Involvement of end-use consumers (e.g., workshops, focus groups, surveys)

3. Involvement of outside parties (e.g., public interest groups, etc.)

4. Other

B-7 Describe your system's activities to analyze the uncertainties and risks associated with different electricity resource scenarios.

1. Perform our own risk assessments for various resource options

2. Participate in power supplier's risk assessment activities

3. Our system is considered in risk assessments done solely by power supplier

4. No risk assessment activities

B-9 Do any of the following factors significantly influence your system's analyses and resulting plans?
1. Surplus supply resources
(Circle your answer)
2. All-requirements power purchase contracts.
Yes
No
3. Long term power sales contracts.
Yes
No
4. Transmission limitations.
Yes
No
5. Limited financial \& personnel resources
Yes
No
6. Unavailable/unreliable data.
Yes
No
7. Lack of supplier \& distributor coordination
Yes
No
8. Inconsistent regulations.
Yes
No
9. Other

\section{Your System's Supply- and Demand-Side Resources}

C-1 Which of the following are used to meet the electrical needs of your system's consumers? (Circle all that apply)

1. Power purchases from another utility (e.g., G\&T, PMA, IOU, etc.)

2. Purchases of customer generation

3. Purchases of independent power producer generation

4. Utility-owned peaking unit (e.g., gas turbine)

5. Utility-owned baseload unit

6. Utility-owned renewables (e.g., hydroelectric plant, wind turbines, biomass facility)

7. Customer-owned renewables (e.g., remove solar photovoltaic systems)

8. Other

C-2 Please complete the following matrix to indicate the various types of demand-side programs which your system currently operates, and the customer classes which these programs are offered to. Put an "X" in the boxes below to indicate your current DSM programs.

\section{DSM Program}

1. Peak clipping (e.g., direct load control)

2. Valley filling (e.g., propane to electric fuel substitution)

3. Load shifting (e.g., load control, TOU rates)

4. Strategic conservation

5. Strategic load growth

6. Other
Residential Commercial Industrial Agricultural

\begin{tabular}{|c|c|c|c|}
\hline $\begin{array}{l}a \\
\square \\
\square \\
\square \\
\square\end{array}$ & $\begin{array}{l}\square \\
\square \\
\square \\
\square \\
\square\end{array}$ & $\begin{array}{l}\square \\
\square \\
\square \\
\square\end{array}$ & $\begin{array}{c}a \\
\square \\
\square \\
\square\end{array}$ \\
\hline
\end{tabular}


In developing its IRP advancement strategy, the Department of Energy is interested in identifying areas where it can provide assistance to rural electric systems. Potential types of assistance include, but are not limited to:

1. Information (e.g., publications, workshops)

2. IRP tools (e.g., software, guidebooks)

3. Technical assistance (e.g. studies, consultations)

4. Financial assistance (e.g., loans, grants)

5. IRP data development (i.e., developing key resource planning data)

D-1 Please rank the five types of IRP assistance listed above in terms of your system's desire to obtain such assistance during the next five years. (Please write the number of each assistance type on appropriate line below)
\#1 Priority:
\#2 Priority:
\#3 Priority:
\#4 Priority:
\#5 Priority:

Please answer questions D-2 through D-6 to indicate your system's interest in obtaining various types of IRP assistance.

D-2 How interested would your system be in the following types of IRP-related information?

(Circle your answer)

1. Publications... Very Somewhat Very Somewhat

2. Audiovisual materials. Very Somewhat

3. Workshops and seminars Very Somewhat

4. Correspondence courses. Very Somewhat

Not at All Don't Know

Not at All Don't Know

Not at All Don't Know

Not at All Don't Know

5. Electronic bulletin boards.

6. Other

D-3 How interested would your system be in tools (e.g., workbooks, software) to address the following topics?

(Circle your answer)

1. Load forecasting.

2. DSM program selection.

3. Externalities costing (e.g., environmental impacts)

4. Integrated supply- \& demand-side resource evaluation.

5. Impact \& process evaluation of DSM programs.

6. Integration of wholesale and retail impacts

7. Other
Very Somewhat Very Somewhat Very Somewhat Very Somewhat Very Somewhat .Very Somewhat
Not at All Don't Know

Not at All Don't Know

Not at All Don't Know

Not at All Don't Know

Not at All Don't Know

Not at All Don't Know

D-4 How interested would your system be in the following types of IRP-related technical assistance?

(Circle your answer)

1. Information hotlines \& clearinghouses. Very Somewhat

Not at All Very Somewhat

Not at All

Very Somewhat

Not at All

Very Somewhat

Not at All

Don't Know

3. Peer consultation.

es in a region.

5. Other

* An IRP circuit rider is a resource planning expert shared by several utilities in a region.

D-5

How interested would your system be in the following types of IRP-related financial assistance?

(Circle your answer)

1. Loans.

Very Somewhat

Not at All

Very Somewhat

Not at All

Very Somewhat

Not at All

Very Somewhat

Not at All

Very Somewhat

Not at All

Don't Know

Don't Know

Don't Know

4. Collective funding by group of utilities.

6. Awards for IRP performance.

7. Other 
D-6 How interested would your system be in obtaining improved data in the following areas?

(Circle your answer)

1. Transmission \& distribution options/economics.

Very Somewhat

2. Regional power purchase options/costs

Very Somewhat

3. DSM impacts (e.g., KW, KWH, \& economic).

Very Somewhat

4. Externality costs (e.g., environmental impacts)

Very Somewhat

5. Customer facility \& end-use characteristics.

Very Somewhat

6. Customer attitudes \& behavior.

Very Somewhat

Not at All

Not at All

Not at All

Not at All

Not at All

Not at All

Don't Know

Don't Know

Don't Know

7. Other

D-7 Questions D-2 through D-6 presented various types of IRP assistance which could be of interest to your system. What other types of IRP-related assistance are you interested in?

D-8 How likely would your system be to obtain IRP assistance from the following organizations if each offered IRP services to cooperatives?

(Circle your answer)

1. National utility organization (e.g., NRECA, EPRI)

Very Somewhat

Not at All

2. Federal power agency (e.g., BPA, SEPA, SWPA, TVA, WAPA) Very Somewhat

Not at All

Very Somewhat

3. Rural Electrification Administration.

Very Somewhat

4. G\&T cooperative.

Not at All

Don't Know

4. Regional or state utilit

Very

Not at All

Not at All

Don't Know

5. Private organization (e.g., consultant, information service)

Very Somewhat

Not at All

Don't Know

6. Other

\section{E. Your System's Profile}

E-1 Your system's average retail energy rates for general service commercial consumers.
1. Less than $2 \varnothing / \mathrm{KWH}$
2. $2 \notin / \mathrm{KWH}$ to $4 \varnothing / \mathrm{KWH}$
3. $4 \notin / \mathrm{KWH}$ to $7 \notin / \mathrm{KWH}$
4. $7 \phi / \mathrm{KWH}$ to $10 \phi / \mathrm{KWH}$
5. Greater than $10 \notin / \mathrm{KWH}$

E-2 Your system's average retail demand rates for general service commercial consumers.

1. Less than $\$ 4 / \mathrm{KW}$-month

2. $\$ 4 / \mathrm{KW}$ to $\$ 8 / \mathrm{KW}$-month

3. $\$ 8 / \mathrm{KW}$ to $\$ 12 / \mathrm{KW}$-month

4. $\$ 12 / \mathrm{KW}$ to $\$ 16 / \mathrm{KW}$-month

5. Greater than $\$ 16 / \mathrm{KW}$-month

E-3 Average annual load growth in your service area.

1. Negative load growth

2. 0 to $1.0 \%$

3. 1.1 to $2.0 \%$

4. 2.1 to $4.0 \%$

5. $4.1 \%$ or greater

E-4 Total number of electric system employees.

1. Less than 20

2. 20 to 50

3. 51 to 100

4. 101 to 200

5. Greater than 200

E-5 1993 Meters and Sales. (Please complete the table)

\begin{tabular}{|l|l|l|}
\hline Customer Class & No. of Meters & $\mathrm{kWh}$ Sales \\
\hline Residential & & \\
\hline Commercial & & \\
\hline Industrial & & \\
\hline Agricultural & & \\
\hline Other & & \\
\hline
\end{tabular}

As part of this study, we will also be contacting a limited number of cooperative utilities by telephone. If we do call you, we will ask a few brief questions about your system's planning approaches and needs. The information that we obtain from these discussions will benefit cooperative utilities across the U.S. If you are interested in participating in a telephone interview, please provide your name and telephone number.

Name: System: Telephone: 


\section{Attachment E}

Regional IRP Assistance Needs 


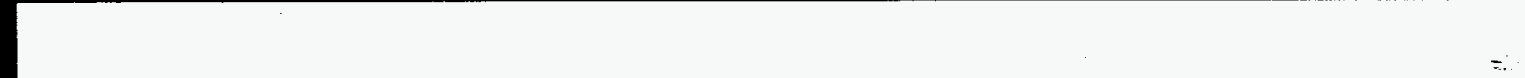


IRP Assistance Interests of JAAs

\begin{tabular}{|c|c|c|c|c|}
\hline$\overline{\text { Rank }}$ & Non-PMA JAAs & SEPA JAAs & SWPA JAAs & WAPA JAAS \\
\hline$\# 1$. & DSM impact data & Publications & Load forecasting tools & DSM impact data \\
\hline$\# 2$. & $\begin{array}{l}\text { Customer attitude \& } \\
\text { behavior data }\end{array}$ & Load forecasting tools & DSM impact data & $\begin{array}{l}\text { Customer facility \& end- } \\
\text { use characteristics data }\end{array}$ \\
\hline \#3. & $\begin{array}{l}\text { Regional power purchase } \\
\text { options/costs data }\end{array}$ & $\begin{array}{l}\text { Integrated supply- \& } \\
\text { demand-side resource } \\
\text { evaluation tools }\end{array}$ & Publications & $\begin{array}{l}\text { Integrated supply- \& } \\
\text { demand-side resource } \\
\text { evaluation tools }\end{array}$ \\
\hline \#4. & $\begin{array}{l}\text { Customer facility \& end- } \\
\text { use characteristics data }\end{array}$ & Externality costs data & Workshops and seminars & $\begin{array}{l}\text { Customer attitude \& } \\
\text { behavior data }\end{array}$ \\
\hline$\# 5$. & Publications & $\begin{array}{l}\text { Customer facility \& end- } \\
\text { use characteristics data }\end{array}$ & $\begin{array}{l}\text { DSM program selection } \\
\text { tools }\end{array}$ & $\begin{array}{l}\text { DSM program selection } \\
\text { tools }\end{array}$ \\
\hline$\# 6$. & $\begin{array}{l}\text { Transmission \& } \\
\text { distribution } \\
\text { options/economics data }\end{array}$ & $\begin{array}{l}\text { Customer attitude \& } \\
\text { behavior data }\end{array}$ & Externality costs data & $\begin{array}{l}\text { Impact \& process } \\
\text { evaluation tools }\end{array}$ \\
\hline$\# 7$. & $\begin{array}{l}\text { Integrated supply- \& } \\
\text { demand-side resource } \\
\text { evaluation tools }\end{array}$ & Audiovisual materials & $\begin{array}{l}\text { Customer attitude \& } \\
\text { behavior data }\end{array}$ & $\begin{array}{l}\text { Regional power purchase } \\
\text { options/costs data }\end{array}$ \\
\hline \#8. & $\begin{array}{l}\text { Impact \& process } \\
\text { evaluation tools }\end{array}$ & $\begin{array}{l}\text { DSM program selection } \\
\text { tools }\end{array}$ & Correspondence courses & Externalities costing tools \\
\hline \#9. & Grants & Grants & $\begin{array}{l}\text { Integrated supply- \& } \\
\text { demand-side resource } \\
\text { evaluation tools }\end{array}$ & Grants \\
\hline \#10. & $\begin{array}{l}\text { DSM program selection } \\
\text { tools }\end{array}$ & Loans & $\begin{array}{l}\text { Impact \& process } \\
\text { evaluation tools }\end{array}$ & Externality costs data \\
\hline
\end{tabular}


IRP Assistance Interests of Munis

\begin{tabular}{|c|c|c|c|c|c|c|}
\hline Rank & BPA Munis & Non-PMA Munis & SEPA Munis & SWPA Munis & TVA Munis & WAPA Munis \\
\hline$\# 1$. & Publications & Publications & Load forecasting tools & $\begin{array}{l}\text { Transmission \& } \\
\text { distribution options/ } \\
\text { economics data }\end{array}$ & $\begin{array}{l}\text { Customer attitudes \& } \\
\text { behaviors data }\end{array}$ & DSM impacts data \\
\hline$\# 2$. & $\begin{array}{l}\text { DSM program selection } \\
\text { tools }\end{array}$ & $\begin{array}{l}\text { Transmission \& } \\
\text { distribution options/ } \\
\text { economics data }\end{array}$ & $\begin{array}{l}\text { Transmission \& } \\
\text { distribution options/ } \\
\text { economics data }\end{array}$ & Publications & Load forecasting tools & Grants \\
\hline \#3. & Workshops and seminars & $\begin{array}{l}\text { DSM program selection } \\
\text { tools }\end{array}$ & Publications & Grants & $\begin{array}{l}\text { Transmission \& } \\
\text { distribution options/ } \\
\text { economics data }\end{array}$ & $\begin{array}{l}\text { Customer attitudes \& } \\
\text { behaviors data }\end{array}$ \\
\hline \#4. & DSM impacts data & DSM impacts data & Workshops and seminars & Load forecasting tools & Publications & Publications \\
\hline$\# 5$. & $\begin{array}{l}\text { Integrated supply- \& } \\
\text { demand-side resource } \\
\text { evaluation tools }\end{array}$ & Load forecasting tools & Grants & $\begin{array}{l}\text { Customer attitudes \& } \\
\text { behaviors data }\end{array}$ & $\begin{array}{l}\text { Customer facility \& end- } \\
\text { use characteristics data }\end{array}$ & $\begin{array}{l}\text { Customer facility \& end- } \\
\text { use characteristics data }\end{array}$ \\
\hline \#6. & Grants & Grants & $\begin{array}{l}\text { Customer facility \& end- } \\
\text { use characteristics data }\end{array}$ & $\begin{array}{l}\text { Integrated supply- \& } \\
\text { demand-side resource } \\
\text { evaluation tools }\end{array}$ & DSM impacts data & Workshops and seminars \\
\hline$\# 7$. & $\begin{array}{l}\text { Regional power purchase } \\
\text { options/costs data }\end{array}$ & $\begin{array}{l}\text { Customer attitudes \& } \\
\text { behaviors data }\end{array}$ & $\begin{array}{l}\text { Customer attitudes \& } \\
\text { behaviors data }\end{array}$ & DSM impacts data & $\begin{array}{l}\text { Audiovisual materials } \\
\text { data }\end{array}$ & Load forecasting tools \\
\hline$\# 8$. & $\begin{array}{l}\text { Transmission \& } \\
\text { distribution options/ } \\
\text { economics data }\end{array}$ & $\begin{array}{l}\text { Regional power purchase } \\
\text { options/costs data }\end{array}$ & DSM impacts data & $\begin{array}{l}\text { DSM program selection } \\
\text { tools }\end{array}$ & $\begin{array}{l}\text { DSM program selection } \\
\text { tools }\end{array}$ & $\begin{array}{l}\text { Transmission \& } \\
\text { distribution options/ } \\
\text { economics data }\end{array}$ \\
\hline \#9. & $\begin{array}{l}\text { Customer attitudes \& } \\
\text { behaviors data }\end{array}$ & Workshops \& seminars & $\begin{array}{l}\text { Regional power purchase } \\
\text { options/costs data }\end{array}$ & $\begin{array}{l}\text { Customer facility \& end- } \\
\text { use characteristics data }\end{array}$ & Workshops and seminars & $\begin{array}{l}\text { DSM program selection } \\
\text { tools }\end{array}$ \\
\hline$\# 10$. & Load forecasting tools & $\begin{array}{l}\text { Customer facility \& end- } \\
\text { use characteristics data }\end{array}$ & $\begin{array}{l}\text { DSM program selection } \\
\text { tools }\end{array}$ & $\begin{array}{l}\text { Regional power purchase } \\
\text { options/costs data }\end{array}$ & $\begin{array}{l}\text { Externalities costing } \\
\text { tools }\end{array}$ & $\begin{array}{l}\text { Regional power purchase } \\
\text { options/costs data }\end{array}$ \\
\hline
\end{tabular}


IRP Assistance Interests of G\&T Cooperatives

\begin{tabular}{|c|c|c|c|c|}
\hline Rank & Non-PMA G\&Ts & SEPA G\&Ts & SWPA G\&Ts & WAPA G\&Ts \\
\hline$\# 1$. & DSM impacts data & DSM impacts data & $\begin{array}{l}\text { Integrated supply- \& } \\
\text { demand-side resource } \\
\text { evaluation }\end{array}$ & $\begin{array}{l}\text { Integration of wholesale } \\
\& \text { retail impacts tools }\end{array}$ \\
\hline \#2. & $\begin{array}{l}\text { Customer facility \& end- } \\
\text { use characteristics }\end{array}$ & $\begin{array}{l}\text { Customer facility \& end- } \\
\text { use characteristics }\end{array}$ & Publications & DSM impacts data \\
\hline \#3. & $\begin{array}{l}\text { Customer attitudes \& } \\
\text { behaviors data }\end{array}$ & $\begin{array}{l}\text { Integration of wholesale } \\
\& \text { retail impacts tools }\end{array}$ & DSM impacts data & $\begin{array}{l}\text { DSM program selection } \\
\text { tools }\end{array}$ \\
\hline$\# 4$. & $\begin{array}{l}\text { Integrated supply- \& } \\
\text { demand-side resource } \\
\text { evaluation }\end{array}$ & $\begin{array}{l}\text { Transmission \& } \\
\text { distribution } \\
\text { options/economics data }\end{array}$ & $\begin{array}{l}\text { Impact \& process } \\
\text { evaluation of DSM } \\
\text { programs tools }\end{array}$ & $\begin{array}{l}\text { Impact \& process } \\
\text { evaluation of DSM } \\
\text { programs tools }\end{array}$ \\
\hline$\# 5$. & $\begin{array}{l}\text { Peer consultation } \\
\text { assistance }\end{array}$ & $\begin{array}{l}\text { Customer attitudes \& } \\
\text { behaviors data }\end{array}$ & Load forecasting tools & $\begin{array}{l}\text { Customer facility \& end- } \\
\text { use characteristics }\end{array}$ \\
\hline \#6. & Publications & Publications & $\begin{array}{l}\text { Transmission \& } \\
\text { distribution } \\
\text { options/economics data }\end{array}$ & Publications \\
\hline \#7. & Workshops \& seminars & Workshops \& seminars & $\begin{array}{l}\text { Integration of wholesale } \\
\text { \& retail impacts tools }\end{array}$ & $\begin{array}{l}\text { Integrated supply- \& } \\
\text { demand-side resource } \\
\text { evaluation }\end{array}$ \\
\hline \#8. & $\begin{array}{l}\text { Impact \& process } \\
\text { evaluation of DSM } \\
\text { programs tools }\end{array}$ & $\begin{array}{l}\text { DSM program selection } \\
\text { tools }\end{array}$ & $\begin{array}{l}\text { Customer attitudes \& } \\
\text { behaviors data }\end{array}$ & $\begin{array}{l}\text { Customer attitudes \& } \\
\text { behaviors data }\end{array}$ \\
\hline \#9. & $\begin{array}{l}\text { Integration of wholesale } \\
\& \text { retail impacts tools }\end{array}$ & $\begin{array}{l}\text { Impact \& process } \\
\text { evaluation of DSM } \\
\text { programs tools }\end{array}$ & Workshops \& seminars & $\begin{array}{l}\text { Peer consultation } \\
\text { assistance }\end{array}$ \\
\hline \#10. & $\begin{array}{l}\text { DSM program selection } \\
\text { tools }\end{array}$ & Load forecasting tools & $\begin{array}{l}\text { DSM program selection } \\
\text { tools }\end{array}$ & Grants \\
\hline
\end{tabular}


IRP Assistance Interests of Distribution Cooperatives

\begin{tabular}{|c|c|c|c|c|c|c|}
\hline Rank & BPA Distributors & Non-PMA Distributors & SEPA Distributors & SWPA Distributors & TVA Distributors & WAPA Distributors \\
\hline$\# 1$. & Publications & DSM impacts data & $\begin{array}{l}\text { Customer attitudes \& } \\
\text { behavior data }\end{array}$ & $\begin{array}{l}\text { Customer attitudes \& } \\
\text { behavior data }\end{array}$ & Load forecasting tools & Grants \\
\hline$\# 2$. & $\begin{array}{l}\text { Externalities costing } \\
\text { tools }\end{array}$ & $\begin{array}{l}\text { Customer attitudes \& } \\
\text { behavior data }\end{array}$ & Grants & DSM impacts data & $\begin{array}{l}\text { Transmission \& } \\
\text { distribution options/ } \\
\text { economics data }\end{array}$ & $\begin{array}{l}\text { Customer attitudes \& } \\
\text { behavior data }\end{array}$ \\
\hline \#3. & $\begin{array}{l}\text { Integrated supply- \& } \\
\text { demand-side resource } \\
\text { evaluation tools }\end{array}$ & Grants & DSM impacts data & Publications & $\begin{array}{l}\text { Customer facility \& end- } \\
\text { use characteristics data }\end{array}$ & DSM impacts data \\
\hline$\# 4$. & $\begin{array}{l}\text { Impact \& process } \\
\text { evaluation of DSM } \\
\text { programs tools }\end{array}$ & $\begin{array}{l}\text { Customer facility \& end- } \\
\text { use characteristics data }\end{array}$ & $\begin{array}{l}\text { Transmission \& } \\
\text { distribution options/ } \\
\text { economics data }\end{array}$ & Load forecasting tools & $\begin{array}{l}\text { DSM program selection } \\
\text { tools }\end{array}$ & $\begin{array}{l}\text { Customer facility \& end- } \\
\text { use characteristics data }\end{array}$ \\
\hline$\# 5$. & $\begin{array}{l}\text { Integration of wholesale } \\
\& \text { retail impacts tools }\end{array}$ & Publications & Publications & Grants & $\begin{array}{l}\text { Customer attitudes \& } \\
\text { behavior data }\end{array}$ & $\begin{array}{l}\text { Transmission \& } \\
\text { distribution options/ } \\
\text { economics data }\end{array}$ \\
\hline$\# 6$. & $\begin{array}{l}\text { Peer consultation } \\
\text { assistance }\end{array}$ & $\begin{array}{l}\text { DSM program selection } \\
\text { tools }\end{array}$ & $\begin{array}{l}\text { Customer facility \& end- } \\
\text { use characteristics data }\end{array}$ & $\begin{array}{l}\text { Transmission \& } \\
\text { distribution options/ } \\
\text { economics data }\end{array}$ & Publications & Publications \\
\hline$\# 7$. & Load forecasting tools & Load forecasting tools & $\begin{array}{l}\text { Impact \& process } \\
\text { evaluation of DSM } \\
\text { programs tools }\end{array}$ & $\begin{array}{l}\text { Customer facility \& end- } \\
\text { use characteristics data }\end{array}$ & Grants & Load forecasting tools \\
\hline$\# 8$. & DSM impacts data & Audiovisual materials & Cost shared funding & Workshops \& seminars & Audiovisual materials & Workshops \& seminars \\
\hline \#9. & Workshops \& seminars & $\begin{array}{l}\text { Impact \& process } \\
\text { evaluation of DSM } \\
\text { programs tools }\end{array}$ & Audiovisual materials & $\begin{array}{l}\text { DSM program selection } \\
\text { tools }\end{array}$ & $\begin{array}{l}\text { Integration of wholesale } \\
\text { \& retail impacts tools }\end{array}$ & $\begin{array}{l}\text { Integration of wholesale } \\
\text { \& retail impacts tools }\end{array}$ \\
\hline \#10. & Cost shared funding & $\begin{array}{l}\text { Transmission \& } \\
\text { distribution options/ } \\
\text { economics data }\end{array}$ & $\begin{array}{l}\text { Integration of wholesale } \\
\& \text { retail impacts tools }\end{array}$ & $\begin{array}{l}\text { Impact \& process } \\
\text { evaluation of DSM } \\
\text { programs tools }\end{array}$ & $\begin{array}{l}\text { Impact \& process } \\
\text { evaluation of DSM } \\
\text { programs tools }\end{array}$ & $\begin{array}{l}\text { DSM program selection } \\
\text { tools }\end{array}$ \\
\hline
\end{tabular}




\title{
Appendix C
}

\section{Federal and State IRP Policies}

\author{
Prepared by
}

Garrick \& Associates and the

National Renewable Energy Laboratory

Principal Investigators:

Jan Eckert, NREL

Cynthia J. Garrick, Garrick \& Associates 


\section{Summary}

More than 20 federal and state agencies have established IRP policies or rules that influence publicly and cooperatively owned utility IRP practices, and several additional agencies are currently developing IRP policies. Many of these policies apply to publicly and cooperatively owned utilities under state PUC jurisdiction. Other policies apply across a region of the United States, such as a federal power agency's region. In addition, the REA's planning requirements apply to most cooperatively owned utilities in the country.

Table S-1 lists the various federal, state, and "other" agencies with IRP policies and indicates the type of policy (e.g., legislation, rule, etc.) and the approximate number of publicly and cooperatively owned utilities to which it applies. Table S-2 indicates the IRP elements required by each of the federal, state, and "other" agencies with IRP policies for publicly and cooperatively owned utilities. The required IRP elements indicated in Table S-2 are not based on survey input, but rather reflect NREL and Garrick \& Associates' interpretation of the various federal and state policies.

\section{Federal Policies}

The REA has required all cooperative borrowers to consider both demand- and supply-side resource options since 1992, when 7 CFR Part 1710, "General and Pre-loan Policies and Procedures Common to Insured and Guaranteed Electric Loans," was published. It is REA's position that the 1710 rule, which requires two primary documents-power requirements studies and construction work plans-to be submitted on a routine basis, provides an IRP requirement for approval of all loans. With the passage of the 1993 Rural Electric Loan Restructuring Act, a historical impediment to cooperative IRP was removed. The Act gives REA the ability to make loans for all types of DSM programs. In the past, REA could only provide loan funds for load control equipment. In response to the Act, REA published Subpart $H$, Demand Side Management and Renewable Energy Systems, of the 1710 regulation. Subpart $H$ requires an REA-approved IRP prior to approval of loans that include funds for DSM activities and/or on- or offgrid renewable energy systems. REA specifically requires a power supply borrower and all member systems to coordinate in the development of a system-wide IRP and the IRP to be approved by the board of directors of the power supply borrower. Virtually all cooperatives are affected by the 1710 requirements. The requirements cover both routine reporting and new loan approval policies for G\&T and distribution cooperatives. The only cooperatives that are not subject to these policies and procedures are those few that are not REA borrowers.

The EPAct (Section 113) requires TVA to conduct a least-cost planning process. The agency expects to complete the initial plan in its process by December 1995. TVA, a federal corporation that provides electric power in an area that covers most of Tennessee and parts of Alabama, Georgia, Kentucky, Mississippi, North Carolina, and Virginia, has the utility responsibility for meeting the electric power needs of this region. The agency provides all-requirements electric service to 110 publicly owned utilities and 50 cooperatively owned utilities. EPAct requires that TVA provide distributors with both an opportunity to participate in the IRP process and assistance in the planning and implementation of costeffective energy-efficiency options.

WAPA is currently developing an integrated resource planning requirement to replace its Guidelines and Acceptance Criteria for the Conservation and Renewable Energy Program. The IRP requirement is mandated by Section 114 of EPAct, which amended Title II of the Hoover Power Plant Act of 1984 to require that WAPA customers implement IRP. EPAct states that the IRP requirement is applicable to any WAPA customer that purchases electric capacity (with or without energy) under a long-term firm power 
Table S-1. IRP Policies Affecting Publicly and Cooperatively Owned Utilities: Type and Applicability

\begin{tabular}{|c|c|c|c|c|c|c|c|c|c|}
\hline \multirow[t]{2}{*}{ Agency } & & \multicolumn{6}{|c|}{ Type of Policy } & \multicolumn{2}{|c|}{$\begin{array}{c}\text { Number of Utilities Which } \\
\text { Policy Applies To }\end{array}$} \\
\hline & & 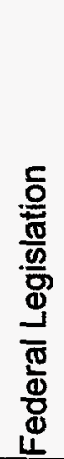 & 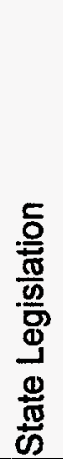 & $\stackrel{\mathscr{O}}{\vec{\alpha}}$ & 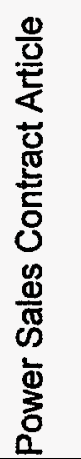 & 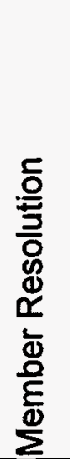 & 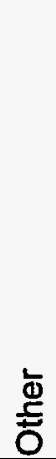 & 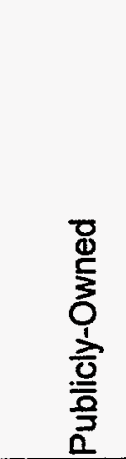 & 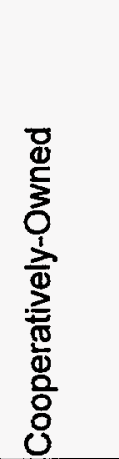 \\
\hline \multicolumn{10}{|c|}{ Federal } \\
\hline & NWPPC/BPA & $x$ & & & & & & 68 & 56 \\
\hline & REA & & & $x$ & & & & 20 & 800 \\
\hline & SEPA & & & & & & $x$ & 0 & 0 \\
\hline & SWPA & & & & $x$ & & & 13 & 3 \\
\hline & TVA & $x$ & & & & & & 110 & 50 \\
\hline & U.S. Congress - PURPA IRP Standard & $x$ & & & & & & 200 & 300 \\
\hline & WAPA & $x$ & & $x$ & & & & 350 & 45 \\
\hline \multicolumn{10}{|c|}{ State } \\
\hline & Alaska PUC & & & & & & $x$ & 1 & 5 \\
\hline & Arizona CC & & & $\dot{x}$ & & & & 0 & 1 \\
\hline & Arkansas PSC & & $x$ & & & & $x$ & 0 & 17 \\
\hline & Delaware PSC & $x$ & & $x$ & & & & 0 & 1 \\
\hline & Indiana URC* & & $x$ & $x$ & & & & 1 & 2 \\
\hline & lowa Utilities Board & & $x$ & $x$ & & & & 148 & 59 \\
\hline & Kansas CC* & & & $x$ & & & & 0 & 2 \\
\hline & Kentucky PSC & & & $x$ & & & & 0 & 2 \\
\hline & Maryland PSC & & & $x$ & & & & 5 & 4 \\
\hline & Massachusetts DPU & & $x$ & $x$ & & & & 40 & 0 \\
\hline & Minnesota PUC & & $x$ & & & & & 1 & 4 \\
\hline & Nebraska & & $x$ & & & & & 130 & 40 \\
\hline & New Mexico PUC* & & & $x$ & & & & 0 & 20 \\
\hline & Oklahoma CC* & & & $x$ & & & & 0 & $31^{* *}$ \\
\hline & South Carolina PSC and SEO & & $x$ & $x$ & & & & 22 & 23 \\
\hline & Vermont & & $x$ & $x$ & & & & 14 & 2 \\
\hline & Virginia SCC & & $x$ & & & & $x$ & 0 & 13 \\
\hline & Wisconsin & & $x$ & $x$ & & & & 82 & 1 \\
\hline \multicolumn{10}{|c|}{ Other } \\
\hline & NRECA & & & & & $x$ & & 0 & 900 \\
\hline
\end{tabular}

*Proposed policy

**The OCC is currently investigating whether the proposed regulation will apply to all 31 distribution cooperatives. 
Table S-2. IRP Policies Affecting Publicly and Cooperatively Owned Utilities: Required IRP Elements

\begin{tabular}{|c|c|c|c|c|c|c|c|c|c|}
\hline \multirow[t]{2}{*}{ Agency } & & \multicolumn{8}{|c|}{ Required IRP Elements } \\
\hline & & 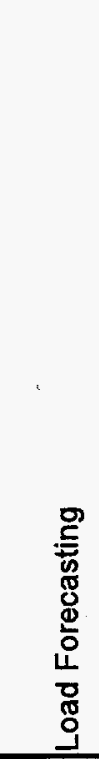 & 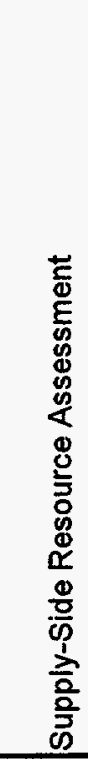 & 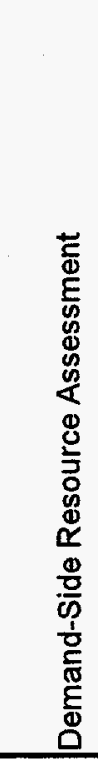 & 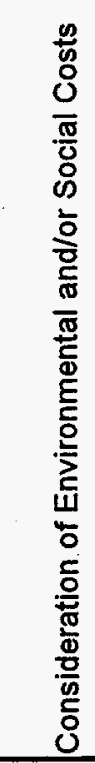 & 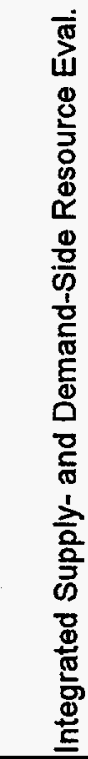 & 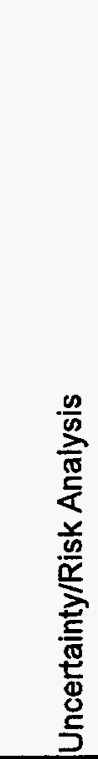 & 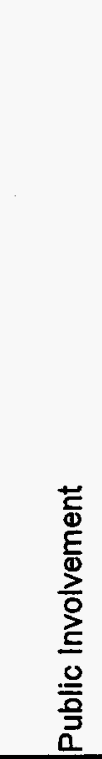 & 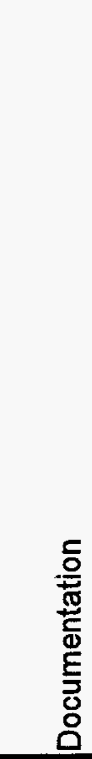 \\
\hline \multicolumn{10}{|l|}{$\overline{\text { Federal }}$} \\
\hline & NWPPC/BPA & $\mathbf{x}$ & $\mathbf{x}$ & $\mathbf{x}$ & $\mathbf{x}$ & $x$ & $x$ & $x$ & $x$ \\
\hline & REA & $x$ & $\mathbf{x}$ & $x$ & $\mathbf{x}$ & & & & $\mathbf{x}$ \\
\hline & SEPA & nla & nla & nla & nla & nla & nla & nla & nla \\
\hline & SWPA & & $x$ & $\mathbf{x}$ & & $x$ & & $x$ & \\
\hline & TVA & & $\dot{x}$ & $x$ & & $x$ & $\mathbf{x}$ & $x$ & $x$ \\
\hline & U.S. Congress - PURPA IRP Standard & nla & nla & nla & nla & nla & nla & nla & nla \\
\hline & WAPA & $x$ & $x$ & $x$ & $x$ & & & $x$ & $x$ \\
\hline \multicolumn{10}{|l|}{ State } \\
\hline & Alaska PUC & nla & nla & nla & nla & nla & nla & nla & nla \\
\hline & Arizona CC & $x$ & $\mathbf{x}$ & $x$ & $x$ & $x$ & $x$ & & $x$ \\
\hline & Arkansas PSC & $\mathbf{x}$ & $x$ & $x$ & $x$ & $x$ & $x$ & 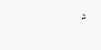 & $\mathbf{x}$ \\
\hline & Delaware PSC & $\mathbf{x}$ & $\mathbf{x}$ & $x$ & $x$ & $x$ & $x$ & & $x$ \\
\hline & lowa Utilities Board & $\mathbf{x}$ & $\mathbf{x}$ & $x$ & $x$ & & & & $x$ \\
\hline & Indiana URC* & tbd & tbd & tbd & tbd & tbd & tbd & tbd & tbd \\
\hline & Kansas $C^{*}$ & tbd & tbd & tbd & tbd & tbd & tbd & tbd & tbd \\
\hline & Kentucky PSC & $x$ & $x$ & $x$ & & $x$ & $x$ & & $x$ \\
\hline & Maryland PSC & nla & nla & nla & nla & nla & nla & nla & nla \\
\hline & Massachusetts DPU & $x$ & $x$ & & $x$ & & $x$ & & $\mathbf{x}$ \\
\hline & Minnesota PUC & $x$ & $x$ & $x$ & $x$ & $x$ & $x$ & & $x$ \\
\hline & Nebraska & $x$ & $x$ & $x$ & & & & & \\
\hline & Oklahoma CC* & tbd & tbd & tbd & tbd & tbd & tbd & tbd & tbd \\
\hline & New Mexico PUC* & tbd & tbd & tbd & tbd & tbd & tbd & tbd & tbd \\
\hline & South Carolina PSC and SEO & $x$ & $x$ & $x$ & $x$ & & & & $x$ \\
\hline & Vermont & $x$ & $x$ & $x$ & $x$ & $x$ & $\mathbf{x}$ & $x$ & \\
\hline & Virginia SCC & $x$ & $x$ & $x$ & & $x$ & $\mathbf{x}$ & & $x$ \\
\hline & Wisconsin & $x$ & $x$ & $x$ & $x$ & & & & $x$ \\
\hline \multicolumn{10}{|l|}{ Other } \\
\hline & NRECA & nla & nla & nla & nla & nla & nla & nla & nla \\
\hline
\end{tabular}

*Proposed policy 
service contract, with the possible exception of certain small customers. WAPA serves more than 600 long-term firm power customers in 15 western states from Minnesota in the Northeast to California in the Southwest, including approximately 45 cooperative utilities and 350 government-owned utilities. EPAct also establishes specific penalties for noncompliance by WAPA customers, including rate surcharges and reduced power allocations. EPAct requires WAPA to prepare an environmental impact statement on the development of the IRP rule. IRP rule development and the corresponding EIS process are in progress. WAPA expects to publish a final IRP rule by the spring of 1995.

Two federal power agencies have begun using power sales contract articles to promote customer IRP practice. SWPA has developed an IRP clause for inclusion in all new or updated power sales contracts which states, "...the customer agrees to the extent practical to perform activities associated with IRP in securing future power resources... ." The contract clause does not establish a schedule for customer IRP efforts, nor does it require customers to submit an IRP to SWPA. Since it was developed in 1992, the article has been incorporated into the power sales contracts for three cooperatively owned utilities and 13 publicly owned utilities. The contract article will be added to additional SWPA customer contracts in 1997, when a number of existing contracts are scheduled for renewal. SEPA adopted a new power marketing policy for its Cumberland Basin Project, which includes an Energy and Economic Efficiency Measures clause to be placed in renewed power sales contracts to encourage IRP. The clause states, "Each customer who purchases Southeastern's power is encouraged to participate in an integrated resource plan that considers both supply and demand side alternatives... ." SEPA anticipates adding this IRP clause to all future contracts.

The U.S. Congress established an IRP Standard in 1992. Section 111(a) of EPAct amended Section 111(d)(7) of the Public Utilities Regulatory Policy Act of 1978 (PURPA) to require "each state regulatory authority (with respect to each electric utility for which it has ratemaking authority) and each nonregulated electric utility..." to consider implementation of IRP. State regulatory authorities and nonregulated electric utilities must consider the standard within 2 years of its passage (i.e., October 1994) by making public notice and holding a public hearing. Based on the findings of the hearing, each state commission and nonregulated utility can either implement the IRP standard or decline to implement the standard. More than 20 PUCs have full ratemaking authority over publicly and cooperatively owned utilities, regulating approximately 500 total utilities. ${ }^{1}$ In addition, several other state PUCs have limited ratemaking authority over publicly and cooperatively owned utilities. The PURPA IRP standard also applies to nonregulated utilities over a certain size.

\section{State Policies}

IRP policies for publicly and cooperatively owned utilities have been established by at least 14 states. These states require IRP by means of legislation and/or rules. A few of the IRP policies were developed in the 1970s or early 1980s (Maryland, 1972; Wisconsin, 1975; Virginia, 1978; Nebraska, 1981). However, most were established in the late 1980 s or early 1990 s. Several of the most recently established policies have yet to be implemented.

Of the 14 state IRP policies, 13 apply to cooperatively owned utilities, whereas only nine apply to government-owned utilities. Typically, states require utilities to prepare 10- to 20-year IRPs 2 or 3 years. Some state commission have authority to approve or disapprove utility IRPs, while others provide review comments to the utilities for their use.

\footnotetext{
${ }^{1}$ Rodgers, P. National Association of Regulatory Utility Commissioners. 1993. Utility Regulatory Policy in the United States and Canada.
} 
State IRP requirements may affect wholesale and/or distribution utilities, depending on the regulatory authority of the PUC. For example, the Virginia Corporation Commission regulates ten distribution cooperatives but does not have regulatory authority over G\&T cooperatives. In Minnesota, the IRP policy applies only to the state's four largest G\&Ts. However, these four G\&Ts are owned and controlled by a total of 72 distribution cooperatives that will indirectly be affected by, and involved in, the IRP process.

Four state PUCs are in the process of developing IRP requirements that will apply to publicly and cooperatively owned utilities. In Indiana, a rulemaking is in progress (in response to state legislation) to require electric utilities filing for a certificate of need to submit an IRP as part of the hearing process. Two Kansas G\&Ts will be required to file triennial IRP plans if the Kansas Corporation Commission adopts its proposed rule. The New Mexico PUC is also considering an IRP rule that would affect all of the state's cooperative utilities. In addition, the Oklahoma Corporation Commission is involved in an IRP rulemaking process that may apply to distribution cooperatives.

\section{Other Policies}

The $900+$ member cooperatives of NRECA adopted an IRP resolution in 1992. Continuing Resolution \#53 reads as follows:

Rural electric systems must continue to plan to meet the energy service needs of their members in a manner which effectively integrates supply-side and demand-side resources. Since integrated resource planning for rural electric systems requires the concerted efforts of member consumers, distribution systems, power suppliers, statewide organizations, and regulatory agencies we urge continued cooperation and coordination in the development of rate design, policies and programs.

We urge all segments of our program to continue to use integrated resource planning to assist in providing reliable electrical services at the lowest overall cost by carefully integrating both supply-side and demand-side resources.

The remainder of this document provides a summary of the various federal, state, and other IRP policies. 


\section{Contents}

\section{Federal IRP Policies}

Northwest Power Planning Council/Bonneville Power Administration $\ldots \ldots \ldots \ldots \ldots \ldots$ C-7

Rural Electrification Administration $\ldots \ldots \ldots \ldots \ldots \ldots \ldots \ldots \ldots \ldots \ldots \ldots \ldots$ C-10

Southeastern Power Administration $\ldots \ldots \ldots \ldots \ldots \ldots \ldots \ldots \ldots \ldots \ldots \ldots \ldots$ C $\ldots \ldots \ldots$

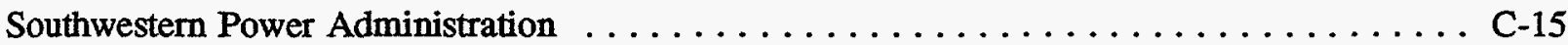

Tennessee Valley Authority . . . . . . . . . . . . . . . . . . . . . . C-17

U.S. Congress-PURPA IRP Standard . . . . . . . . . . . . . . . . . . . . . . . . C-19

Westem Area Power Administration $\ldots \ldots \ldots \ldots \ldots \ldots \ldots \ldots \ldots \ldots \ldots \ldots \ldots \ldots$. . . . . . . . . . .

\section{State IRP Policies}

Alaska Public Utilities Commission $\ldots \ldots \ldots \ldots \ldots \ldots \ldots \ldots \ldots \ldots \ldots \ldots \ldots \ldots \ldots$

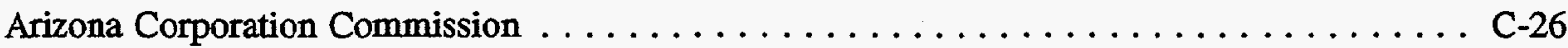

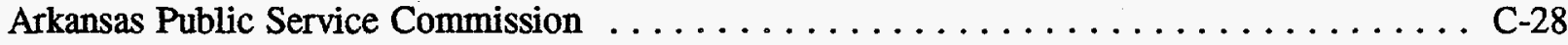

Delaware Public Service Commission $\ldots \ldots \ldots \ldots \ldots \ldots \ldots \ldots \ldots \ldots \ldots \ldots \ldots$ C $\ldots \ldots$.30

Indiana Utility Regulatory Commission $\ldots \ldots \ldots \ldots \ldots \ldots \ldots \ldots \ldots \ldots \ldots \ldots \ldots$

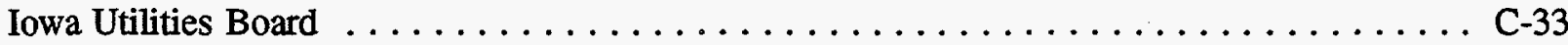

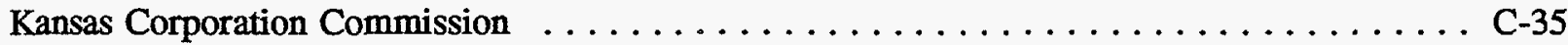

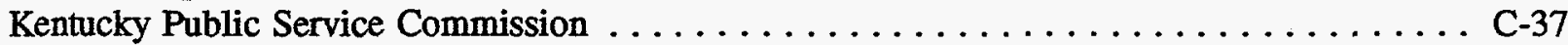

Maryland Public Service Commission . . . . . . . . . . . . . . . . . . . . . . C-39

Massachusetts Department of Public Utilities $\ldots \ldots \ldots \ldots \ldots \ldots \ldots \ldots \ldots \ldots \ldots$. . . . . . . .

Minnesota Public Utilities Commission . . . . . . . . . . . . . . . . . . . . C-43

Nebraska Power Review Board . . . . . . . . . . . . . . . . . . . . . C-45

New Mexico Public Utility Commission . . . . . . . . . . . . . . . . C 47

Oklahoma Corporation Commission . . . . . . . . . . . . . . . . . . . . . . C-49

South Carolina Public Service Commission and South Carolina State Energy Office . . . . . . C-50

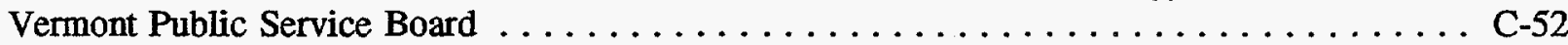

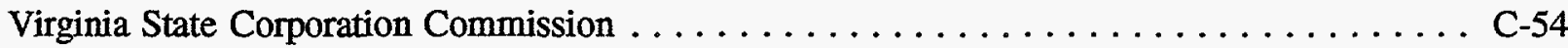

Wisconsin Public Service Commission $\ldots \ldots \ldots \ldots \ldots \ldots \ldots \ldots \ldots \ldots \ldots$

\section{Other IRP Policies}

National Rural Electric Cooperative Association . . . . . . . . . . . . . . . . . C-58 


\section{Federal IRP Policies}

AGENCY:

CONTACT:

SUMMARY OF REQMT:

TYPE OF REQUIREMENT:

ENABLING AUTHORITY:

EFFECTIVE DATE:

APPLICABILITY:

SPECIFIC REQUIREMENTS:
Northwest Power Planning Council/Bonneville Power Administration

Dick Watson, Director of Planning, NWPPC, (503) 222-5161; Mike Bull, Senior Policy Analyst, BPA, (503) 230-3811

In the Pacific Northwest region served by BPA, centralized, regional IRP is practiced by the Northwest Power Planning Council (NWPPC) - which is funded through BPA's rates. The NWPPC develops a regional IRP and works with BPA and its utility customers, the region's six IOUs, and other agencies (e.g., PUCs) who help to implement the plan.

Legislative

The Northwest Power Act

1980

The Pacific Northwest regional IRP is developed for the region of Washington, Oregon, Idaho, and western Montana. The BPA-which has direct responsibility for planning and acquiring resources to meet the loads of its customers-implements the plan. The region's other utilities, including IOUs, cooperatives, and municipalities, are encouraged to help implement the regional IRP.

- Cooperatively owned Utilities: BPA serves approximately 56 rural electric cooperatives.

- Publicly Owned Utilities: BPA serves approximately 68 publicly owned utilities, including 40 municipalities and 28 public utility districts.

The Northwest Power Act of 1980 authorized the creation of the NWPPC, which was charged with developing a 20-year conservation and electric power plan for the region. The NWPPC, which is funded through BPA's rates, develops a regional integrated resource plan for the Pacific Northwest. The NWPPC adopted its first IRP in 1983, with revisions following in 1986 and 1991.

The council's power plans are characterized by sophisticated methodologies and innovation, including: 
- Conservation as a Resource: Through the Northwest Power Planning Act, Congress gave conservation a $10 \%$ system cost advantage over conventional resources.

- Integration: The IRP process includes full integration of demand-side efficiency resources into the planning process.

- Uncertainty Analysis: The council considers a range of forecasts and possible futures to develop a leastcost strategy that accounts for the effects of risk. The council's ISAAC [Integrated System for the Analysis of ACquisitions] model allows in-depth evaluation of risk mitigation strategies.

- Public Participation: The Northwest Power Planning Act requires the NWPPC to actively involve the public in its planning activities. The council's open public process allows widespread opportunities for participation, comment, and review as its plans are developed.

- Action Plan: This plan explicitly delineates how the IRP will be implemented during the first few years after the plan is adopted. The action plan is critical to achievement of plan goals, and provides a means of tracking progress and identifying problems.

- Implementation: Unlike a utility that implements its own IRP, the council's regional power plan is implemented by more than 120 electric utilities in the region. The NWPPC works with BPA, the region's IOUs, and other agencies (e.g., PUCs) in the implementation of the plan.

The centralized, regional planning practiced by the NWPPC and BPA are consistent with the BPA's charter, which requires it to meet the future electric needs of its customers. The agency's active role in planning and development of the region's future power facilities includes development of a biannual "Resource Program" (or BPA-specific IRP) to determine the specific resources BPA will acquire over the coming 10 years to meet loads and to help implement the Northwest Power Plan adopted by the NWPPC. Development of the Resource Program is a collaborative effort involving customers and outside interests in determining how much power will be needed and which resources to acquire. BPA's Area Offices also develop. Local 
Conservation Plans and work with individual customers to implement the plans. 
AGENCY:

CONTACT:

SUMMARY OF REQMT:

TYPE OF REQUIREMENT:

ENABLING AUTHORITY:

EFFECTIVE DATE:

APPLICABILITY:
Rural Electrification Administration ${ }^{1}$

Georg Shultz, Chief of Energy Forecasting Branch, Electric Staff Division, (202) 720-1920

Subpart H of REA's "General and Pre-loan Policies and Procedures Common to Insured and Guaranteed Electric Loans" requires an IRP for approval of loans that include funds for DSM and renewable energy activities. In addition, it is REA's position that its General and Pre-loan Policies and Procedures, which require all borrowers to consider both demand- and supply-side resource options, provide an "IRP" requirement for approval of all loans.

Rule

Department of Agriculture, Rural Electrification Administration, 7 CFR Part 1710, General and Pre-loan Policies and Procedures Common to Insured and Guaranteed Electric Loans.

REA has required borrowers to consider both demandand supply-side resource options since 1992, when the Part 1710 requirements were originally published. Subpart H of Part 1710 (which provides an explicit IRP requirement for approval of loans that include funds for DSM and renewable energy activities) was published on January 4, 1994.

Part 1710 is applicable to all existing and future REA borrowers. While its primary focus is on policies and procedures for acquisition of new REA loans, it includes routine reporting requirements for existing REA borrowers.

- Cooperatively owned Utilities: Virtually all cooperatives are affected by the 1710 requirements. The requirements cover both routine reporting and new loan approval policies for G\&T and distribution cooperatives. The only cooperatives that are not subject to these policies and procedures are those limited few that are not REA borrowers.

- Publicly Owned Utilities: REA's requirements apply to a limited number of publicly owned utilities who hold (or apply for) REA loans to serve

\footnotetext{
${ }^{1}$ In December 1994, the REA became the Rural Utilities Service (RUS).
} 
rural loads. These utilities primarily consist of about 20 public utility districts (PUDs).

SPECIFIC REQUIREMENTS:
The specific IRP requirements are delineated in Part 1710 of REA's "General and Pre-loan Policies and Procedures Common to Insured and Guaranteed Electric Loans" (most recently published in the Federal Register on January 4, 1994). This rule requires two primary documents, power requirements studies and construction work plans, to be submitted on a routine basis:

- Power Requirements Study (PRS): Provides borrower and REA with an understanding of the borrower's system loads, the factors influencing these loads, and valid estimates of future loads. It provides a basis for projecting $\mathrm{kWh}$ sales and revenues, and for engineering estimates of plant additions required to accommodate future loads.

- Construction Work Plan (CWP): Specifies and documents the capital investments required to serve a borrowers planned new loads, improve service reliability and quality, and service the changing needs of existing loads. As part of the CWP, REA requires that the construction or purchase of additional generating capacity by a power supply (G\&T) or distribution borrower be supported by comprehensive project-specific engineering and cost studies. These studies must include "comprehensive economic present value analyses of the costs and revenues of the available selfgeneration, load management, energy conservation, and purchased power options, including assessments of service reliability and financing requirements and risk"(1710.253[b]).

REA requires coordination between power supply borrowers and their members in the preparation of their respective PRSs.

Two additional support documents required for loan approval are long-range financial forecasts and borrower's environmental reports:

- Long-Range Financial Forecasts: REA encourages borrowers to maintain on a current basis a longrange financial forecast, which should be used by a borrower's board of directors and manager to guide the system toward its financial goals. 
- Borrower's Environmental Report (BER): This document is used to determine what effect the construction of the facilities included in the construction work plan will have on the environment.

As a result of the 1993 Rural Electric Loan Restructuring Act, REA now has the ability to make loans for all types of DSM programs. (Prior to that time, REA could only provide loan funds load control equipment.) Subpart H-Demand Side Management and Renewable Energy Systems, of the current 1710 regulation, requires an REA-approved IRP prior to approval of loans that include funds for DSM activities and/or on- or off-grid renewable energy systems. ${ }^{2}$ REA specifically requires a power supply borrower and all member systems to coordinate in the development of a system-wide IRP and that the IRP be approved by the board of directors of the power supply borrower. Further, if a distribution borrower desires a DSM or renewable energy loan from REA, it is required to use the overall system IRP prepared by its power supplier as the IRP submittal to REA. REA indicates the rationale for such coordination: "...DSM activities and renewable energy activities must be coordinated among all parties to insure that the activities of one member do not jeopardize the financial integrity or loan security of any other member or that of the power supply borrower" (1710.355[b][1]).

\footnotetext{
${ }^{2}$ The IRP requirement currently applies only for approval of DSM and renewable energy loans (i.e., not for supply-side loans), as this is the extent of the authority granted to REA under the 1993 Rural Electric Loan Restructuring Act. The Act expanded the agency's DSM/renewables authority and required updating of related loan approval policies and procedures.
} 
AGENCY:

CONTACT:

SUMMARY OF REQMT: ${ }^{3}$

TYPE OF REQUIREMENT:

ENABLING AUTHORITY:

EFFECTIVE DATE:

APPLICABILITY:
Southeastern Power Administration

Al Pless, Energy Efficiency/IRP Program, (706) 213-3846; E.B. Crenshaw, Power Marketing, (706) 213-3837

SEPA has adopted a Power Marketing Policy for the agency's Cumberland Basin Project which includes an Energy and Economic Efficiency Measures clause for inclusion in the project's renewed power sales contracts.

Power Marketing Policy; Power Sales Contract Article

Power Marketing Policy for the agency's Cumberland Basin Project

The Cumberland Basin Power Marketing Policy was adopted in 1993. It will be implemented through power sales contract articles within each Cumberland Basin customer's renewed power contract. These contracts are under negotiation; however, the execution dates are undetermined.

The contract article will be included in power sales contracts for the 10 customers of SEPA's Cumberland Basin Project. These contracts are currently under negotiation.

- Cooperatively owned Utilities: The contract article will apply to six cooperatives that receive power from SEPA's Cumberland Basin Project as well as the TVA, which distributes SEPA power to its 160 distributors (including 50 cooperatives). ${ }^{4}$

- Publicly Owned Utilities: The contract article will apply to three publicly owned utilities that receive power from SEPA's Cumberland Basin Project, as well as the TVA, which distributes SEPA power to its 160 distributors (including 110 municipalities).

SEPA also plans to include an Energy and Economic Efficiency Measures clause in all future renewed power sales contracts to encourage IRP.

${ }^{3}$ SEPA's IRP "requirement" is actually a voluntary IRP policy.

${ }^{4}$ TVA is required by Section 113 of the Energy Policy Act of 1992 to conduct a least-cost planning program. Section 113(e) of the Act also states that TVA is not subject to any requirement that might arise out of TVA's electric power transactions with SEPA. 
The Energy and Economic Efficiency Measures clause reads as follows:

Each customer who purchases Southeastern's power is encouraged to participate in an integrated resource plan that considers both supply and demand side alternatives. It is recognized that some Southeastern customers are members of a power supply organization that does resource planning for their customers (i.e., power supply cooperatives and joint action agencies). Where a customer, or a power supply organization that does resource planning for a Southeastern customer, is responsible to a regulatory body or another Government agency for an integrated resource plan, the customer will make a copy of such integrated resource plan available to Southeastern. All Southeastern customers shall agree to encourage the efficient use of energy by ultimate customers.

It is SEPA's policy to accept IRPs submitted to REA by its cooperative customers. 
AGENCY:

CONTACT:

SUMMARY OF REQMT:

TYPE OF REQUIREMENT:

ENABLING AUTHORITY:

EFFECTIVE DATE:

APPLICABILITY:

SPECIFIC REQUIREMENTS:
Southwestern Power Administration

Jerry Martin, Energy Conservation Officer, (918) 5817516

SWPA has developed an IRP clause for inclusion in all new or updated power sales contracts which states that "...the customer agrees to the extent practical to perform activities associated with IRP in securing future power resources... ." The contract clause does not establish a schedule for customer IRP efforts, nor does it require customers to submit an IRP to SWPA.

Power Sales Contract Article

Article XII, Integrated Resource Planning

1992

To date, Article XII has been incorporated into 16 customer power sales contracts. The contract article will be added to a significant number of additional contracts in 1997, when a number of existing contracts are scheduled for renewal.

- Cooperatively owned Utilities: SWPA's IRP clause currently applies to 3 cooperatives.

- Publicly Owned Utilities: SWPA's IRP clause currently applies to 13 municipalities.

The integrated resource planning article reads as follows:

In order to encourage the process of comparing supply and demand options as a mechanism for meeting future electrical power requirements, the customer covenants and agrees to the extent practicable to perform activities associated with Integrated Resource Planning (hereinafter, IRP) in securing future power resources. Such activities shall include the analyses of both supply-side and demandside measures in order to evaluate the full range of applicable alternatives for satisfying future load requirements. Such activities shall treat supply-side and demand-side resources on a consistent and integrated basis and shall provide for the inclusion of public participation appropriate to the customer. In analyzing supply and demand resource options, the 
customer shall consider all direct and quantifiable net costs for an energy resource over its available life, including the cost of production, transportation, utilization, waste management, and compliance with environmental laws. The customer further agrees to furnish non-proprietary information relative to its IRP activities as may be requested periodically by Southwestern and agrees that such information may be furnished by Southwestern to its other customers in order to promote the IRP process for Southwestern's marketing region. Completion of IRP activities, which are required of the customer by a state or another Federal agency, shall be acceptable to Southwestern as compliance with this Article.

The contract clause does not establish a schedule for customer IRP efforts, nor does it require customers to submit an IRP to SWPA 
AGENCY:

CONTACT:

SUMMARY OF REQMT:

TYPE OF REQUIREMENT:

ENABLING AUTHORITY:

EFFECTIVE DATE:

APPLICABLITY:

SPECIFIC REQUIREMENTS:
Tennessee Valley Authority

Dr. Lynn Maxwell, Manager of Resource Planning, (615) 751-2539

The Energy Policy Act requires TVA to conduct a least-cost planning process. It also requires that TVA provide distributors with both an opportunity to participate in the process and with assistance in the planning and implementation of cost-effective energy efficiency options.

Legislative

Section 113 of the Energy Policy Act of 1992

EPAct passed in October of 1992. TVA expects to complete the initial plan in its process by December of 1995.

The requirement applies specifically to TVA, a federal corporation that provides electric power in an area that covers most of Tennessee and parts of Alabama, Georgia, Kentucky, Mississippi, North Carolina, and Virginia. TVA has the utility responsibility for meeting the electric power needs of this region.

- Cooperatively owned Utilities: TVA provides all requirements electric service to 50 cooperatives, whose needs are addressed by the agency's plan.

- Publicly owned Utilities: TVA provides all requirements electric service to 110 municipalities, whose needs are addressed by the agency's plan.

EPAct directs that TVA shall "employ and implement a planning and selection process for new energy resources which evaluates the full range of existing and incremental resources (including new power supplies, energy conservation and efficiency, and renewable energy resources) in order to provide adequate and reliable service to electric customers of the Tennessee Valley Authority at the lowest system cost" (Section 113[b][1]). A number of requirements are delineated for the planning and selection process, including:

- Accounting for diversity, reliability, dispatchability, and other factors of risk; 
- Consistent and integrated treatment of demand- and supply-side resources;

- Participation of TVA distributors in the planning process, including obtaining recommendations for cost-effective energy efficiency opportunities, rate structure incentives, and renewable energy proposals; and

- Verification of energy savings achieved through energy conservation and efficiency.

Before the selection and addition of a major new resource, the Act requires TVA to provide an opportunity for public review and comment and to report on this in an annual report to the President and Congress. The Act also directs TVA to provide appropriate assistance to distributors in the planning and implementation of energy efficiency and renewable energy programs. Such assistance could involve education and information dissemination, technical and financial assistance, etc.

The EPAct requirements serve to reinforce TVA's long-term commitment to a least-cost energy planning process. The agency has been preparing long range planning documents for supply and demand resources since the early 1980 s. The agency also developed one of the nation's largest conservation programs during the late 1970s. In response to EPAct, TVA has initiated the development of a 25-year energy strategy involving power distributors, industries, and the public. The IRP process began in January of 1994 and will be completed within 2 years. 
AGENCY:

CONTACT(S):

SUMMARY OF REQMT:

TYPE OF REQUIREMENT:

ENABLING AUTHORITY:

EFFECTIVE DATE:

APPLICABILITY:

\section{U.S. Congress-PURPA IRP Standard}

Andrew Krantz, DOE; Paul Galen, IRP Policy Analyst, NREL, (202) 484-1090

Section 111 of the Public Utilities Regulatory Policies Act (PURPA) requires each state regulatory authority and each nonregulated electric utility to consider implementation of integrated resource planning.

Legislative

Section 111(d)(7) of the PURPA, as amended by Section 111(a) of the Energy Policy Act (EPAct)

The IRP standard was added to the PURPA (of 1978) by the Energy Policy Act of 1992.

The IRP standard applies to "each state regulatory authority (with respect to each electric utility for which it has ratemaking authority) and each nonregulated electric utility...."

- Cooperatively owned Utilities: Twenty PUCs have full ratemaking authority over cooperatively-owned utilities (Arizona CC, Arkansas PSC, Delaware PSC, D.C. PSC, Florida PSC, Indiana URC, Kentucky PSC, Louisiana PSC, Maine PUC, Maryland PSC, Michigan PSC, New Hampshire PUC, New Mexico PUC, Oklahoma CC, Rhode Island PUC, Texas PUC, Vermont PSB, Virginia, West Virginia, and Wyoming PSC). Over 300 cooperatives are regulated by these agencies (NARUC, 1993). In addition, several other state PUCs have limited ratemaking authority over cooperatively-owned utilities. For example, cooperatives in Alaska and Kansas can vote to opt out of state regulation. The PURPA IRP standard also applies to large nonregulated cooperatively owned utilities.

- Publicly Owned Utilities: Seven PUCs have full ratemaking authority over publicly owned utilities, including the Alaska PUC, Florida PSC, Indiana URC, Maryland PSC, Massachusetts DPU, New York PSC (for non NYPA-customers), Vermont PSB, and Wisconsin PSC. Close to 200 municipal electric utilities are regulated by these agencies. (NARUC, 1993) In addition, a number of other state PUCs have limited ratemaking authority over publicly owned utilities. For example, at least 
eight states regulate municipal rates outside of municipal boundaries. The PURPA IRP standard also applies to large nonregulated publicly owned utilities.

\section{SPECIFIC REQUIREMENTS:}

PURPA Section 111 states that "each state regulatory authority...and each nonregulated electric utility shall consider each standard established by subsection (d) and make a determination concerning whether or not it is appropriate to implement such standard to carry out the purposes of this title."

The IRP standard reads as follows: "(7) Integrated Resource Planning-Each electric utility shall employ integrated resource planning. All plans or filings before a State regulatory authority to met the requirements of this paragraph must be updated on a regular basis, must provide the opportunity for public participation and comment, and contain a requirement that the plan be implemented."

State regulatory authorities and nonregulated electric utilities must consider the standard within 2 years of its passage (i.e., October of 1994) by making public notice and holding a public hearing. Based on the findings of the hearing, each state commission and nonregulated utility can either implement the IRP standard or decline to implement the standard. 
AGENCY:

CONTACT:

SUMMARY OF REQMT:

TYPE OF REQUIREMENT:

ENABLING AUTHORITY:

EFFECTIVE DATE:

APPLICABILITY:
Western Area Power Administration

Theresa Williams, Director of Energy Services, (303) 275-1730

WAPA is currently developing an integrated resource planning requirement to replace its Guidelines and Acceptance Criteria for the Conservation and Renewable Energy Program. In 1992, the Energy Policy Act amended Title II of the Hoover Power Plant Act of 1984 to require that WAPA customers implement IRPs.

Legislative

Section 114 of the Energy Policy Act of 1992

To be determined. EPAct requires WAPA to prepare an environmental impact statement on the development of the IRP rule. IRP rule development and the corresponding EIS process are in progress. WAPA expects to publish a final EIS and final IRP rule by spring of 1995.

EPAct states that the IRP requirement is applicable to any WAPA customer who purchases electric capacity (with or without energy) under a long-term firm power service contract, with the following caveats:

- WAPA may establish different regulations for certain small customers (i.e., those with total annual sales or usage of $25 \mathrm{GWh}$ or less that are not members of a joint action agency or G\&T cooperative with power supply responsibility) (Section 202[b]). WAPA is considering the establishment of different regulations for approximately 80 customers that fit the EPActdefined small customer criteria.

- If a customer or group of customers is implementing IRP in response to other federal, state, or other initiatives, WAPA is directed to accept such plan as fulfillment of the Title II if it plan substantially complies with the requirements. (Section 204[c]).

As proposed by WAPA, long-term firm power customers could submit IRPs individually or jointly with other purchasers who have common interests (e.g., power supplier and distribution members). WAPA serves over 600 long-term firm power customers, 
including approximately 400 publicly and cooperatively owned utilities ${ }^{5}$ in 15 western states from Minnesota in the northeast to California in the southwest. The following provides a breakout in the number of public utilities served by WAPA.

- Cooperatively owned Utilities ${ }^{6}$ : Approximately 45 cooperative utilities purchase electric capacity from WAPA under a long-term firm power service contract. These include about $20 \mathrm{G} \& \mathrm{~T}$ cooperatives and some 25 distribution cooperatives. Numerous additional distribution cooperatives receive WAPA power through the 20 G\&Ts served by WAPA.

- Publicly Owned Utilities ${ }^{7}$ : Approximately 350 publicly owned utilities purchase electric capacity from WAPA under a long-term firm power service contract. These include two state agencies, approximately 12 joint action agencies, close to 300 municipalities, and about 60 public utility districts and electrical/irrigation districts. Numerous municipalities, public utility districts, and electrical/irrigation districts receive WAPA power through the state and joint action agencies served by WAPA.

\section{SPECIFIC REQUIREMENTS:}

EPAct amends Title II of the Hoover Power Plant Act to require that

Within 1 year after the enactment of this section, the Administrator shall, by regulation, revise the Final Amended Guidelines and Acceptance Criteria for Customer Conservation and Renewable Energy Programs published in the Federal Register on August 21, 1985...to require each customer purchasing electricity under a long-term firm power service contract with the Western Area Power Administration to implement, within 3 years after the enactment of this section, integrated resource planning in

${ }^{5}$ In addition to some 400 publicly- and cooperatively-owned utilities, WAPA serves approximately 200 other customers, including IOUs, state agencies, and other federal agencies.

${ }^{6}$ The number of cooperatives served by WAPA is taken from Statistical Appendix to the 1993 Annual Report, Western Area Power Administration.

${ }^{7}$ The number of publicly-owned utilities served by WAPA is taken from Statistical Appendix to the 1993 Annual Report, Western Area Power Administration. 
accordance with the requirements of this title (Section 202[a]).

EPAct establishes seven minimum criteria for WAPA's approval of customer IRP submittals. These are:

1. Load forecasting;

2. Demand- and supply-side resource assessments;

3. Use of "least-cost options" to provide reliable electric service to retail consumers;

4. Minimization of adverse environmental effects of new resource acquisitions;

5. Full public participation in plan preparation and development;

6. Two- and 5-year action plans;

7. Validation of predicted performance in order to determine whether plan objectives are being met.

In addition, EPAct establishes specific penalties for noncompliance by WAPA customers, including rate surcharges and reduced power allocations. The Act also directs WAPA to provide technical assistance to customers related to conducting and implementing IRPs. Such assistance may include education and information dissemination, technical and financial assistance, etc. The Act directs WAPA to give priority in providing technical assistance to customer that have limited capability to conduct IRP (Section 203).

The EPAct requirements serve to reinforce WAPA's long-term commitment to customers' efficient use of energy. In 1981, WAPA published its "Customer Guidelines and Acceptance Criteria," which required all customers signing new firm power contracts to develop conservation and renewable energy programs. This requirement became federal law in 1984, with the passage of Title II of the Hoover Power Plant Act. As part of a required review of the G\&AC provisions, WAPA proposed an Energy Planning and Management Program in 1991, which would link the agency's power resource allocations with long-term energy planning and Western's customers' efficient energy use through the preparation of IRPs. Since the inception of its Energy Services program in 1981, WAPA has offered a wide variety of services to support its customers' energy efficiency, renewable energy, and IRP efforts.

WAPA's implementation of the EPAct requirements is subject to the provisions of the National Environmental Policy Act (NEPA). The NEPA process, which 
supersedes the EPAct legislation, is currently driving the schedule associated with development of WAPA's IRP rule. 


\section{State IRP Policies}

AGENCY:

CONTACT:

SUMMARY OF REQMT:

TYPE OF REQUIREMENTS:

ENABLING AUTHORITY:

EFFECTIVE DATE:

APPLICABILITY:

SPECIFIC REQUIREMENTS:
Alaska Public Utilities Commission

Don Baxter, Utility Engineer Analyst 4, (907)

276-6222;

(907) 276-0160 fax

Utilities submit IRPs on a case-by-case basis. For example, utilities requesting authorization of new plant construction must file 20-year IRP plans. No updates are required unless the plans include a DSM component.

Certificate of public convenience and necessity; power sales contract.

U-91-98 (certificate of public convenience and necessity); U-92-11

February 1993

The informal IRP requirement could be applied to all electric utilities under the commission's jurisdiction.

- Cooperatively-Owned Utilities: The measure could be applied to approximately one G\&T cooperative, two combined generation/distribution cooperatives, and two distribution cooperatives, subject to their vote.

- Publicly Owned Utilities: The informal IRP measure could be applied to one municipal utility.

Only one utility has had cause to submit an IRP plan to the Commission (Docket No. U-92-11). A consulting firm prepared to the plan and followed the general IRP guidelines developed by Oak Ridge National Laboratory. 
AGENCY:

CONTACT(S):

SUMMARY OF REQMT:

TYPE OF REQUIREMENTS:

ENABLING AUTHORITY:

EFFECTIVE DATE:

APPLICABILITY:

\section{Arizona Corporation Commission}

David Berry, Chief of Economics and Research, (602) 542-0742; (602) 542-2129 fax

The Arizona $\mathrm{CC}$ requires all electric utilities that have generation resources to file 10 -year (most utilities submit 20-year) IRP plans every 3 years

Rule

Arizona Administrative Code R14-2-701 et seq. (Sections 701-704)

January/February 1989

This regulation applies to all electric utilities under the jurisdiction of the commission that operate or own generating facilities.

- Cooperatively-Owned Utilities: One cooperative, the Arizona Electric Power Cooperative, is subject to the regulation. Distribution cooperatives are exempt from filing.

- Publicly Owned Utilities: The $\mathrm{CC}$ has no regulatory authority over publicly owned utilities. However, the commission invited the Salt River Project to voluntarily file an IRP.

The specific IRP requirements are delineated in Regulation R14-2-701 et seq. (9 pages). Annual filings of historical data must include demand-side and supply-data (Sections 703 A-B), including detailed data on demand for the previous 10 years and on supply for the previous year.

Triennial IRPs must include the following:

- Demand and supply forecasts: Sections 703 C-D indicate data and analysis requirements to be included in a 10-year demand and supply forecasts, including the levels of disaggregation of forecast information and the documentation required.

- Uncertainty analyses (Section $703 \mathrm{E}$ ).

- Integrated resource plan: Section $703 \mathrm{~F}$ of the regulation requires the development of least-cost plan for meeting forecasted electricity demand. The plan shall take into account the supply, 
demand, and uncertainty analyses required in Sections $703 \mathrm{C}$-E; provide documentation of supply and demand-side conditions, costs, and discount rates used; and include a 3-year action plan.

An Externalities Prioritization Working Group evaluated and prioritized 17 externalities to be considered by utilities in their 1995, 1998, and post1998 IRPs. The group also recommended that (1) utilities perform a carbon tax risk assessment in lieu of monetizing global climate change in their 1995 IRPs, and (2) utilities consider a Nuclear Disaster Plan and Release of Radioactivity if they include a nuclear plant in their IRP prior to 1998. In addition, the group selected five life cycle stages to be included in the 1995 IRP (resource extraction, construction, operation, transportation, and retirement). The working group recommended that certain causes listed by life cycle stage be considered in determining the costs of externalities in the 1995 and 1998 planning cycles. 
AGENCY:

CONTACT:

SUMMARY OF REQMT:

TYPE OF REQUIREMENT:

ENABLING AUTHORITY:

EFFECTIVE DATE:

APPLICABILITY:

SPECIFIC REQUIREMENTS:
Arkansas Public Service Commission (APSC)

Diana Brenske, Manager, Electric Division, (501) 682-5656

The IRP guidelines require that the Arkansas Electric Cooperative Corporation (AECC) submit triennially a 20-year forecast and corresponding resource plan, and a 3-year action plan. In addition, every 6 months after the approval of a 3-year action plan, AECC must file a progress report of the actions taken and expenditure incurred to implement the plan.

State legislation; commission orders (separate docket number assigned to each utility affected)

Utility Environment and Economic Protection Act, Arkansas Code Ann. 23-18-501 et seq. and 23-3-401 et seq.; Docket No. 92-229-U (Arkansas Electric Cooperative)(not rulemaking docket)

1973 (amended in 1977); August 28, 1992 (Docket No. 92-229-U)

The APSC issued separate IRP guidelines for three of Arkansas' four investor-owned utilities. APSC excused the fourth since it served only 3,000 customers in Arkansas and was already subject to Kansas and Missouri IRP filing requirements.

- Cooperatively-owned utilities: The policy affects all of Arkansas' cooperatively-owned utilities with the exception of one distribution cooperative, Farmer's Electric Cooperative, which is not a member. Arkansas Electric Cooperative Corporation (AECC), a 16-member distribution cooperative and the only G\&T in the state, has contested the commission's IRP order on the grounds that the REA already requires AECC to file an IRP. The APSC is currently considering AECC's position.

- Publicly Owned Utilities: The APSC does not have jurisdiction over publicly owned utilities.

The specific IRP requirements are delineated in the Arkansas PSC Guidelines for Arkansas Electric Cooperative Corporation. The triennial IRP plan must include the following: 
- Development of a 3-year action plan describing the utility's short-term resource acquisition plans that includes technical documentation (Section 2).

- Energy and demand forecasts (Section 3): Forecasts must include historical (for 10 preceding years) and forecasted (base year and 20 succeeding years) analyses based on disaggregated end-use methods (if other models are use, the utility must provide a justification of the model design and an explanation of the variables used). Each energy and demand forecast must include an analysis of the sensitivity of results to the major assumptions and estimates used in preparing the forecast, and contingency plans based on base case, high-, and low-growth scenarios.

- Identification and screening of existing and potential resources (Section 4): The APSC requires assessments of existing supply- and demand-side resources; a determination of the adequacy of the existing transmission and distribution systems to meet projected loads over a minimum of the following 10 years; and a description of potential new generation, transmission, and distribution facilities. In addition, the utility must develop and screen a set of demand-side program designs for possible inclusion in the preferred and alternative resource plans.

- Development of integrated resource plans (Section 5): IRPs must include resource plans to meet a range of demand forecast scenarios and objectives (including minimizing rates and customer bills, maximizing environmental protection, maximizing penetration of DSM resources, etc.), assessments of multiple combinations of potential demand- and supply-side resources, a risk and uncertainty analysis for each plan, and a 3-year action plan. 
AGENCY:

CONTACT(S):

SUMMARY OF REQMT:

TYPE OF REQUIREMENT:

ENABLING AUTHORITY:

EFFECTIVE DATE:

APPLICABILITY:
Delaware Public Service Commission

Melinda Carl, Public Affairs, (302) 739-4333; (302) $739-4849$ fax

The Delaware PSC requires its jurisdictional utilities to file 10-year IRPs every 2 years. However, the commission does not have the authority to require these utilities to implement their IRPs.

Legislation; Rule

PURPA Section 111 (d)(7) - (d)(9); Regulation Docket Nos. 29 and 35 (affects cooperative)

1978 (PURPA); February 22, 1994 (Rule)

Delaware IRP regulations affect the state's one IOU and distribution cooperatives that provide retail electric service to consumers/members. The IRP guidelines allow distribution cooperatives to submit the most recent IRP of their power supply cooperative, supplemented with details on the reporting cooperative's specific characteristics and DSM planning.

- Cooperatively-Owned Utilities: One distribution cooperative, Delaware Electric Cooperative, is subject to the regulation. Delaware Electric is the state's only cooperative and is a member of Old Dominion Electric Cooperative in Virginia.

- Publicly Owned Utilities: No government-owned utilities are subject to the regulation.

The Delaware PSC requires that the following be included in an IRP:

- Load and energy forecasting: Section II outlines standards and minimum reporting requirements for peak demand and energy forecasts, including historical (for the previous 10 years) and forecasted (for the following 15 years) information to be provided.

- Demand-side resource analysis: Section III indicates minimum reporting requirements for describing and evaluating existing and potential DSM programs. 
- Supply-side resource analysis: Section IV of the regulation requires the utility to report on existing generation, transmission, and purchased energy resources, and potential supply-side options. The utility must consider environmental abatement and control costs in its analyses of existing and potential supply-side resources.

- Generation reliability plan: Section $V$ indicates the minimum requirements for reporting on the utility's generation reliability plans, which should include information on actual (for the past 10 years) and forecasted (for the following 15 years) reserve margins, the costs and benefits of alternative levels of generation reliability, and an assessment of reliability using multiple performance measures.

- Integrated analysis of demand- and supply-side options: Section VI specifies minimum requirements for reporting on the utility's integrated resource options, which include implementations schedules, revenue requirements, average system rates for each option discussed.

- Uncertainty analysis (Section VII).

- Near-term action plan: Section VIII of the regulation requires the utility to submit a 4-year action plan with documentation. 
AGENCY:

CONTACT:

SUMMARY OF REQMT:

TYPE OF REQUIREMENT:

ENABLING AUTHORITY:

EFFECTIVE DATE:

APPLICABILITY:

SPECIFIC REQUIREMENTS:
Indiana Utility Regulatory Commission

Bradley Borum, Assistant Chief Economist, (317)

232-2304; (317) 232-6758 fax

Indiana state law requires electric utilities to petition the Utility Regulatory Commission for a certificate of public convenience and necessity prior to the construction, purchase, or lease of a power plant. The commission has interpreted the law to require utilities to do least-cost planning. As a result, all electric utilities filing for a certificate of need must submit an integrated resource plan as a part of the hearing process. The proposed IRP rules indicate that 20-year plans must be submitted every 2 years.

Legislation; Rulemaking (in process)

Certificate of Need Statute, Indiana Code 8-1-8.5; and Rulemaking (in process)

To be determined. Rulemaking is in progress.

The proposed IRP rules would be applicable to all electric utilities subject to the requirements of IC 8-1-8.5.

- Cooperatively-Owned Utilities: Two G\&T Cooperatives are subject to the legislative requirement. These are Hoosier Energy Rural Electric Cooperative, Inc. and Wabash Valley Power Association, Inc.

- Publicly Owned Utilities: One joint action agency, Indiana Municipal Power Agency (approximately 30 member municipals), is subject to the legislative requirement. Municipals installing electric generating facilities with capacities of $10 \mathrm{MW}$ or less are exempt from the IRP filing requirement.

In August 1990, the commission sought public comment by releasing a statement of issues regarding integrated resource planning. In June 1993, the commission published a proposed rule covering IRP documentation, DSM cost recovery, and bidding for new resources. Comments were received throughout the fall of 1993. Revised proposed rules appeared in the Indiana Register during the summer of 1994. The commission is currently taking comments received on the revised proposed rules under advisement. 
AGENCY:

CONTACT(S):

SUMMARY OF REQMT:

TYPE OF REQUIREMENTS:

ENABLING AUTHORITY:

EFFECTIVE DATE:

APPLICABILITY:

SPECIFIC REQUIREMENTS:
Iowa Utilities Board

Gordon Dunn, (515) 281-7051; (515) 281-5329 fax

The Iowa Utilities Board requires that a utility application for electric generation certificate of public convenience use and necessity be accompanied by least-cost planning information. ${ }^{8}$

Legislation; Rule

Iowa Code, Chapter $476 \mathrm{~A}$; Iowa Administrative Code 199:24

1983 (revised in 1990); 1983 (revised in 1991)

This regulation applies to all utilities planning to construct or significantly alter generating facilities of $25 \mathrm{MW}$ or more.

- Cooperatively owned utilities: All of Iowa's 59 distribution cooperatives (and their G\&T cooperatives) are subject to this regulation.

- Publicly Owned utilities: All of Iowa's 148 government-owned utilities are subject to this regulation.

Iowa Administrative Code 199, Chapter 24, requires that an application for certificate of public convenience, use, and necessity include the following:

- General information on the utility, the proposed site, and the facility (Section 24.4[1]).

- Supply-side resource assessment: In Section 24.4(3a), the commission requires utilities to provide detailed information on all operating generating units and all other sources of electricity available to serve the participating utilities' service area (for example, installed generating capacity, primary fuel types and sources for each unit, the projected retirement date, total $\mathrm{kW}$ and $\mathrm{kWh}$ available, etc.).

${ }^{8}$ In compliance with the Energy Policy Act of 1992, the Iowa Utilities Board is investigating whether Iowa rules constitute integrated resource planning. The Board has conducted a hearing and the State's utilities are awaiting a decision. 
- System Operating Information: Section 24.4(3b, $3 c)$ outlines system information requirements, which include historical data (for the 10 preceding years) on the system load level, customer consumption in each customer class, and capital costs and operation and maintenance expenses.

- System forecast: Section 24.4(4) provides data requirements for forecasting system capabilities. These include descriptions of projected installed generating capacity for the projected life of the facility, other sources of electricity available to supply participants' service territories, existing and planned DSM programs, an analysis of the new facility's impact on the demand for electricity, and a discussion of the forecasting methodology used.

- An evaluation of the economic feasibility of the proposed facility: Section 24(5) provides data requirements for assessing the cost-effectiveness of the proposed facility, including estimated minimum, maximum, and expected cash inflows and outflows; a graphical present value profile; and a discussion of alternative sources of power generation.

- Forecast of environmental, social, and economic impacts: Section 24.4(6) indicates that the utility must conduct an analysis of the effects that the construction, operation, and maintenance of the proposed facility might have on the surrounding social, economic, and natural environments.

- Discussion of site selection methodology (Section 24.4[7]).

- Informational meeting (Section 24.7[476A]): Prior to filing an application, the commission requires the utility to hold a public meeting in the county of the proposed site for the facility. The purpose of the meeting is to provide a public forum for discussing the proposed facility and its siting, and for the utility to respond to questions or concerns raised by members of the community. 
AGENCY:

CONTACT:

SUMMARY OF REQMT:

TYPE OF REQUIREMENT:

ENABLING AUTHORITY:

EFFECTIVE DATE:

\section{APPLICABILITY:}

SPECIFIC REQUIREMENTS:
Kansas Corporation Commission (KCC)

John Cita, Chief Economist, Economics Section (913) 271-3155; (913) 271-3354 fax

The Kansas CC has proposed an IRP rule that requires triennial IRP plans to be filed by jurisdictional utilities.

Rulemaking (proposed)

Docket \#180,056-U (in process)

To be determined. The KCC opened IRP Docket $\# 180,056-\mathrm{U}$ in January 1992. At present, commission staff are developing revised, proposed rules for commission consideration.

The proposed rule will apply to essentially all electric utilities under commission jurisdiction.

- Cooperatively-Owned Utilities: Two G\&T cooperatives will be subject to the regulation. These are Sunflower Electric Power Corporation and Kansas Electric Power Cooperative, Inc. Distribution cooperatives are not subject to the IRP rule.

- Publicly Owned Utilities: No publicly owned utilities will be subject to the regulation.

The initial proposed IRP rule required that triennial IRP plans include the following:

- Load forecasts, supply-side and demand-side resource evaluations, and consideration of environmental externalities (some of this language may be deleted from the final rule).

- Construction of two IRP plans. One using the total resource cost (TRC) test as the decision-making criteria, the other using the social cost (SC) test. Utilities have the option of selecting a "preferred plan," which may be equivalent to either the TRC or SC plan, or a mixed average of the two.

- Uncertainty and risk analysis.

- Public involvement through implementation of a collaborative process (this provision may be refined as the collaboratives begin to take shape). 
- Four-year action plan describing how the preferred IRP plan will be implemented.

- A method for data collection and resource evaluation. 
AGENCY:

CONTACT:

SUMMARY OF REQMT:

TYPE OF REQUIREMENT:

ENABLING AUTHORITY:

EFFECTIVE DATE:

APPLICABILITY:

SPECIFIC REQUIREMENTS:
Kentucky Public Service Commission

Michael Alexander, Economist, (502)564-3940

The Kentucky PSC requires its six largest jurisdictional utilities to file 15-year IRPs every 2 years

Rule

Regulation 807 KAR 5:058

December 18, 1990. The first utility filings were submitted starting in September of 1991.

This regulation applies to all electric utilities under commission jurisdiction, with the exception of distribution companies with less than $\$ 10,000,000$ in annual revenues and distribution cooperatives organized under KRS Chapter 279. (Section 1, [1]).

- Cooperatively-Owned Utilities: Two generation and transmission cooperatives are subject to the regulation. These are the Big Rivers Electric (with 4 member distribution cooperatives) and the East Kentucky Power Cooperative (with 18 member distribution cooperatives).

- Publicly Owned Utilities: No publicly owned utilities are subject to the regulation, as the Kentucky PSC does have jurisdiction over publicly owned utilities.

The specific IRP requirements are delineated in Regulation 807 KAR 5:058 (13 pages). The biennial IRP must include the following:

- Plan summary: Section 5 of the regulation indicates the minimum contents for a summary of the utility's outlook for load growth and the resources planned to meet that growth.

- Summary of significant changes: Section 6 of the regulation indicates that any IRP (subsequent to the initial IRP) shall include a summary of significant changes from the last plan (e.g., changes in load forecasts, resource plan, assumptions, or methodologies).

- Load forecasts: The PSC provides detailed load forecasting requirements in Section 7 of the regulation, including historical (for base year and 
4 preceding years) and forecasted (for 15 years) information to be provided, level of disaggregation of forecasting information, and forecasting documentation to be included in the plan.

- Resource assessment and acquisition plan: Section 8 of the regulation requires development of a plan to provide for an adequate and reliable supply of electricity to meet forecasted electricity requirements at the lowest possible cost. The plan shall consider the potential impacts of selected, key uncertainties and shall include assessment of potentially cost-effective resource options. The PSC requires consideration of a range of demandand supply-side resource options as part of the plan:

- Financial information: The PSC requires inclusion of financial information (e.g., revenue requirements, discount rate, average system rates, etc.) as specified in Section 9 of the regulation.

- The regulation does not require formal commission approval of utility IRP submittals. The informal review process consists of staff level reviews that culminate in a staff report to each utility. The report provides suggestions and recommendations to the utility for subsequent filings. 
AGENCY:

CONTACT(S):

SUMMARY OF REQMT:

TYPE OF REQUIREMENT:

ENABLING AUTHORITY:

EFFECTIVE DATE:

APPLICABILITY:

SPECIFIC REQUIREMENTS:
Maryland Public Service Commission

Mary Beth Tighe, Director of Integrated Resource Planning, (410) 767-8024; (410) 333-6086 fax

The Maryland PSC requires utilities providing retail electric service in the state to submit 15-year IRPs annually.

Rule

Annotated Code of Maryland, Article 78, Section 59 A-B

1972

This regulation applies to all electric utilities under the commission's jurisdiction providing retail electric service in Maryland.

- Cooperatively-Owned Utilities: Four cooperatively-owned utilities are subject to this regulation. These are A\&N Electric Cooperative, Choptank Electric Cooperative, Somerset Rural Electric Cooperative, and Southern Maryland Electric Cooperative, Inc.

- Publicly Owned Utilities: Five municipal utilities are subject to this regulation. These are Mayor and Council of Berlin, the Easton Utilities Commission, Hagerstown Municipal Electric Light Plant, Thurmond Municipal Light Plant, and the Town of Williamsport.

The commission has not adopted detailed IRP requirements. However, in preparing for its annual 10-year plan, the PSC requires that utilities provide specific data on long-range capacity and resource needs in addition to filing IRPs. These include:

- Sales and load forecasts with documentation.

- A short-term implementation plan: The PSC requires a detailed plan for implementing the utility's long-range integrated resource plan over the next 5 years.

A strategy for reacting to future uncertainties. 
- Demand- and supply-side resource assessments: Discussion must include utility consideration of renewable energy resources.

- Consideration of environmental externalities. 
AGENCY:

CONTACT:

SUMMARY OF REQMT:

TYPE OF REQUIREMENT:

ENABLING AUTHORITY:

EFFECTIVE DATE:

APPLICABILITY:
Massachusetts Department of Public Utilities

Brian Abbanat, [(617) 727-9748], and Robert Harrold, [(617) 727-9748], Co-Acting Directors of the Electric Power Division, (617) 723-8812 fax

Municipal electric utilities under the department's jurisdiction must file 10-year IRPs every 5 years, with supplements filed annually

Legislation and Rule

Massachusetts General Laws, Chapter 164, Sections 69h-69j; 980 Code of Massachusetts

Regulations, Sections 7.01-7.09

December 31, 1974 (legislation); December 31, 1986 corrected (rule)

The IRP legislation applies to all Massachusetts municipal electric companies.

- Cooperative-Owned Utilities: There are no cooperatively owned utilities in Massachusetts.

- Publicly Owned Utilities: All $\mathbf{4 0}$ publicly owned utilities must file a demand plan and resource forecast. Massachusetts Municipal Wholesale Electric Company members (29 municipals) may file as single group. Some of the state's other municipals contract all planning and delivery services with large private suppliers, while a number of municipals are responsible for their own planning.

The specific requirements for 10-year forecasts are delineated in 980 CMR 7.01-7.05, 7.09:

- Demand forecasts: Section 7.03 of the regulation provides detailed load forecasting requirements, including historical (for the 5 preceding years) and forecasted (for the 10 succeeding years)

information to be provided, level of aggregation of forecasting information, and guidelines for describing and justifying the methodology used.

- Summary of supply plans: Section 7.04 of the regulation indicates that a summary of supply plans shall include an inventory of existing resources, a description of planned actions that will affect the utility's ability to meet forecasted demand, a 
statement of planned facility reliability, and an evaluation of environmental and socioeconomic impacts of planned generating facilities.

- Summary of significant proposed changes: Section 7.05 indicates that the utility must file annually a supplement explaining any significant proposed changes in the information contained in previously approved forecasts and supplements, covering a successive 10-year period.

- General requirements for forecasting methodologies and econometric forecasting models (Section 7.09). 
AGENCY:

CONTACTS:

SUMMARY OF REQMT:

TYPE OF REQUIREMENT:

ENABLING AUTHORITY:

EFFECTIVE DATE:

APPLICABILITY:

SPECIFIC REQUIREMENTS:
Minnesota Public Utilities Commission

Janet Gonzalez, Supervisor, Energy Unit (612) 296-1336; (612) 297-7073 fax, and Betsy Engelking (612) 296-1337; (612) 297-7073 fax

The Minnesota PSC requires that utilities submit 15-year IRPs every two years

Legislative (public utilities)

MN Laws Chapter 356, Statute 216B.2422

August 1, 1993 (legislative requirement)

The IRP legislation affects all public utilities generating 100,000 or more $\mathrm{kW}$ of electric power and serving, directly or indirectly, 10,000 retail customers. Federal Power Agencies are unaffected.

- Cooperatively-Owned Utilities: The legislation affects Minnesota's four largest G\&Ts. These are Cooperative Power Association (17 member distribution co-ops), United Power Association (15 member distribution co-ops), Minnkota Power Cooperative (12 member distribution co-ops, 6 in Minnesota), and Dairyland Power Cooperative (28 member distribution co-ops, 4 in Minnesota).

- Publicly Owned Utilities: The legislation affects one municipal utility, the Southern Minnesota Municipal Power Agency.

The specific IRP requirements are delineated in MN Rules Part 7843.0100-0600. The biennial plan must include the following:

- Energy and peak demand forecasts for the next 15 years (Section 7843.0400 Subpart 1)

- A resource plan for meeting the service needs of customers for the forecast period (Section 7843.0400 Subpart 2)

- Resource options for meeting customer service needs when existing resources are inadequate (Section 7843.0400 Subpart 3): This section specifies, at a minimum, the types of resource options that must be considered (range from new generating facilities of various types and sizes and with various fuel types to utility-sponsored 
conservation programs). For those options the utility deems most viable, the utility must evaluate the availability, reliability, cost, socioeconomic effects, and environmental effects. Utilities must include technical documentation for the plan. 
AGENCY:

CONTACT:

SUMMARY OF REQMT:

TYPE OF REQUIREMENT:

ENABLING AUTHORITY:

EFFECTIVE DATE:

APPLICABILITY:

SPECIFIC REQUIREMENTS:
Nebraska Power Review Board

Gary Gustafson, Director, Nebraska Power Review Board (402) 471-2301; (402) 471-3715 fax

Nebraska Power Review Board requests all electric utilities, under the auspices of the Nebraska Power Association, to collectively prepare a 20-year IRP ("Power Supply Plan") every 5 to 6 years.

Legislative

Nebraska Statute 70-1023 to 70-1027; Laws 1981, LB 302

1981

The legislation requires that the Nebraska PRB prepare a long-range power supply plan for the state. The PRB has the authority to request that "a representative organization," the Nebraska Power Association, prepare the plan. The Nebraska Power Association, composed of representatives from each utility, collects individual utility IRPs (submitted voluntarily), then prepares and files the long-range power plan. Every electric utility in the state participate either directly or indirectly in the power supply plan, as well as in associated research and conservation reports.

There are over 170 publicly and cooperatively owned electric utilities in Nebraska (No IOUs operate in the state), as follows:

- Cooperatively-Owned Utilities: There are approximately 40 cooperatives and public power districts in Nebraska. These utilities participate either directly or indirectly in the power supply plan.

- Publicly Owned Utilities: There are approximately 130 publicly owned utilities in Nebraska. These utilities participate either directly or indirectly in the power supply plan.

The specific filing requirements are delineated in Nebraska Statute 70-1023 - 70-1027. The long-range power supply plan submitted to the NE Power Review Board by the NE Power Association must include the following: 
- An annual load and capability report: inciudes statewide utility load forecasts and the resources available to satisfy the loads over a 20 -year period (70-1025)

- Research and conservation report: includes information on $R \& D$, energy conservation, and load management programs; renewable energy sources; and cogeneration (70-1026). 
AGENCY:

CONTACTS:

SUMMARY OF REQMT:

TYPE OF REQUIREMENT:

ENABLING AUTHORITY:

EFFECTIVE DATE:

APPLICABILITY:

SPECIFIC REQUIREMENTS:
New Mexico Public Utility Commission

Stuart Hamilton, Utility Compliance Specialist (505) 827-6953; (505) 827-6973 fax; John Curl, Economic Manager, (505) 827-6960

The proposed rule requires that electric utilities under the commission's jurisdiction file a 20 -year IRP every 3 years.

Rulemaking (proposed)

To be determined

To be determined. The rulemaking process started in March 1991 and the commission released a proposed rule in March of 1994. As of early 1995, New Mexico utilities are still awaiting a commission decision.

Proposed rule would apply to all electric utilities under the commission's jurisdiction.

- Cooperatively-Owned Utilities: All cooperatively-owned utilities would be affected except for those requesting a variance.

- Publicly Owned Utilities: Publicly owned utilities would not be affected by an IRP ruling.

IRPs submitted in accordance with this proposed rule would include the following:

- Documentation: a nontechnical description of the preferred and alternative plans, the 3-year action plan, and technical documentation of the plans

- Electric energy and demand forecasts for the ensuing 20-year period and historic data for the previous 10-years

- Uncertainty analysis

- Supply- and demand-side resource assessments

- Consideration of environmental impacts

- An integrated resource plan consisting of a preferred plan, a short-term action plan (3-year period), and an explanation and justification of the plans 
- Public participation. 
AGENCY:

CONTACT:

SUMMARY OF REQMT:

TYPE OF REQUIREMENT:

EFFECTIVE DATE:

ENABLING AUTHORITY:

APPLICABILITY:

SCHEDULE:
Oklahoma Corporation Commission

Jim Crosslin, Research Coordinator, Research Section (405) 521-6874; (405) 521-3336 fax

To be determined

Rulemaking

To be determined. The commission issued a Notice of Inquiry in 1994 and the rulemaking is in progress.

To be determined

This regulation will apply to electric utilities under commission jurisdiction.

- Cooperatively-Owned Utilities: G\&Ts are not regulated by the commission. The commission is investigating whether the proposed regulation will apply to all 31 distribution cooperatives, particularly those distribution cooperatives that have voted themselves exempt from commission jurisdiction.

- Publicly Owned Utilities: The commission has no regulatory authority over publicly owned utilities.

To be determined. One utility has submitted an IRP voluntarily. 
AGENCIES:

CONTACT(S):

SUMMARY OF REQMT:

TYPE OF REQUIREMENTS:

ENABLING AUTHORITY:

EFFECTIVE DATE:

APPLICABILITY:

SPECIFIC REQUIREMENTS:
South Carolina Public Service Commission and South Carolina State Energy Office

Dr. James E. Spearman, Assistant Director of Research (803) 737-5122, (803) 737-5199 fax, and Randy Erskine, Engineer, Electric Department (803) 737-5115 (SCPSC); Jay Flanagan, Director, State Energy Office (803) 734-3364, (803) 734-2727 fax

All electric utilities under the commission's jurisdiction (IOUs) must file a detailed 15-year IRP every 3-years. These plans must be updated annually.

Legislation and Rule

SC Energy Supply and Efficiency Act S.C. Code No. 58-37-10; Docket No. 87-223-E, Order No. 91-885 and Order No. 93-845 (Generic), Docket No. 93-430-E, Order No. 93-950 and 94-348 (Lockhart)

July 1, 1992 (legislation); October 21, 1991 and September 10, 1993 (Generic); October 14, 1993, and April 21, 1994 (PSC Orders)

The PSC IRP Order affects South Carolina's four IOUs. Lockhart Power, the smallest of the IOUs, is subject to less extensive IRP requirements, delineated in Docket No. 93-430E.

- Cooperatively-Owned Utilities: Twenty-three cooperatively-owned utilities are subject to IRP regulations if they acquire ownership of additional generating capacity greater than $12 \mathrm{MW}$.

- Publicly Owned Utilities: The South Carolina Public Service Authority ("Santee Cooper") must file an IRP with the State Energy Office (SEO). The state's 21 municipally owned utilities must also submit IRPs to the SEO if they plan to acquire, by purchase or construction, ownership of additional generating capacity greater than $12 \mathrm{MW}$.

The specific IRP and DSM requirements are delineated in S.C. Code No. 58-37-10, 58-37-20, 58-37-30, and 58-37-40. The plan filed by Santee Cooper must be developed in consultation with electric cooperatives and municipally owned electric utilities purchasing power and energy from the authority and must include the effect of demand-side management activities of these cooperatives and municipals. 
Electric cooperatives may submit an IRP to the SEO that complies with Rural Electrification Administration regulations (see Table 5)(S.C. Code No. 58-37-10B) or pattern it after the IRP process developed by the PSC (Docket No. 87-223-E, Order No. 93-845), which specifies that the plan include:

- An integrated resource plan that outlines long- and short-term objectives, evaluates the cost effectiveness and reliability of supply- and demandside options, justifies the methodologies used and explains the underlying assumptions, and provides documentation (B1-2, B3, B6);

- A 15-year demand and energy forecast that includes explicit treatment of DSM resources and an uncertainty analysis, and uses forecasting methodologies that include "end-use" modeling techniques (B9) and S.C. Code 58-37-10);

- An assessment of supply-side resources required to support the IRP (B11);

- A demand-side resource assessment (B12);

- Risk assessment (B10);

- A maintenance and refurbishment program for existing units (B15);

- Consideration of environmental costs: costs are to be monetized whenever possible. Costs that cannot be monetized must be addressed on a qualitative basis (B8).

In addition, the PSC directs utilities to solicit customer input in the IRP planning process (B4). 
AGENCY:

CONTACT:

SUMMARY OF REQMT:

TYPE OF REQUIREMENTS:

ENABLING AUTHORITY:

EFFECTIVE DATE:

APPLICABILITY:

SPECIFIC REQUIREMENTS:
Vermont Public Service Board

Kari Dolan, Utilities Analyst, Economics Division (802) 828-2358; (802) 828-3351 fax

The Vermont PSB requires all electric utilities under it jurisdiction to file IRP plans every 3 years

Legislative requirement and Public Service Board Order

Statute 30 V.S.A. $\$ 218($ c); Docket \#5270 (Phases I-IV for larger utilities, including IOUs); Docket \#5270 (Phase V)(small utilities)

Vermont statute went into effect in 1991; Board Order issued on April 16, 1990, (for larger utilities) and March 13, 1991, (Phase V)

This Order applies to all electric utilities under the board's jurisdiction.

- Cooperatively-Owned Utilities: There are only two cooperatives in Vermont: Washington Electric Cooperative, Inc., and Vermont Electric Cooperative, Inc., both of which are subject to the IRP Order.

- Publicly Owned Utilities: Vermont's 14 municipal utilities are subject to the IRP Order. These are Barton Village, Inc., Electric Department; City of Burlington Electric Department; Village of Enosburg Falls Water and Light Department, Inc.; Village of Hyde Park Electric Department; Village of Johnson Water and Light Department; Village of Ludlow Electric Light Department; Village of Lyndonville Electric Department; Village of Morrisville Water and Light Department; Village of Northfield Electric Department; Village of Orleans Electric Department; Town of Readsboro Electric Light Department; Village of Stowe Electric Department; Swanton Village, Inc., Electric Department.

30 V.S.A. 218 (c) requires all of the state's electric and gas utilities to conduct IRP. Docket No. 5270 (Phase V) indicates that IRP plans be consistent in detail and content with the Vermont Department of Public Service Twenty Year Electric Plan, March 1994, and follow the pace and schedule outlined in Docket No. 
5270. The plan recommends that IRPs include the following:

- Demand-side resource assessment;

- Supply-side resource assessment and acquisition plan: Takes into account capacity and fuel source of current generating facility, operating cycle, contractual provisions and lengths of new contracts, and other uncertainties such as environmental and safety risks;

- Base-case load forecasting for a 20-year period;

- An integrated resource plan;

- Impact of transmission and distribution (e.g., EMF effects and development of competitive marketplace for wholesale electricity);

- Uncertainty analysis.

The PSC recommends that utilities seek public input concerning IRP planning and to make information available for public use. 
AGENCY:

CONTACT:

SUMMARY OF REQMT:

TYPE OF REQUIREMENT:

ENABLING AUTHORITY:

EFFECTIVE DATE:

APPLICABILITY:

SPECIFIC REQUIREMENTS:
Virginia State Corporation Commission

Rob Lacy, Utilities Research Manager for Economics, (804) 371-9050, (804) 371-9935 fax

Utilities under commission jurisdiction must submit 20-year IRPs biennially.

Legislative; Commission policy revision

Code of Virginia, Title 56-235.1; Revised 20-Year

Data Request

1978 (Virginia code); May 1986 (policy revision)

The commission's IRP data request applies to all electric utilities under the jurisdiction of the commission that own generating facilities and whose total annual Virginia jurisdictional customers exceed 50,000 .

- Cooperatively-Owned Utilities: The commission regulates 13 distribution cooperatives but does not have regulatory authority over G\&T cooperatives.

- Publicly Owned Utilities: The commission has no regulatory authority over municipal utilities.

The specific IRP requirements are delineated in Sections I-IX of the commission's Electric Utility Resource Planning Information Requirements, 19332012. The biennial IRP plan must include the following:

- Peak load and energy forecasts: Section III, Section VI, and Appendix I indicate detailed forecasting information requirements, including historical (for the previous 3 years) and forecasted (for the next 20 years) data, and complete documentation of the assumptions, data, and model logic used in developing the forecasts;

- A report on load management and conservation programs expected to be in effect during the 20-year period (Section IV)

- Demand- and supply-side resource assessments (Section V): The PSC requires utilities to discuss major factors affecting current and future resource supplies, including system load characteristics, operation and maintenance requirements of 
proposed and existing plants, the impact of forecast uncertainty on resource plans, and system reliability criteria and adequacy of projected capacity.

- Explanation of major changes in 20-year forecast and methodologies since previous IRP filing (Section VII)

- A 20-year integrated resource plan (Section VIII)

- Evaluation of utility's progress toward achieving goals established in previous IRP (Section IX). 
AGENCY:

CONTACT(S):

SUMMARY OF REQMT:

TYPE OF REQUIREMENTS:

ENABLING AUTHORITY:

EFFECTIVE DATE:

APPLICABILITY:

SPECIFIC REQUIREMENTS:
Wisconsin Public Service Commission

Paul C. Newman, Assistant Administrator, Electric Division (608) 267-5112; (608) 266-3957 fax

The Wisconsin PSC requires all utilities involved in the generation, distribution, and sale of electricity to individually or collectively submit a 10-year IRP (the "Advanced Plan") biennially. They are all required to jointly develop a statewide plan.

Legislative and Rule

Wisconsin Statute Chapter 196.491; PSC Administrative Code, Chapter 111

1975 (legislative requirement); 1976 (PSC Administrative Code)

This regulation applies to all electric utilities under the commission's jurisdiction that generate, distribute, and sell electricity.

- Cooperatively-Owned Utilities: All G\&T and distribution cooperatives owning or planning to own high voltage lines (greater than 1 mile and in excess of $100 \mathrm{kV}$ ) or generating capacity in excess of $300 \mathrm{MW}$ are subject to the regulation. This affects only one cooperative, Dairyland Power Cooperative (29 member cooperatives).

- Publicly Owned Utilities: Eighty-two municipals are subject to the regulation.

Utilities develop a 10-year "Advance Plan" (joint IRP). Utility task forces devoted to specific subject areas (e.g., supply-side, load forecast, externalities, cogeneration, etc.) prepare individual sections of the joint IRP. The specific IRP requirements are delineated in Wisconsin Administrative Code, Chapter PSC 111. The biennial IRP plan must include:

- Statewide forecast of demand and energy requirements: Section PSC 111.12 and PSC 111.22 provide detailed guidelines for forecasting peak demand and energy requirements over a 20 year period. The PSC requires that each utility provide weekly and annual load duration curves, forecast the impact of policy on these curves, describe the methodology and data used to derive the forecasted information, and identify any 
underlying assumptions. Section 111.225 indicates that utilities with a current or planned generating capacity of at least $50 \mathrm{MW}$ must cooperatively develop a forecast of annual and monthly coincident demand and load duration curves for the state of Wisconsin;

- Description and assessment of DSM programs: Sections 111.27 and 111.28 establish DSM program information requirements. These include identifying and describing ongoing planned conservation programs, and assessing the probability of success for each program;

- Plans for altering system capacity: Section PSC 111.13 indicates that utilities must provide information on adjustments to existing generating capacity (e.g., the addition of generating facilities, the removal of facilities from service) planned for the following 15-year period. In Sections 111.135, $111.14,111.15,111.23,111.24,111.25$, and 111.26 the PSC requires utilities to provide detailed information on alternative generation systems, sites, and transmission routes considered; explain the reasons for selecting the method, fuel type and site proposed in 111.13; and list the environmental impacts associated with the proposed method and the means by which these effects can be minimized or avoided;

- Description of utility research activities and their effect on electric utility operation (Sections $\mathbf{1 1 1 . 1 6}$ and 111.27)

- Public review of advance plans: Section 111.31 directs the commission to make advance plans available for public review. The section includes detailed guidelines for publicizing the availability of the plans. 


\section{Other IRP Policies}

AGENCY:

CONTACT:

SUMMARY OF REQMT:

TYPE OF REQUIREMENT:

ENABLING AUTHORITY:

EFFECTIVE DATE:

APPLICABILITY:

SPECIFIC REQUIREMENTS:
National Rural Electric Cooperative Association

Matt Hastings, Manager of Consulting (202) 857-9772

Member cooperatives of the NRECA have adopted an IRP resolution. The resolution emphasizes that rural electric systems must continue to use IRP and states the need for cooperation and coordination amongst the various entities involved in IRP.

Member Resolution

Continuing Resolution \#53

1992

- Cooperatively owned Utilities: The resolution applies to over 900 cooperative utilities across the U.S.

- Publicly Owned Utilities: This cooperative utility resolution does not apply to publicly owned utilities.

Continuing Resolution \#53 reads as follows:

\section{INTEGRATED RESOURCE PLANNING}

Rural electric systems must continue to plan to meet the energy service needs of their members in a manner which effectively integrates supply-side and demand-side resources. Since integrated resource planning for rural electric systems requires the concerted efforts of member consumers, distribution systems, power suppliers, statewide organizations, and regulatory agencies we urge continued cooperation and coordination in the development of rate design, policies and programs.

We urge all segments of our program to continue to use integrated resource planning to assist in providing reliable electrical services at the lowest overall cost by carefully integrating both supply-side and demand-side resources. 
This resolution was developed through the cooperative policy development process, which is summarized below (taken from NRECA Rural Electric Sourcebook, 1990, p. 81).

The cooperative policy development process begins each May with the identification of key areas of importance to the rural electric program by the NRECA Issues Committee. The committee (which is appointed by NRECA's board of directors) is composed of ten members, one from each of the NRECA regions. The committee serves as a forum for identifying concerns, issues, and trends occurring in their respective regions, and develops recommendations that form the basis for new or amended member resolutions. The Issues Committee presents its final recommendations to the NRECA board of directors and to the NRECA membership prior to the start of the regional meetings.

These recommendations then go to the regional Resolution Committees. These committees consist of an equal number of members (usually only one) from each state. Each regional Resolution Committee draws up recommendations based on input by the membership of directors and managers of local systems and others. These recommendations are then acted upon during the business sessions of the ten regional meetings, held throughout the nation in the fall of each year. Also at the regional meeting, the members of each region elect their representatives to the national standing committees.

At the annual meeting, usually held in February of each year, the final steps in policy development are taken. Members of the 12 standing committees meet to review recommendations and develop resolutions based on those passed at the 10 regional meetings as well as in response to other membership suggestions. Eleven of the standing committees deal with specific subject matter areas, while the twelfth-the Resolutions Committee-serves as an overall review committee to put resolutions in final form for presentation to voting delegates during the meeting's business session. 


\section{Appendix D}

\section{Technical and Economic Market Characterization}

Prepared by

National Renewable Energy Laboratory

Prinicipal Investigator: Thomas Holt

August 1994 


\section{Introduction}

This Technical and Economic Market Characterization was prepared by NREL as part of the of IRP in Public Power program. Its purpose is to present various characteristics of the nation's public and cooperatively owned utilities that are useful for understanding these utilities' integrated resource planning (IRP) needs and capabilities. Technical and economic characteristics presented here include:

- Current electricity supply situation;

- Average annual load growth in the service area;

- Source of peak load power;

- Average rates;

- Average number of employees;

- Annual system sales;

- Peak load;

- Business characteristics, generation plans, and DSM participation;

- Supply sources; and

- Electricity disposition and revenues.

Characteristics data are obtained primarily from NREL's Public Power Survey (see Appendix B) and from the Energy Information Administration's (EIA's) Form 861. Some generation and transmission cooperative data were provided by the Rural Electrification Administration (REA). The data presented here reflect the 659 publicly and cooperatively owned utilities that responded to NREL's Public Power Survey (i.e., not all 3,000 of the nation's publicly and cooperatively owned utilities). Limiting the characterization effort to the 659 Public Power Survey respondents results in a more detailed profile because it draws heavily from the survey information, while still providing a statistically valid representation of the entire publicly and cooperatively owned utility sector.

The Technical and Economic Market Characterization is divided into five sections. Each section includes ten characterization tables-one for each of the above-listed characteristics. All data are presented as a percentage distribution of the total number of utilities in the applicable population. Each of the five sections provides information for a distinct population, as indicated below:

1. Summary Tables: characterizes Joint Action Agencies (JAAs), municipal utilities (Muni), generation and transmission cooperative (G\&T Coop), and distribution cooperatives (Dist Coop) on a nationwide basis (this section draws directly from the four following sections).

2. Joint Action Agency Tables: characterize JAAs located in six regions of the country.

3. Municipal Utility Tables: characterize municipals located in six regions of the country.

4. Generation and Transmission Cooperatives Tables: characterize G\&Ts located in six regions of the country

5. Distribution Cooperatives Tables: characterize distribution cooperatives located in six regions of the country. 


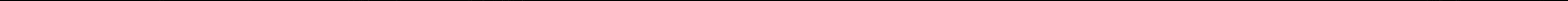


$\frac{\frac{9}{0}}{\frac{2}{6}}$ 



\begin{tabular}{lccc}
\hline & $\begin{array}{c}\text { Current Electricity Supply Situation - Percentage Distribution } \\
\text { JAA }\end{array}$ & Munl & G\&T Coop \\
\hline Capacity & & & \\
\hline Deficit & 7 & 7 & 5 \\
Balance & 29 & 51 & 41 \\
Surplus & 64 & 42 & 55 \\
Energy & & & \\
\hline Deficit & & 7 & 0 \\
Balance & 7 & 51 & 38 \\
Surplus & 26 & 41 & 62
\end{tabular}

Source: Survey data.

Note: Percentage totals may not equal $100 \%$ due to rounding.

\begin{tabular}{lcccc}
\hline & Average Annual Load Growth in Service Area-Percentage Distribution & & \\
& JAA & Munl & G\&T Coop & Dist. Coop \\
\hline Negative & & 4 & 0 & 4 \\
0 to $1.0 \%$ & 0 & 24 & 19 & 19 \\
1.1 to $2.0 \%$ & 11 & 38 & 44 & 29 \\
2.1 to $4.0 \%$ & 37 & 27 & 37 & 37 \\
$4.1 \%$ or greater & 52 & 7 & 0 & 12
\end{tabular}

Source: Survey data.

Note: Percentage totals may not equal $100 \%$ due to rounding.

\begin{tabular}{|c|c|c|c|}
\hline \multicolumn{4}{|c|}{ Source of Peak Load Power - Percentage Dlstributlon } \\
\hline & $J A A$ & Muni & G\&T CoOP \\
\hline Own generation & 51 & 18 & 30 \\
\hline Power supply organization in which have ownership & 9 & 25 & 0 \\
\hline Federal power agency & 17 & 34 & 14 \\
\hline Investor-owned utility & 14 & 14 & 16 \\
\hline Other & 9 & 9 & 41 \\
\hline $\begin{array}{l}\text { Source: Survey data. } \\
\text { Note: Percentage totals may not equal } 100 \% \text { due to }\end{array}$ & & & \\
\hline
\end{tabular}




\begin{tabular}{|c|c|c|c|c|}
\hline \multicolumn{5}{|c|}{ Average Rates ${ }^{\star}$ - Percentage Distribution } \\
\hline & $J A A$ & Muni & G\&T CoOp & Dist. Coop \\
\hline \multicolumn{5}{|l|}{ Energy Rates } \\
\hline Less than 2 cents/kWh & 22 & 2 & 18 & 0 \\
\hline 2 to 4 cents $/ \mathrm{kWh}$ & 63 & 16 & 55 & 6 \\
\hline 4 to 6 cents $/ \mathrm{kWh}$ ( 4 to 7 for retail) & 7 & 59 & 26 & 47 \\
\hline 6 to 8 cents $/ \mathrm{kWh}$ ( 7 to 10 for retail) & 7 & 21 & 0 & 44 \\
\hline Greater than 8 cents $/ \mathrm{kWh}$ ( $>10$ for retail) & 0 & 2 & 0 & 3 \\
\hline \multicolumn{5}{|l|}{ Capacity Rates } \\
\hline Less than $\$ 3 / \mathrm{kW}$-month ( $<4$ for retail) & 0 & 24 & 0 & 10 \\
\hline$\$ 3$ to $\$ 6 / \mathrm{kW}$-month (4 to 8 for retail) & 23 & 41 & 8 & 53 \\
\hline$\$ 6$ to $\$ 10 / \mathrm{kW}$-month ( 8 to 12 for retail) & 35 & 32 & 46 & 32 \\
\hline$\$ 10$ to $\$ 14 / \mathrm{kW}$-month (12 to 16 for retail) & 39 & 3 & 32 & 4 \\
\hline Greater than $\$ 14 / \mathrm{kW}$-month ( $>16$ for retail) & 4 & 0 & 14 & 1 \\
\hline
\end{tabular}

"Wholesale rates for JAA and G\&T cooperatives and retail rates for municipals and distribution cooperatives.

Source: Survey data.

Note: Percentage totals may not equal $100 \%$ due to rounding.

\begin{tabular}{lcccc}
\hline & Average Number of Emplovees - Percentage Distribution & & \\
\hline & JAA & Muni & G\&T Coop & Dist. Coop \\
\hline Less than 50 & 68 & 74 & 21 & 61 \\
50 to 200 & 21 & 18 & 17 & 36 \\
201 to 500 & 7 & 2 & 45 & 2 \\
501 to t000 & 0 & 3 & 10 & 0 \\
Greater than 1000 & 4 & 3 & 7 & 0 \\
Source: Survey data. & & & & \\
Note: Percentage totals may not equal 100\% due to rounding. & & & & \\
\hline
\end{tabular}

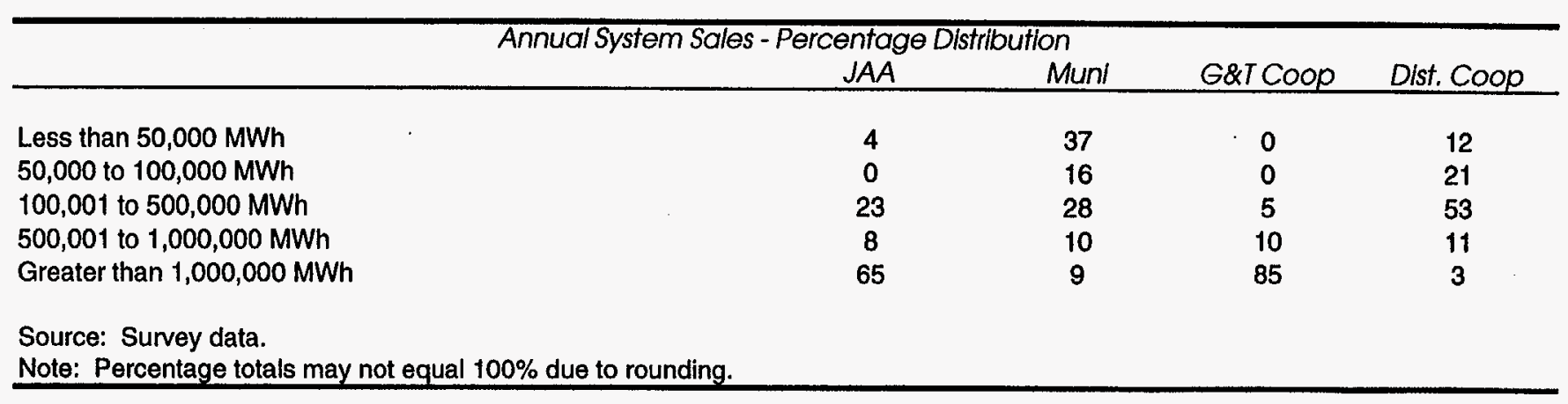




\begin{tabular}{|c|c|c|c|c|}
\hline Peak Load - Pe & $\begin{array}{l}\text { Jge DIs } \\
\text { JAA }\end{array}$ & Muni & G\&T COOP & Dist. Coop \\
\hline \multicolumn{5}{|l|}{ Winter } \\
\hline Less than $100 \mathrm{MW}$ & 23 & 82 & 8 & 85 \\
\hline 100 to $250 \mathrm{MW}$ & 27 & 12 & 23 & 12 \\
\hline 251 to $500 \mathrm{MW}$ & 23 & 2 & 23 & 2 \\
\hline 501 to $1000 \mathrm{MW}$ & 14 & 2 & 28 & 1 \\
\hline Greater than $1000 \mathrm{MW}$ & 14 & 3 & 20 & 1 \\
\hline \multicolumn{5}{|l|}{ Summer } \\
\hline Less than $100 \mathrm{MW}$ & 17 & 83 & 5 & 85 \\
\hline 100 to $250 \mathrm{MW}$ & 26 & 10 & 20 & 13 \\
\hline 251 to $500 \mathrm{MW}$ & 22 & 2 & 27 & 1 \\
\hline 501 to $1000 \mathrm{MW}$ & 22 & 3 & 27 & $\mathbf{0}$ \\
\hline Greater than $1000 \mathrm{MW}$ & 13 & 2 & 22 & 1 \\
\hline $\begin{array}{l}\text { Source: DOËEIA Form } 861 \text { - } 1991 \\
\text { Note: Percentage totals may not equal } 100 \% \text { due to rounding. }\end{array}$ & & & & \\
\hline
\end{tabular}

\begin{tabular}{|c|c|c|c|c|}
\hline \multicolumn{5}{|c|}{ Business Characteristics, Generation Plans, and DSM Participation-Percentage Distribution } \\
\hline \multicolumn{5}{|l|}{ Utilities involved in: } \\
\hline Generation & 87 & 30 & 84 & 2 \\
\hline Transmission & 100 & 13 & 100 & 12 \\
\hline Distribution & 3 & 100 & 11 & 100 \\
\hline Plans to construct generation facilities within next 10 years & 32 & 12 & 28 & 1 \\
\hline Participation in DSM Programs & 28 & 30 & 39 & 36 \\
\hline Source: DOE/EIA Form 861 - 1991 & & & & \\
\hline
\end{tabular}




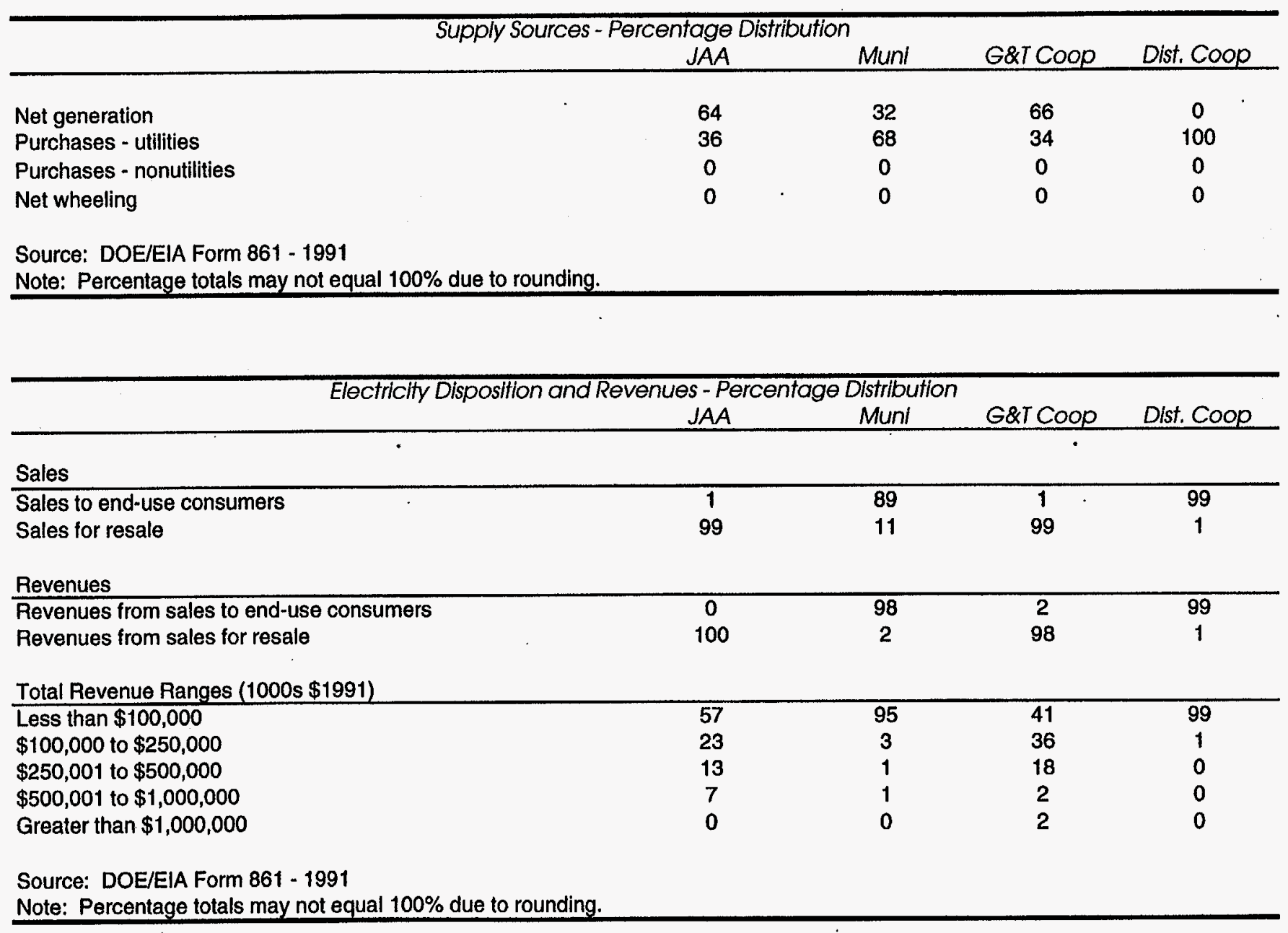




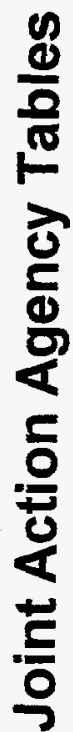





\begin{tabular}{lcc}
\hline Region & $\begin{array}{c}\text { Jolnt Action Agencles: Total Number vs. Survey Respondents } \\
\text { Total No. of JAAs* }\end{array}$ & No. of JAAs Responding to Survey \\
\hline BPA & 1 & 1 \\
Non-PMA & 13 & 9 \\
SEPA & 6 & 6 \\
SWPA & 5 & 5 \\
TVA & 0 & 0 \\
WAPA & 13 & 9 \\
& & 30 \\
Total & 38 & \\
&
\end{tabular}




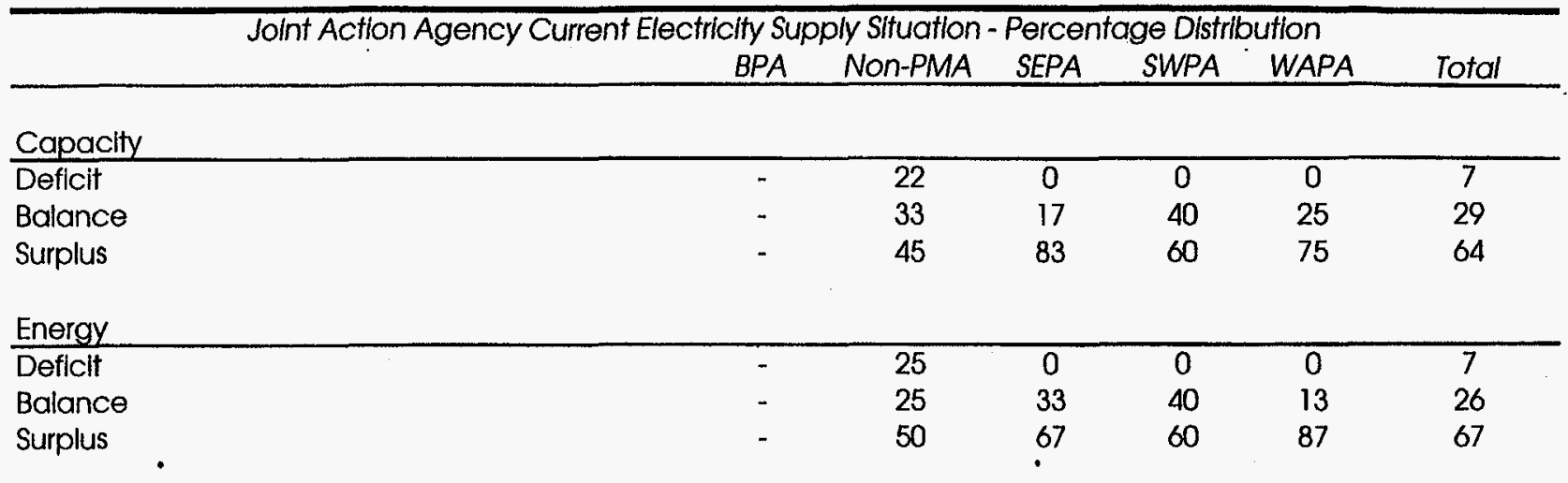

Source: Survey data.

Note: Percentage totals may not equal $100 \%$ due to rounding

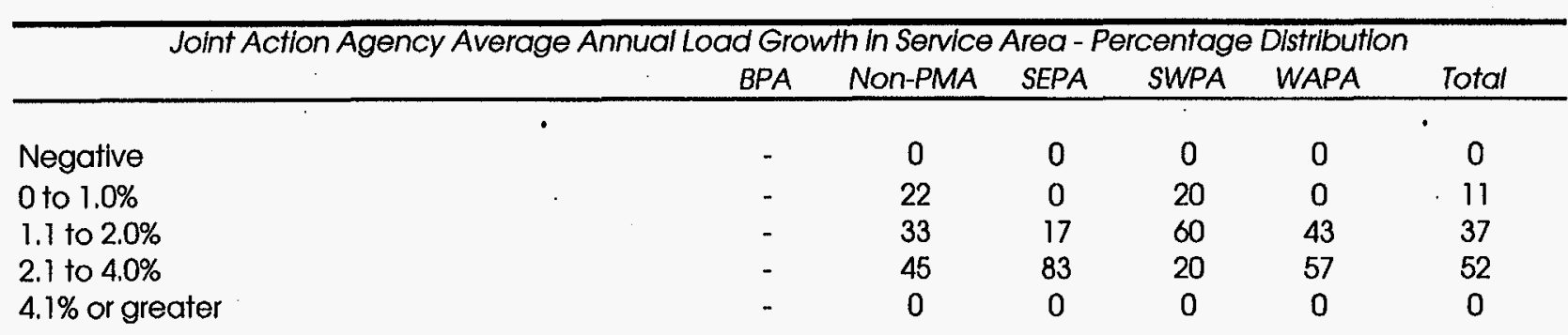

Source: Survey data.

Note: Percentage totals may not equal $100 \%$ due to rounding.

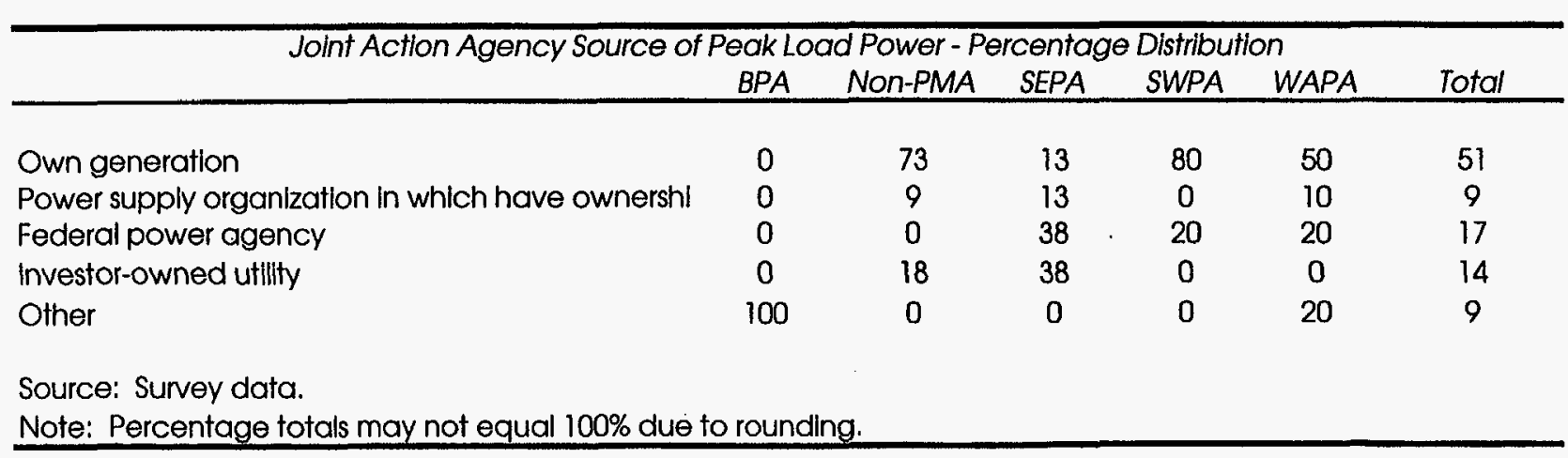




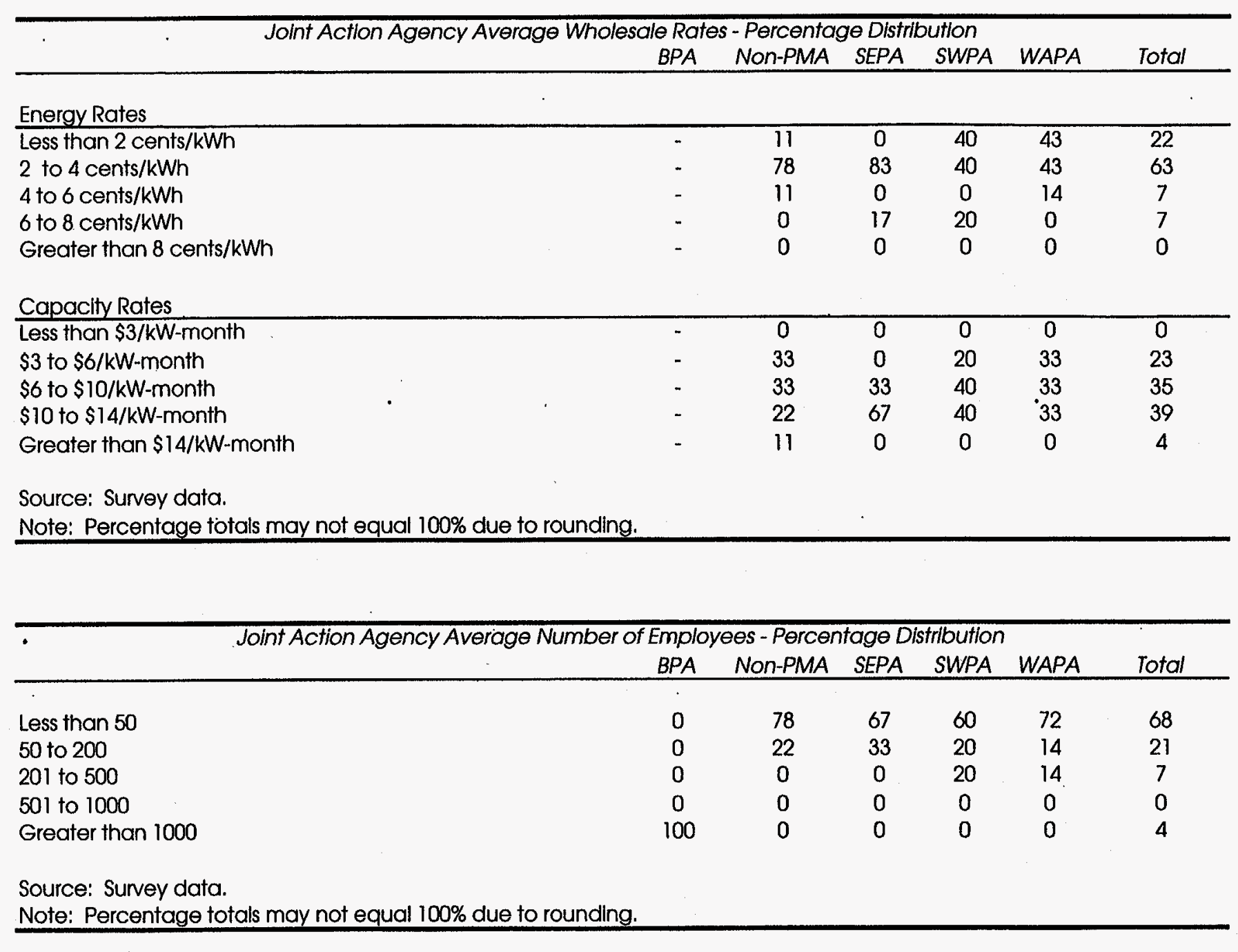

\begin{tabular}{lccccccc}
\hline & Joint Action Agency Annual System Sales & Percentage Distribution & & \\
& BPA & Non-PMA & SEPA & SWPA & WAPA & Total \\
\hline & & 0 & 0 & 20 & 0 & 0 & 4 \\
Less than 50,000 MWh & 0 & 0 & 0 & 0 & 0 & 0 \\
50,000 to 100,000 MWh & 0 & 22 & 0 & 40 & 29 & 23 \\
100,001 to $500,000 \mathrm{MWh}$ & 0 & 0 & 0 & 0 & 29 & 8 \\
500,001 to 1,000,000 MWh & 100 & 78 & 80 & 60 & 43 & 65 \\
Greater than 1,000,000 MWh & & & & & & \\
Source: Survey data. & & & & & & \\
Note: Percentage totals may not equal 100\% due to rounding.
\end{tabular}




\begin{tabular}{|c|c|c|c|c|c|c|}
\hline \multicolumn{7}{|c|}{ Joint Action Agency Peak Load - Percentage Distribution } \\
\hline & $B P A$ & Non-PMA & SEPA & SWPA & WAPA & Total \\
\hline \multicolumn{7}{|l|}{ Winter } \\
\hline Less than $100 \mathrm{MW}$ & 0 & 14 & 0 & 67 & 29 & 23 \\
\hline 100 to $250 \mathrm{MW}$ & 0 & 29 & 0 & 33 & 43 & 27 \\
\hline 251 to $500 \mathrm{MW}$ & 0 & 29 & 40 & 0 & 14 & 23 \\
\hline 501 to $1000 \mathrm{MW}$ & 0 & 29 & 0 & 0 & 14 & 14 \\
\hline Greater than $1000 \mathrm{MW}$ & $100^{\circ}$ & 0 & 60 & 0 & 0 & 14 \\
\hline \multicolumn{7}{|l|}{ Summer } \\
\hline Less than $100 \mathrm{MW}$ & $\overline{0}$ & 14 & $\overline{0}$ & 67 & 14 & 17 \\
\hline 100 to $250 \mathrm{MW}$ & 0 & 14 & 17 & 0 & 57 & 26 \\
\hline 251 to $500 \mathrm{MW}$ & 0 & 43 & 17 & 33 & 0 & 22 \\
\hline 501 to $1000 \mathrm{MW}$ & 0 & 29 & 17 & 0 & 29 & 22 \\
\hline Greater than $1000 \mathrm{MW}$ & 100 & 0 & 50 & 0 & 0 & 13 \\
\hline \multicolumn{7}{|l|}{$\begin{array}{l}\text { Source: DOE/EIA Form } 861 \text { - } 1991 \\
\text { Note: Percentage totals may not equal } 100 \% \text { due to rounding. }\end{array}$} \\
\hline \multicolumn{7}{|c|}{ Joint Action Agency Business Characteristics, Generation Plans, and DSM Participation - Percentage Distributlon } \\
\hline & & & & & & \\
\hline \multicolumn{7}{|l|}{ JAAs involved in: } \\
\hline Generation & 100 & 100 & 67 & 80 & 89 & 87 \\
\hline Transmission & 100 & 100 & 100 & 100 & 100 & 100 \\
\hline Distribution & 0 & 11 & 0 & 0 & 0 & 3 \\
\hline Plans to construct generation facillites within next 10 year & 100 & 33 & 0 & 40 & 38 & 32 \\
\hline Participation in DSM Programs & 0 & 33 & 50 & 0 & 25 & 28 \\
\hline Source: DOE/EIA Form 861 - 1991 & & & & & & \\
\hline
\end{tabular}




\begin{tabular}{lccccccc}
\hline & Joint Action Agency Supply Sources - Percentage Distribution & & \\
& BPA & Non-PMA & SEPA & SWPA & WAPA & Total \\
\hline Net generation & 100 & 38 & 64 & 69 & 78 & 64 \\
Purchases - utlltles & 0 & 62 & 36 & 31 & 22 & 36 \\
Purchases - nonutilitles & 0 & 0 & 0 & 0 & 0 & 0 \\
Net wheeling & 0 & 0 & 0 & 0 & 0 & 0 \\
Source: DOE/EIA Form 861 - 1991 & & & & & & \\
Note: Percentage totals may not equal 100\% due to rounding. & & & & & \\
\hline
\end{tabular}

\begin{tabular}{|c|c|c|c|c|c|c|}
\hline Joint Action AgencyE & $\begin{array}{l}\text { sition c } \\
B P A\end{array}$ & $\begin{array}{l}\text { dd Revenue } \\
\text { Non-PMA }\end{array}$ & $\begin{array}{l}- \text { Perce } \\
\text { SEPA }\end{array}$ & $\begin{array}{l}\text { age DIst } \\
\text { SWPA }\end{array}$ & WAtion & Total \\
\hline \multicolumn{7}{|l|}{ Sales } \\
\hline Sales to end-use consumers & 0 & 3 & $\overline{0}$ & $\overline{0}$ & $\overline{0}$ & $T$ \\
\hline Sales for resale & 100 & 97 & 100 & 100 & 100 & 99 \\
\hline \multicolumn{7}{|l|}{ Revenues } \\
\hline Revenues from sales to end-use consumers & 0 & 2 & 0 & 0 & 0 & 0 \\
\hline Revenues from sales for resale & 100 & 98 & 100 & 100 & 100 & 100 \\
\hline \multicolumn{7}{|l|}{ Iotal Revenue Ranges (1000s \$1991) } \\
\hline less than $\$ 100,000$ & 0 & 56 & $\overline{33}$ & 80 & 67 & 57 \\
\hline$\$ 100,000$ to $\$ 250,000$ & 0 & 33 & 17 & 20 & 22 & 23 \\
\hline$\$ 250,001$ to $\$ 500,000$ & 100 & 11 & 33 & 0 & 0 & 13 \\
\hline$\$ 500,001$ to $\$ 1,000,000$ & 0 & 0 & 17 & 0 & 11 & 7 \\
\hline Greater than $\$ 1,000,000$ & 0 & 0 & 0 & 0 & 0 & 0 \\
\hline
\end{tabular}



Municipal Utility Tables 



\begin{tabular}{lcc}
\hline Reglon & $\begin{array}{c}\text { Municipal Utilities: Total Number vs. Survey Respondents } \\
\text { Total No. of Municipals }\end{array}$ & $\begin{array}{c}\text { No. of Municipals Respor } \\
\text { B. }\end{array}$ \\
BPA & 70 & 41 \\
Non-PMA & 798 & 61 \\
SEPA & 209 & 48 \\
SWPA & 387 & 52 \\
TVA & 107 & 50 \\
WAPA & 364 & 74 \\
Total & & 326
\end{tabular}

- The list of JAAs contacted in the survey was taken from the American Public Power Assoclation and modifled as necessary to reflect utllity types and reglons addressed in the survey.

** Surveys were sent only to a representative sample of municipal utllities, and the tables that follow include data for 321 of the 326 responding munlcipals because of matching problems between EIA's Form 861 and survey results. 


\begin{tabular}{|c|c|c|c|c|c|c|c|}
\hline \multicolumn{8}{|c|}{ Municipal Utility Current Electricity Supply Situation - Percentage Distribution } \\
\hline & $B P A$ & Non-PMA & SEPA & SWPA & TVA & WAPA & Total \\
\hline \multicolumn{8}{|l|}{ Capacity } \\
\hline Deficit & 13 & 7 & 10 & 2 & 0 & 8 & 7 \\
\hline Balance & 71 & 50 & 42 & 52 & 45 & 48 & 51 \\
\hline Surplus & 16 & 43 & 49 & 46 & 55 & 44 & 42 \\
\hline \multicolumn{8}{|l|}{ Energy } \\
\hline Deficit & 16 & 5 & 12 & 0 & 0 & 11 & 7 \\
\hline Balance & 76 & 50 & 42 & 57 & 34 & 52 & 51 \\
\hline Surplus & 8 & 45 & 46 & 44 & 66 & 37 & 41 \\
\hline
\end{tabular}

\begin{tabular}{|c|c|c|c|c|c|c|c|}
\hline \multicolumn{8}{|c|}{ Municipal Utility Average Annual Load Growth in Senice Area - Percentage Distribution } \\
\hline & $B P A$ & Non-PMA & SEPA & SWPA & TVA & WAPA & Total \\
\hline Negative & 5 & 4 & 5 & 7 & 2 & 5 & 4 \\
\hline 0 to $1.0 \%$ & 25 & 26 & 17 & 30 & 11 & 29 & 24 \\
\hline 1.1 to $2.0 \%$ & 50 & 40 & 29 & 23 & 56 & 31 & 38 \\
\hline 2.1 to $4.0 \%$ & 15 & 18 & 36 & 36 & 29 & 31 & 27 \\
\hline $4.1 \%$ or greater & 5 & 12 & 14 & 5 & 2 & 5 & 7 \\
\hline
\end{tabular}

\begin{tabular}{|c|c|c|c|c|c|c|c|}
\hline \multicolumn{8}{|c|}{ Municlpal Utility Source of Peak Load Power - Percentage Distribution } \\
\hline Own generation & 15 & 25 & 20 & 42 & 0 & 8 & 18 \\
\hline Power supply organization in which have ownership & 2 & 42 & 32 & 18 & 0 & 43 & 25 \\
\hline Federal power agency & 80 & 2 & 20 & 6 & 90 & 24 & 34 \\
\hline Investor-owned utllity & 2 & 28 & 18 & 18 & 0 & 16 & 14 \\
\hline Other & 0 & 4 & 11 & 16 & 10 & 9 & 9 \\
\hline
\end{tabular}




\begin{tabular}{|c|c|c|c|c|c|c|c|}
\hline & $\begin{array}{r}\text { Municlpal Utillty Average R } \\
\text { BPA }\end{array}$ & $\begin{array}{l}\text { all Rates - PE } \\
\text { Non-PMA }\end{array}$ & $\begin{array}{l}\text { entag } \\
\text { SEPA }\end{array}$ & $\begin{array}{l}\text { tribution } \\
\text { SWPA }\end{array}$ & TVA & WAPA & Total \\
\hline \multicolumn{8}{|l|}{ Energy Rates } \\
\hline Less than 2 cents/kWh & 8 & 2 & 0 & 2 & $\overline{0}$ & 0 & 2 \\
\hline 2 to 4 cents/kWh & 46 & 11 & 8 & 9 & 9 & 16 & 16 \\
\hline 4 to 7 cents/kWh & 46 & 48 & 51 & 58 & 91 & 61 & 59 \\
\hline 7 to 10 cents/kWh & 0 & 38 & 31 & 26 & 0 & 23 & 21 \\
\hline Greater than 10 cents $/ \mathrm{kWh}$ & 0 & 2 & 10 & 5 & 0 & 0 & 2 \\
\hline \multicolumn{8}{|l|}{ Capacity Rates } \\
\hline Less than \$4/kW-month & 50 & 25 & 29 & 18 & 0 & 24 & 24 \\
\hline$\$ 4$ to $\$ 8 / \mathrm{kW}$-month & 50 & 39 & 23 & 61 & 16 & 58 & 41 \\
\hline$\$ 8$ to $\$ 12 / \mathrm{kW}$-month & 0 & 29 & 37 & 21. & 84 & 18 & 32 \\
\hline$\$ 12$ to $\$ 16 / \mathrm{kW}$-month & 0 & 8 & 9 & $0^{\circ}$ & 0 & 0 & 3 \\
\hline Greater than $\$ 16 / \mathrm{kW}$-month & 0 & 0 & 3 & 0 & 0 & 0 & 0 \\
\hline
\end{tabular}

\begin{tabular}{|c|c|c|c|c|c|c|c|}
\hline \multicolumn{8}{|c|}{ Munlcipal Utility Average Nwmber of Emplayees - Percentage Distribution } \\
\hline & $B P A$ & Non-PMA & SEPA & SWPA & $T V A$ & WAPA & Total \\
\hline Less than 50 & 48 & 92 & 76 & 77 & 55 & 85 & 74 \\
\hline 50 to 200 & 35 & 7 & 17 & 17 & 36 & 7 & 18 \\
\hline 201 to 500 & 5 & 2 & 0 & 0 & 2 & 3 & 2 \\
\hline 501 to 1000 & 10 & 0 & 2 & 2 & 5 & 2 & 3 \\
\hline Greater than 1000 & 3 & 0 & 5 & 4 & 2 & 3 & 3 \\
\hline
\end{tabular}

\begin{tabular}{|c|c|c|c|c|c|c|c|}
\hline & $\begin{array}{r}\text { Municipal Utility Annual Sy } \\
\text { BPA }\end{array}$ & $\begin{array}{l}m \text { Sales - } P \\
\text { Non-PMA }\end{array}$ & $\begin{array}{l}\text { entag } \\
\text { SEPA }\end{array}$ & $\begin{array}{l}\text { tribution } \\
\text { SWPA }\end{array}$ & TVA & WAPA & Tota \\
\hline Less than $50,000 \mathrm{MWh}$ & 13 & 45 & 39 & 48 & 16 & 50 & 37 \\
\hline 50,000 to $100,000 \mathrm{MWh}$ & 18 & 24 & 10 & 14 & 12 & 14. & 16 \\
\hline 100,001 to $500,000 \mathrm{MWh}$ & 26 & 22 & 37 & 25 & 42 & 22 & 28 \\
\hline 500,001 to $1,000,000 \mathrm{MWh}$ & 23 & 4 & 10 & 7 & 16 & 6 & 10 \\
\hline Greater than $1,000,000 \mathrm{MWh}$ & 21 & 5 & 5 & 7 & 14 & 8 & 9 \\
\hline
\end{tabular}




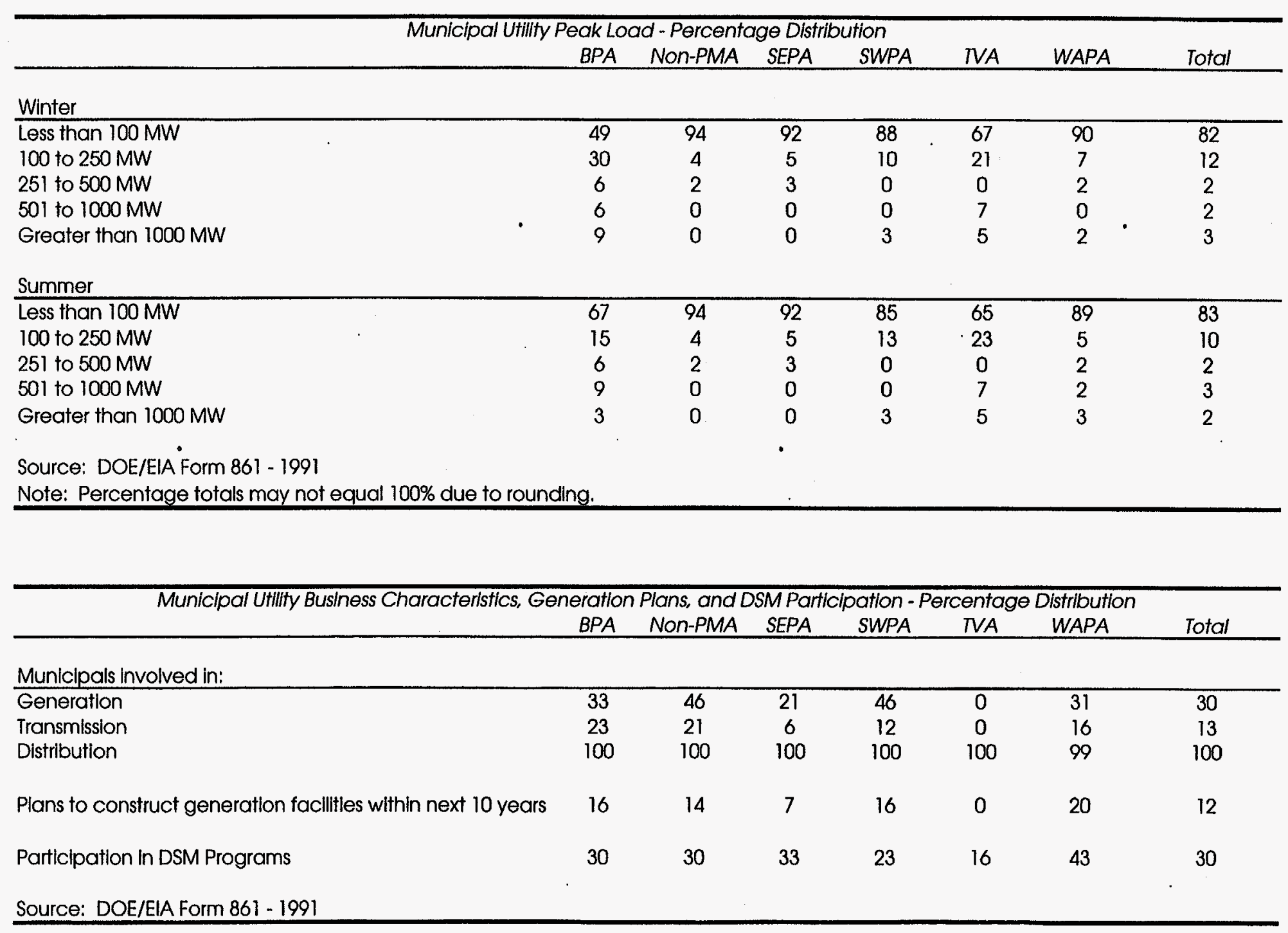




\begin{tabular}{lcccccccc}
\hline & Municipal Utillty Supply Sources - Percentage Distribution & & \\
& BPA & Non-PMA & SEPA & SWPA & TVA & WAPA & Total \\
\hline Net generation & 49 & 27 & 21 & 67 & 0 & 34 & 32 \\
Purchases - utilities & 49 & 73 & 79 & 33 & 100 & 66 & 68 \\
Purchases - nonutilities & 2 & 0 & 0 & 0 & 0 & 0 & 0 \\
Net wheeling. & 0 & 0 & 0 & 0 & 0 & 0 & 0 \\
Source: DOE/EIA Form 861 - 1991 & & & & & & & & \\
Note: Percentage totals may not equal 100\% due to rounding. & & & & & & \\
\hline
\end{tabular}

Note: Percentage totals may not equal $100 \%$ due to rounding

\begin{tabular}{|c|c|c|c|c|c|c|c|}
\hline \multicolumn{8}{|c|}{ Munlcipal Utillty Electricity Disposition and Revenues - Percentage Distribution } \\
\hline & $B P A$ & Non-PMA & SEPA & SWPA & IVA & WAPA & Total \\
\hline \multicolumn{8}{|l|}{ SSles } \\
\hline Sales to end-use consumers & 72 & 97 & 85 & 96 & 100 & 98 & $\overline{89}$ \\
\hline Sales for resale & 28 & 3 & 15 & 4 & 0 & 2 & 11 \\
\hline \multicolumn{8}{|l|}{ Revenues } \\
\hline Revenues from sales to end-use consumers & 90 & 98 & 97 & 97 & 100 & 100 & 98 \\
\hline Revenues from sales for resale & 10 & 2 & 3 & 3 & 0 & 0 & 2 \\
\hline \multicolumn{8}{|l|}{ Total Revenue Ranges (1000s \$1991) } \\
\hline less than $\$ 100,000$ & 85 & 98 & 98 & 98 & 90 & 96 & 95 \\
\hline$\$ 100,000$ to $\$ 250,000$ & 13 & 2 & 2 & 0 & 2 & 1 & 3 \\
\hline$\$ 250,001$ to $\$ 500,000$ & 3 & 0 & 0 & 0 & 4 & 0 & 1 \\
\hline$\$ 500,001$ to $\$ 1,000,000$ & 0 & 0 & 0 & 2 & 4 & 1 & 1 \\
\hline Greater than $\$ 1,000,000$ & 0 & 0 & 0 & 0 & 0 & 1 & 0 \\
\hline
\end{tabular}

Source: DOE/EIA Form 861 - 1991

Note: Percentage totals may not equal $100 \%$ due to rounding. 


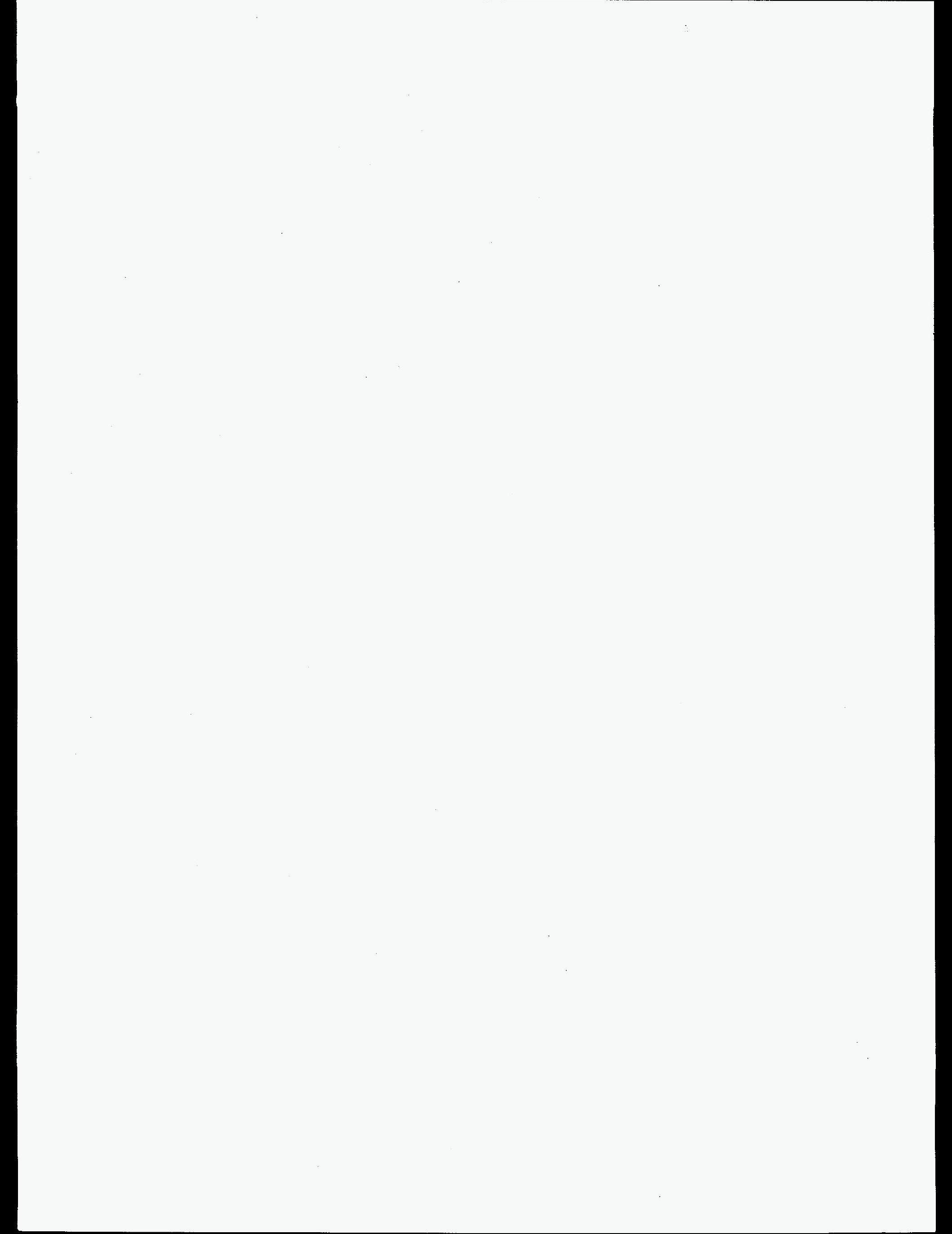




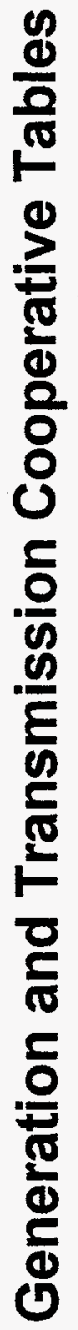





\begin{tabular}{l}
\hline Generation and Transmission Cooperatives: Total Number vs. Sunvey Respondents \\
Reglon \\
Total No. of G\&Ts* No. of G\&Ts Responding to Survey**
\end{tabular}

$\begin{array}{lc}\text { BPA } & 3 \\ \text { Non-PMA } & 11 \\ \text { SEPA } & 9 \\ \text { SWPA } & 21 \\ \text { TVA } & 0 \\ \text { WAPA } & 20 \\ & \\ \text { Total } & \end{array}$

2
7
7
17
0
14

- The list of G\&Ts contacted in the survey was extracted from the Utility Data Institute's Utility Database.

The database was modifled per data provided by the National Rural Electric Cooperatives Association and the

Rural Electrification Administration to provide an accurate list of cooperatives that reflected the utllity types and reglons addressed in the survey.

** The tables that follow include data for 44 of the 47 responding G\&Ts because of matching problems between the EIA Form 861 and survey results. 


\begin{tabular}{|c|c|c|c|c|c|c|}
\hline \multicolumn{7}{|c|}{ G\&T Cooperative Current Electricity Supply Situation - Percentage Dlstribution } \\
\hline & $B P A$ & Non-PMA & SEPA & SWPA & WAPA & Total \\
\hline \multicolumn{7}{|l|}{ Capacity } \\
\hline Deficit & 0 & $\overline{0}$ & 0 & 0 & 17 & 5 \\
\hline Balance & 0 & 50 & 83 & 40 & 0 & 41 \\
\hline Surplus & 100 & 50 & 17 & 60 & 83 & 55 \\
\hline \multicolumn{7}{|l|}{ Energy } \\
\hline Deficit & 0 & 0 & 0 & 0 & 0 & 0 \\
\hline Balance & 0 & 25 & 83 & 40 & 0 & 38 \\
\hline Surplus & 100 & 75 & 17 & 60 & 100 & 62. \\
\hline
\end{tabular}

\begin{tabular}{|c|c|c|c|c|c|c|}
\hline \multicolumn{7}{|c|}{ G\&T Cooperative Average Annual Load Growth in Servlce Area - Percentage Distribution } \\
\hline & $B P A$ & Non-PMA & SEPA & SWPA & WAPA & Total \\
\hline Negative & 0 & 0 & 0 & 0 & 0 & 0 \\
\hline 0 to $1.0 \%$ & 100 & 0 & 0 . & 10 & 27 & 19 \\
\hline 1.1 to $2.0 \%$ & 0 & 0 & 25 & 50 & 55 & 44 \\
\hline 2.1 to $4.0 \%$ & 0 & 100 & 75 & 40 & 18 & 37 \\
\hline $4.1 \%$ or greater & 0 & 0 & 0 & 0 & 0 & 0 \\
\hline
\end{tabular}

\begin{tabular}{|c|c|c|c|c|c|c|}
\hline \multicolumn{7}{|c|}{ G\&T Cooperative Source of Peak Load Power - Percentage Distribution } \\
\hline Own generation & 0 & 43 & 57 & 13 & 29 & 30 \\
\hline Power supply organization in which have ownershik & 0 & 0 & 0 & 0 & 0 & 0 \\
\hline Federal power agency & 100 & 0 & 14 & 13 & 14 & 14 \\
\hline Investor-owned utility & 0 & 29 & 14 & 27 & 0 & 16 \\
\hline Other & 0 & 29 & 14 & 47 & 57 & 41 \\
\hline
\end{tabular}




\begin{tabular}{|c|c|c|c|c|c|c|}
\hline & $\begin{array}{c}\text { Wholes } \\
\text { BPA }\end{array}$ & $\begin{array}{l}\text { Rates - Pe } \\
\text { Non-PMA }\end{array}$ & $\begin{array}{c}\text { zentage } \\
\text { SEPA }\end{array}$ & $\begin{array}{l}\text { tribution } \\
\text { SWPA }\end{array}$ & WAPA & Total \\
\hline \multicolumn{7}{|l|}{ Energy Rates } \\
\hline 2 to 4 cents/kWh & - & 50 & 40 & 71 & 46 & 55 \\
\hline 4 to 6 cents/kWh & - & 17 & 40 & 29 & 23 & 26 \\
\hline 6 to 8 cents $/ \mathrm{kWh}$ & - & 0 & 0 & 0 & 0 & 0 \\
\hline \multicolumn{7}{|l|}{ Capacity Rates } \\
\hline Less than $\$ 3 / \mathrm{kW}$-month & - & 0 & $\overline{0}$ & 0 & 0 & 0 \\
\hline$\$ 3$ to $\$ 6 / \mathrm{kW}$-month & - & 0 & 0 & 15 & 8 & 8 \\
\hline$\$ 6$ to $\$ 10 / \mathrm{kW}-$ month & - & 50 & 20 & 54 & 46 & 46 \\
\hline$\$ 10$ to $\$ 14 / \mathrm{kW}$-month & - & 50 & 40 & 31 & 23 & 32 \\
\hline
\end{tabular}

\begin{tabular}{|c|c|c|c|c|c|c|}
\hline & G\&T Cooperative Average Number & mployees - & ercento & Distributh & & \\
\hline & $B P A$ & Non-PMA & SEPA & SWPA & WAPA & Total \\
\hline Less than 50 & 100 & 40 & 17 & 25 & 0 & 21 \\
\hline 50 to 200 & 0 & 0 & 17 & 25 & 22 & 17 \\
\hline 201 to 500 & 0 & 40 & 50 & 25 & 67 & 45 \\
\hline 501 to 1000 & 0 & 20 & 17 & 13 & 0 & 10 \\
\hline Greater than 1000 & 0 & 0 & 0 & 13 & 11 & 7 \\
\hline
\end{tabular}

\begin{tabular}{lcccccc}
\hline & G\&T Cooperative Annual System Sales - Percentage Distribution & & \\
& BPA & Non-PMA & SEPA & SWPA & WAPA & Total \\
\hline Less than 50,000 MWh & - & 0 & 0 & 0 & 0 & 0 \\
50,000 to 100,000 MWh & - & 0 & 0 & 0 & 0 & 0 \\
100,001 to 500,000 MWh & - & 17 & 0 & 0 & 7 & 5 \\
500,001 to 1,000,000 MWh & - & 0 & 0 & 7 & 21 & 10 \\
Greater than 1,000,000 MWh & - & 83 & 100 & 93 & 71 & 85 \\
Source: Survey data. & & & & & & \\
Note: Percentage totals may not equal 100\% due to rounding.
\end{tabular}




\begin{tabular}{|c|c|c|c|c|c|c|}
\hline G\&T Cooperative Pec & Load & Percentage & istributit & & & \\
\hline & $B P A$ & Non-PMA & SEPA & SWPA & WAPA & Total \\
\hline Winter & & & & & & \\
\hline Less than $100 \mathrm{MW}$ & - & 0 & 0 & 7 & $\overline{8}$ & 8 \\
\hline 100 to $250 \mathrm{MW}$ & - & 0 & 0 & 40 & 25 & 23 \\
\hline 251 to $500 \mathrm{MW}$ & - & 17 & 14 & 27 & 25 & 23 \\
\hline 501 to $1000 \mathrm{MW}$ & - & 67 & 29 & 13 & 33 & 28 \\
\hline Greater than $1000 \mathrm{MW}$ & - & 17 & 57 & 13 & 8 & 20 \\
\hline Summer & & & & & & \\
\hline Less than $100 \mathrm{MW}$ & - & 0 & $\overline{0}$ & 7 & 8 & 5 \\
\hline 100 to $250 \mathrm{MW}$ & - & 0 & 0 & 33 & 23 & 20 \\
\hline 251 to $500 \mathrm{MW}$ & - & 17 & 14 & 27 & 39 & 27 \\
\hline 501 to $1000 \mathrm{MW}$ & - & 67 & 14 & 20 & 23 & 27 \\
\hline Greater than $1000 \mathrm{MW}$ & - & 17 & 71 & 13 & 8 & 22 \\
\hline $\begin{array}{l}\text { Source: DOE/EIA Form } 861 \text { - } 1991 \\
\text { Note: Percentage totals may not equal } 100 \% \text { due to roun }\end{array}$ & ing. & & & & & \\
\hline G\&T Cooperative Business Characteristlcs, Genel & tion $P$ & רs, andDSM & articipc & n-Perce & gge Distr & \\
\hline & $B P A$ & Non-PMA & SEPA & SWPA & WAPA & Total \\
\hline G\&Ts involved in: & & & & & & \\
\hline Generation & 100 & 100 & 100 & 73 & 79 & 84 \\
\hline Ttransmission & 100 & 100 & 100 & 100 & 100 & 100 \\
\hline Ddistribution & 0 & 14 & 0 & 20 & 7 & 11 \\
\hline Plans to construct generation facllities within next 10 yeal & 0 & 17 & 50 & 20 & 36 & 28 \\
\hline Participation in DSM Programs & & 43 & 57 & 13 & 57 & 39 \\
\hline Source: DOE/EIA Form 861 - 1991 & & & & & & \\
\hline
\end{tabular}




\begin{tabular}{lccccccc}
\hline & G\&T Cooperative Supply Sources - Percentage DIstribution & & \\
& BPA & Non-PMA & SEPA & SWPA & WAPA & Total \\
\hline Net generation & 93 & 81 & 55 & 57 & 78 & 66 \\
Purchases - utillties & 7 & 19 & 45 & 43 & 22 & 34 \\
Purchases - nonutilities & 0 & 0 & 0 & 0 & 0 & 0 \\
Net wheeling & 0 & 0 & 0 & 0 & 0 & 0 \\
Source: DOE/EIA Form $861-1991$ & & & & & & \\
Note: Percentage totals may not equal 100\% due to rounding.
\end{tabular}

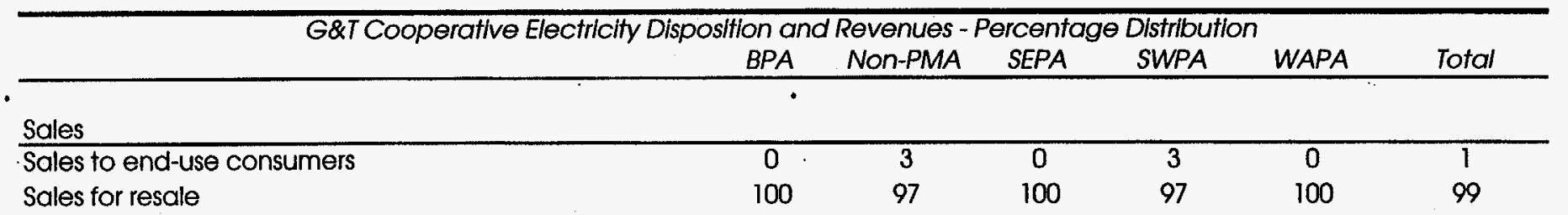

\section{Revenues}

Revenues from sales to end-use consumers

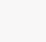

07

Revenues from sales for resale

$\begin{array}{cccccc}0 & 5 & 0 & 3 & 0 & 2 \\ 100 & 95 & 100 & 97 & 100 & 98\end{array}$

Total Revenue Ranges (1000s \$1991)

\begin{tabular}{lcccccc}
\hline Less than $\$ 100,000$ & 100 & 0 & 0 & 67 & 50 & 41 \\
$\$ 100,000$ to $\$ 250,000$ & 0 & 71 & 29 & 20 & 43 & 36 \\
$\$ 250,001$ to $\$ 500,000$ & 0 & 29 & 43 & 13 & 7 & 18 \\
$\$ 500,001$ to $\$ 1,000,000$ & 0 & 0 & 14 & 0 & 0 & 2 \\
Greater than $\$ 1,000,000$ & 0 & 0 & 14 & 0 & 0 & 2
\end{tabular}

Source: DOE/EIA Form 861 - 1991

Note: Percentage totals may not equal $100 \%$ due to rounding. 


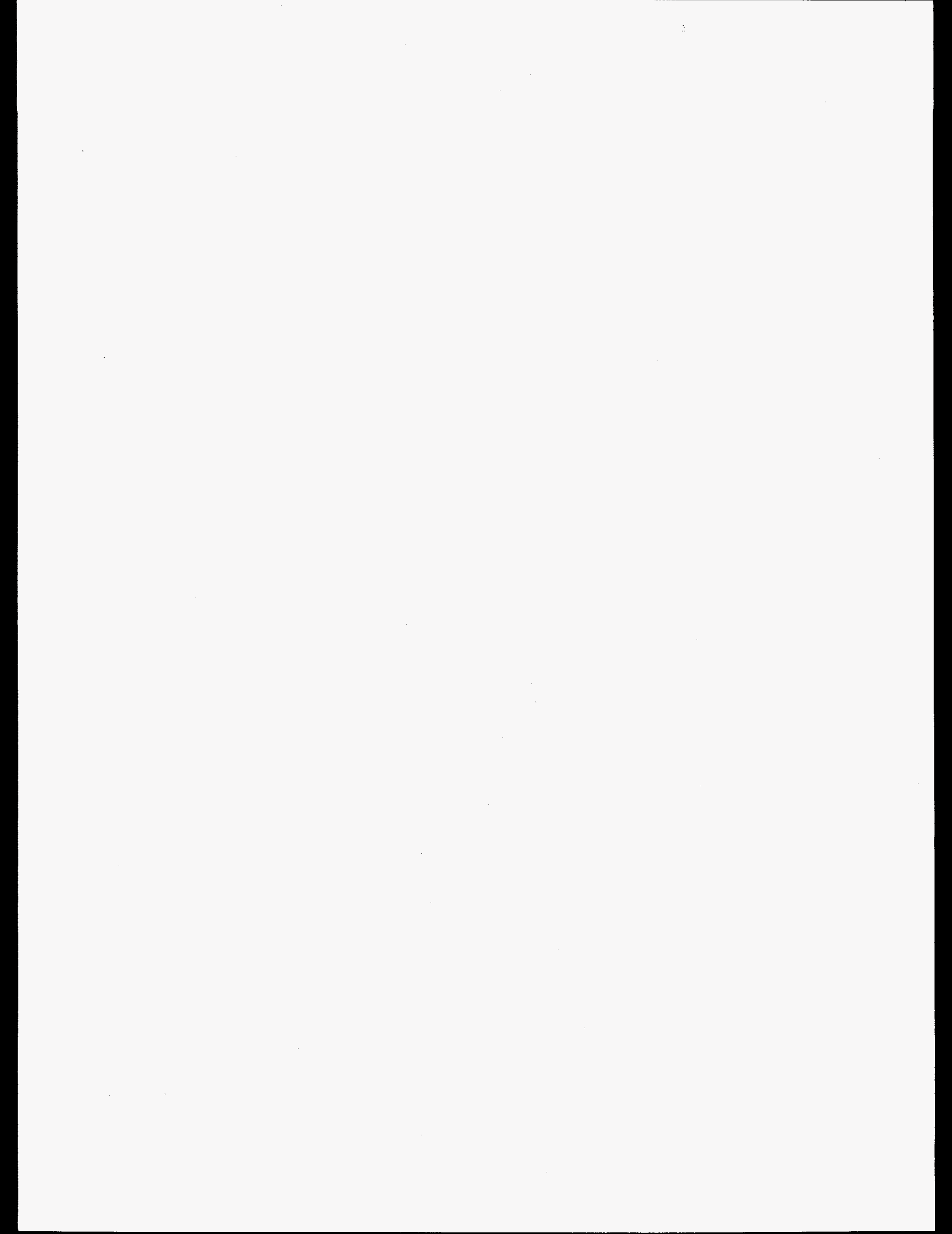




\section{Distribution Cooperative Tables}





\begin{tabular}{|c|c|c|}
\hline \multicolumn{3}{|c|}{ Distribution Cooperatives: Total Number vs. Survey Respondents } \\
\hline Region & Total No. of Dist. Coops* & No. of Dist. Coops Responding to Survey ${ }^{* *}$ \\
\hline BPA & 40 & 14 \\
\hline Non-PMA & 272 & 62 \\
\hline SEPA & 149 & 46 \\
\hline SWPA & 203 & 62 \\
\hline TVA & 49 & 18 \\
\hline WAPA & 146 & 54 \\
\hline Total & 859 & 256 \\
\hline \multicolumn{3}{|c|}{$\begin{array}{l}\text { "The list of G\&Ts contacted in the survey was extracted from the Utility Data Institute's Utillty Database. } \\
\text { The database was modified per data provided by the National Rural Electric Cooperatives Assoclation and the } \\
\text { Rural Electrification Administration to provide an accurate list of cooperatives that reflected the utility types and } \\
\text { reglons addressed in the survey. }\end{array}$} \\
\hline \multicolumn{3}{|c|}{$\begin{array}{l}\text { ** Surveys were sent only to a representative sample of distributlon cooperatives, and the tables that follow include datc } \\
\text { for } 253 \text { of the } 256 \text { responding distribution cooperatives because of matching problems between the EIA Form } 861 \\
\text { and survey results. }\end{array}$} \\
\hline
\end{tabular}




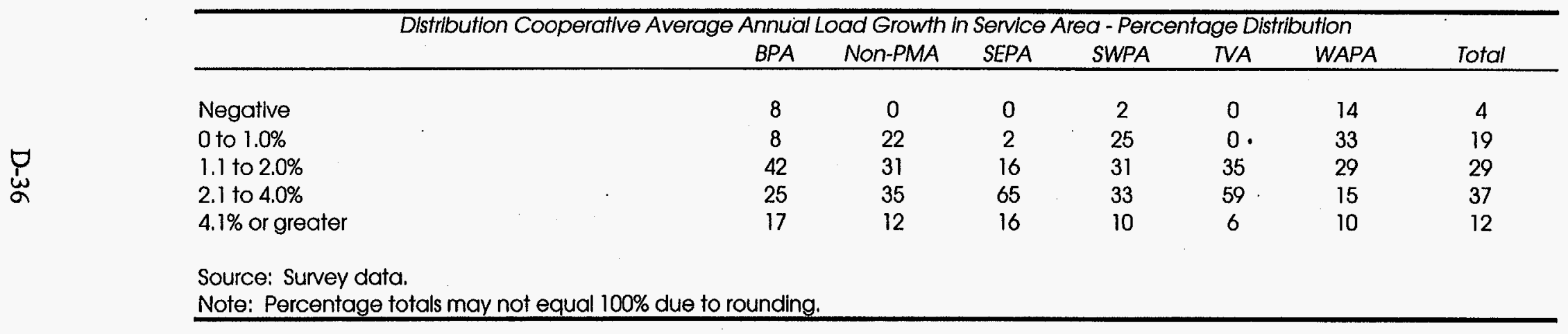




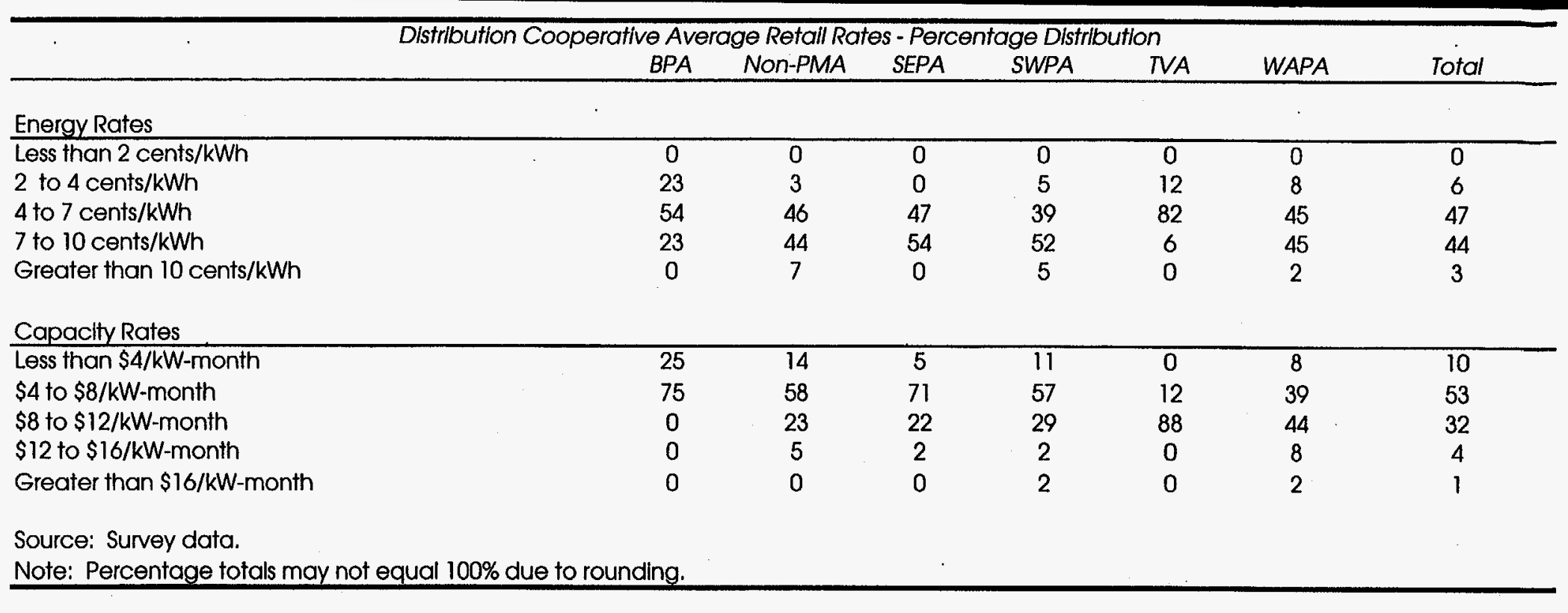

\begin{tabular}{|c|c|c|c|c|c|c|c|}
\hline & $\begin{array}{r}\text { Distibution Cooperative Average } \\
\text { BPA }\end{array}$ & $\begin{array}{l}\text { Imber of En } \\
\text { Non-PMA }\end{array}$ & $\begin{array}{l}\text { Syees } \\
\text { SEPA }\end{array}$ & $\begin{array}{l}\text { Sentag } \\
\text { SWPA }\end{array}$ & $\begin{array}{l}\text { ibutiol } \\
\text { TVA }\end{array}$ & WAPA & Total \\
\hline Less than 20 & 42 & 16 & 0 & 16 & 0 & 28 & 16 \\
\hline 20 to 50 & 33 & 59 & 32 & 49 & 18 & 49 & 45 \\
\hline 51 to 100 & 25 & 19 & 34 & 25 & 47 & 17 & 25 \\
\hline 101 to 200 & 0 & 3 & 30 & 8 & 29 & 6 & 11 \\
\hline Greater than 200 & 0 & 3 & 5 & 2 & 6 & 0 & 2 \\
\hline
\end{tabular}

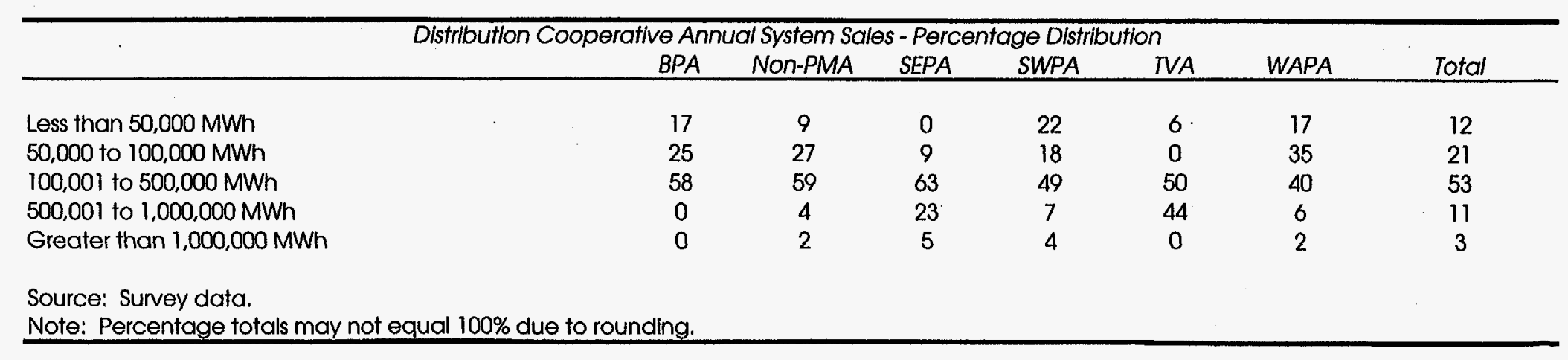




\begin{tabular}{|c|c|c|c|c|c|c|c|}
\hline Distribution COC & $\begin{array}{l}\text { erativ } \\
\text { BPA }\end{array}$ & $\begin{array}{l}\text { eak Load-1 } \\
\text { Non-PMA }\end{array}$ & $\begin{array}{l}\text { centag } \\
\text { SEPA }\end{array}$ & $\begin{array}{l}\text { stribution } \\
\text { SWPA }\end{array}$ & TVA & WAPA & Total \\
\hline \multicolumn{8}{|l|}{ Winter } \\
\hline Less than $100 \mathrm{MW}$ & 100 & 95 & 67 & 89 & 50 & 93 & 85 \\
\hline 100 to $250 \mathrm{MW}$ & 0 & 4 & 28 & 6 & 44 & 7 & 12 \\
\hline 251 to $500 \mathrm{MW}$ & 0 & 2 & 5 & 2 & 6 & 0 & 2 \\
\hline 500 to $1000 \mathrm{MW}$ & 0 & 0 & 0 & 2 & 0 & 0 & 1 \\
\hline Greater than $1000 \mathrm{MW}$ & $0^{\circ}$ & 0 & 0 & 2 & 0 & 0 & 1 \\
\hline \multicolumn{8}{|l|}{ Summer } \\
\hline Less than $100 \mathrm{MW}$ & 92 & 95 & 64 & 88 & 53 & 96 & 85 \\
\hline 100 to $250 \mathrm{MW}$ & 8 & 5 & 33 & 9 & 40 & 4 & 13 \\
\hline 251 to $500 \mathrm{MW}$ & 0 & 0 & 3 & 2 & 7 & 0 & 1 \\
\hline 501 to $1000 \mathrm{MW}$ & 0 & 0 & 0 & 0 & 0 & 0 & 0 \\
\hline Greater than $1000 \mathrm{MW}$ & 0 & 0 & 0 & 2 & 0 & 0 & 1 \\
\hline \multicolumn{8}{|l|}{ Source: DOE/EIA Form 861 - 1991} \\
\hline \multirow{2}{*}{\multicolumn{8}{|c|}{$\begin{array}{l}\text { Distribution Cooperative Business Characteristics, Generation Plans, and DSM Participation - Percentage Distributtion } \\
\qquad \text { BPA Non-PMA SEPA SWPA IVA WAPA }\end{array}$}} \\
\hline & & & & & & & \\
\hline \multicolumn{8}{|l|}{ Distribution Coops involved in: } \\
\hline Generation & 0 & 2 & 4 & 0 & 6 & 2 & 2 \\
\hline Transmission & 14 & 13 & 2 & 18 & 6 & 15 & 12 \\
\hline Distribution & 100 & 100 & 100 & 100 & 100 & 100 & 100 \\
\hline Plans to construct generation facllities within next 10 yea & 0 & 2 & 0 & 0 & 0 & 2 & 1 \\
\hline Particlpation in DSM Programs & 0 & 57 & 41 & 26 & 24 & 30 & 36 \\
\hline Source: DOE/ElA Form 861 - 1991 & & & & & & & \\
\hline
\end{tabular}




\begin{tabular}{|c|c|c|c|c|c|c|c|}
\hline & ative & ply Source & ercent & Distribu & & & \\
\hline & $B P A$ & Non-PMA & SEPA & SWPA & TVA & WAPA & Total \\
\hline Nẹt generation & 0 & 0 & 0 & 0 & 0 & 0 & 0 \\
\hline Purchases - utilities & 100 & 100 & 100 & 100 & 100 & 100 & 100 \\
\hline Purchases - nonutillities & 0 & 0 & 0 & 0 & 0 & 0 & 0 \\
\hline Net wheeling & 0 & 0 & 0 & 0 & 0 & 0 & 0 \\
\hline
\end{tabular}

Source: DOE/EIA Form 861 - 1991

Note: Percentage totals may not equal $100 \%$ due to rounding

\begin{tabular}{|c|c|c|c|c|c|c|c|}
\hline Distribution Co & $\begin{array}{l}\text { tricity L } \\
B P A \\
\end{array}$ & $\begin{array}{l}\text { osition ano } \\
\text { Non-PMA }\end{array}$ & $\begin{array}{l}\text { venue } \\
\text { SEPA }\end{array}$ & $\begin{array}{l}\text { Ircenta } \\
\text { SWPA }\end{array}$ & $\begin{array}{l}\text { itributh } \\
\text { TVA }\end{array}$ & WAPA & Total \\
\hline \multicolumn{8}{|c|}{ Sales } \\
\hline Sales to end-use consumers & 100 & 99 & 100 & 98 & 98 & 100 & 99 \\
\hline Sales for resale & 0 & 1 & 0 & 2 & 2 & 0 & 1 \\
\hline \multicolumn{8}{|l|}{ Revenues } \\
\hline Revenues from sales to end-use consumers & 100 & 100 & 100 & 99 & 99 & 100 & 99 \\
\hline Revenues from sales for resale & 0 & 0 & 0 & 1 & 2 & 0 & 1 \\
\hline \multicolumn{8}{|l|}{ Total Revenue Ranges (1000s \$1991) } \\
\hline Less than $\$ 100,000$ & 100 & 100 & 98 & 98 & 100 & 100 & 99 \\
\hline$\$ 100,000$ to $\$ 250,000$ & 0 & 0 & 2 & 2 & 0 & 0 & 1 \\
\hline$\$ 250,001$ to $\$ 500,000$ & 0 & 0 & 0 & 0 & 0 & 0 & 0 \\
\hline$\$ 500,001$ to $\$ 1,000,000$ & 0 & 0 & 0 & 0 & 0 & 0 & 0 \\
\hline Greater than $\$ 1,000,000$ & 0 & 0 & 0 & 0 & 0 & 0 & 0 \\
\hline
\end{tabular}




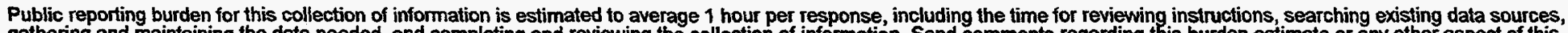

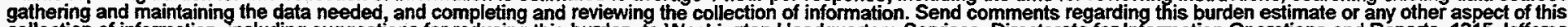

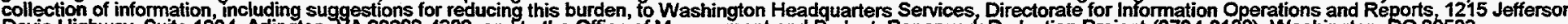

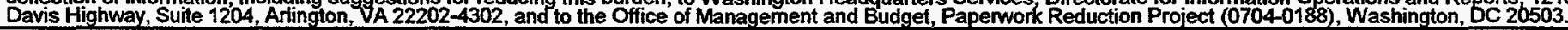
1. AGENCY USE ONLY (Leave blank)
2. REPORT
DATE.

\section{REPORT TYPE AND DATES COVERED} Subcontractor report

\section{October 1995}

4. TITLE AND SUBTITLE Strategy for Advancement of IRP in Public Power-Volume 2: Technical Appendices

\section{FUNDING NUMBERS}

AS115504

Subcontract AAW-3-13353-01

6. AUTHOR(S)

Cynthia J. Garrick

7. PERFORMING ORGANIZATION NAME(S) AND ADDRESS(ES)

Garrick \& Associates

6188 Willow Springs Drive

Morrison, Colorado 80465

9. SPONSORINGIMONITORING AGENCY NAME(S) AND ADDRESS(ES)

National Renewable Energy Laboratory

1617 Cole Boulevard

Golden, CO $80401-3393$
8. PERFORMING ORGANIZATION REPORT NUMBER

11. SUPPLEMENTARY NOTES DE95009228

12a. DISTRIBUTION/AVAILABILITY STATEMENT

National Technical Information Service

U.S. Department of Commerce

5285 Port Royal Road

Springfield, VA 22161 12b. DISTRIBUTION CODE

UC

1320

13. ABSTRACT (Maximum 200 words)

Volume 2: Technical Appendices is the second part of a subcontractor report prepared for the U. S. Department of Energy (DOE).

Volume 1 of the report presents a 5-year strategy to advance integrated resource planning (IRP) among publicly and cooperatively owned utilities. Volume 2 consists of appendices containing needs assessment results, mail survey findings, summaries of federal and state IRP policies, and technical and economic market characterizations.

14. SUBJECT TERMS

integrated resource planning; public power; public utilities; utility cooperatives

15. NUMBER OF PAGES

186

16. PRICE CODE
17. SECURITY CLASSIFICATION OF REPORT

unclassified
18. SECURITY CLASSIFICATION OF THIS PAGE unclassified
19. SECURITY CLASSIFICATION OF ABSTRACT unclassified
20. LIMITATION OF ABSTRACT UL 